\title{
SIMULATION STUDIES TO EVALUATE THE EFFECT OF FRACTURE CLOSURE ON THE PERFORMANCE OF NATURALLY FRACTURED RESERVOIRS \\ Contract No. DE-AC22-90BC14654
}

ANNUAL REPORT

submitted to:

U.S. Department of Energy

Bartlesville Project Office

220 North Virginia Avenue

Bartlesville, OK 74003

submitted by:

K\&A Energy Consultants, Inc. 6849 East 13th Street

Tulsa, Oklahoma 74112

October 1991

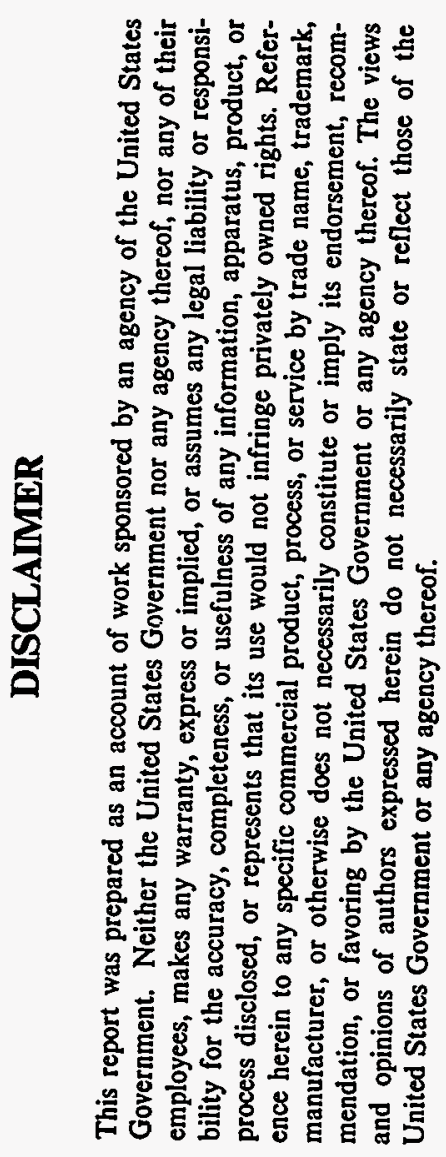

Second Draft - November 6, 1992

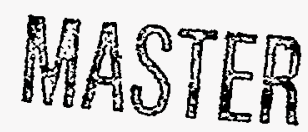




\section{DISCLAIMER}

Portions of this document may be illegible in electronic image products. Images are produced from the best available original document. 


\section{TABLE OF CONTENTS}

\section{ABSTRACT}

\section{EXECUTIVE SUMMARY}

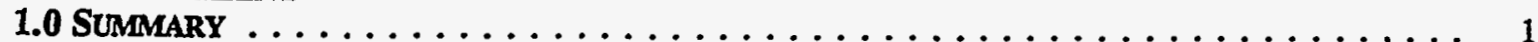

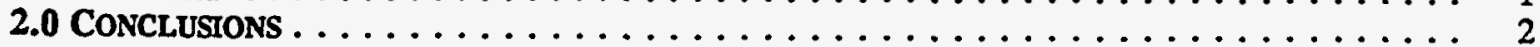

INTRODUCTION

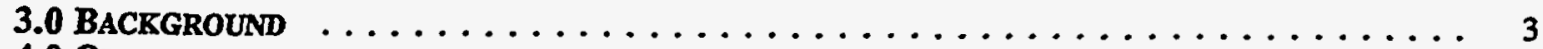

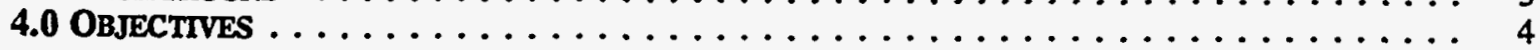

\section{DISCUSSION}

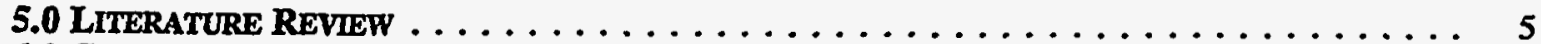

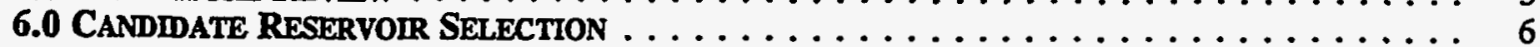

7.0 RESERVOIR DESCRIPTION $\ldots \ldots \ldots \ldots \ldots \ldots \ldots \ldots \ldots \ldots \ldots \ldots \ldots \ldots \ldots$

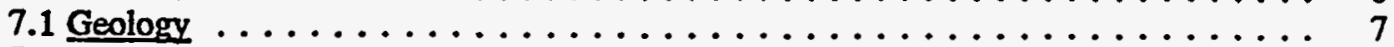

7.2 Reservoir Properties . . . . . . . . . . . . . . . . . 10

7.3 Reservoir Performance Data . . . . . . . . . . . . . . . . 12

8.0 Examination of Vertical and. Horizontal Weli Performance $\ldots \ldots \ldots \ldots \ldots \ldots 12$

8.1 Sample Selection . . . . . . . . . . . . . . . . . . 13

8.2 Determination of Ultimate Recovery $\ldots \ldots \ldots \ldots \ldots \ldots \ldots \ldots \ldots$

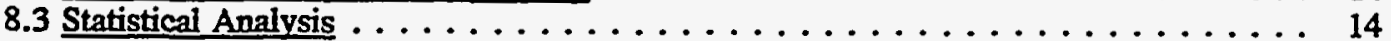

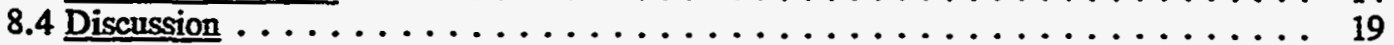

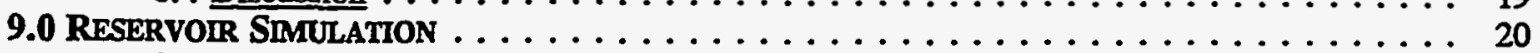

9.1 Model Description .......................... 20

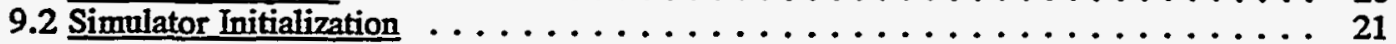

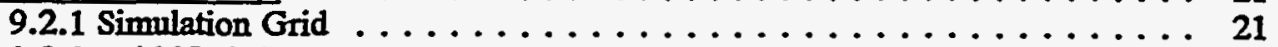

9.2 .2 Grid Node Data $\ldots \ldots \ldots \ldots \ldots \ldots \ldots \ldots \ldots \ldots \ldots \ldots \ldots . \ldots \ldots . \ldots \ldots$

9.2.3 Rock-Fluid Properties . . . . . . . . . . . . . . 24

9.2.4 Initial Reservoir Conditions . . . . . . . . . . . . . 25

9.2.5 Reservoir Fluid Properties . . . . . . . . . . . . . 25

9.2.6 Well Productivity and Injectivity . . . . . . . . . . . 25

9.3 Primary Recovery Forecasts for a Horizontal Well . . . . . . . . . . 26

9.3.1 Completion Layer $\ldots \ldots \ldots \ldots \ldots \ldots \ldots \ldots \ldots \ldots \ldots \ldots$

9.3.2 Number of Fracture Swarms $\ldots \ldots \ldots \ldots \ldots \ldots \ldots \ldots \ldots \ldots \ldots \ldots . \ldots \ldots \ldots$

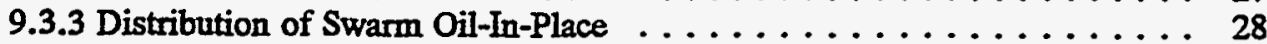

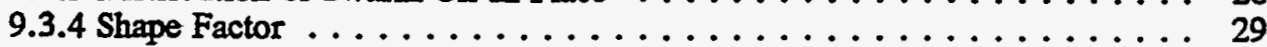

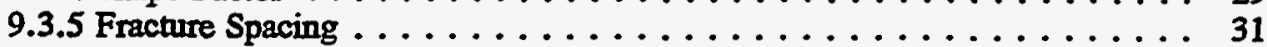

9.3.6 Relative Conductivity (matrix/fracture) $\ldots \ldots \ldots \ldots \ldots \ldots \ldots \ldots$

9.3.7 Relative Storativity (fracture/matrix) $\ldots \ldots \ldots \ldots \ldots \ldots \ldots \ldots . \ldots 33$

9.3.8 Fracture Capillary Pressure $\ldots \ldots \ldots \ldots \ldots \ldots \ldots \ldots \ldots \ldots \ldots$

9.3.9 Fracture Relative Permeability $\ldots \ldots \ldots \ldots \ldots \ldots \ldots \ldots \ldots \ldots$

9.3.10 Matrix Capillary Pressure $\ldots \ldots \ldots \ldots \ldots \ldots \ldots \ldots \ldots \ldots .37$

9.4 Primary Recovery Forecasts for a Vertical Well $\ldots \ldots \ldots \ldots \ldots \ldots \ldots \ldots \ldots \ldots . . \ldots$

9.5 Secondary Recovery Forecasts for a Horizontal Well $\ldots \ldots \ldots \ldots \ldots \ldots \ldots \ldots 41$

9.6 Secondary Recovery Forecasts for a Vertical Well $\ldots \ldots \ldots \ldots \ldots \ldots \ldots \ldots \ldots 41$

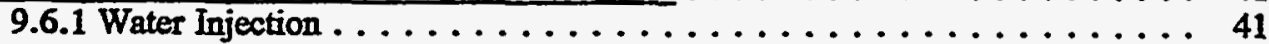

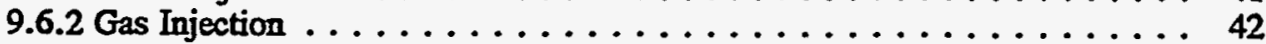

9.6 .3 Combined Injection of Gas and Water . . . . . . . . . 43

NOMENCLATURE $\ldots \ldots \ldots \ldots \ldots \ldots \ldots \ldots \ldots \ldots \ldots \ldots \ldots \ldots \ldots \ldots \ldots$

REFERENCES $\ldots \ldots \ldots \ldots \ldots \ldots \ldots \ldots \ldots \ldots \ldots \ldots \ldots \ldots \ldots \ldots \ldots \ldots \ldots$

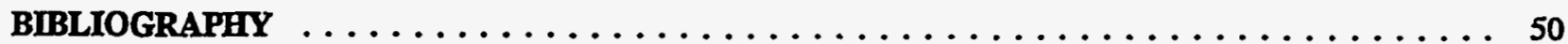




\section{LIST OF FIGURES}

Figure 7.1.1

Figure 7.1.2 Figure 7.1.3 Figure 7.1.4 Figure 7.1.5 Figure 7.1.6 Figure 7.3.1 Figure 7.3.2 Figure 7.3.3 Figure 7.3.4 Figure 7.3.5 Figure 8.0.1 Figure 9.1.1 Figure 9.1.2 Figure 9.1.3 Figure 9.1.4 Figure 9.2.1 Figure 9.2.2 Figure 9.2.3 Figure 9.2.4 Figure 9.2.5 Figure 9.2.6 Figure 9.2.7 Figure 9.3.1 Figure 9.3.2 Figure 9.3.3 Figure 9.3.4 Figure 9.3.5 Figure 9.3.6 Figure 9.3.7 Figure 9.3.8

Figure 9.3.9

Figure 9.3.10 Figure 9.3.11 Figure 9.3.12 Figure 9.3.13 Figure 9.3.14 Figure 9.3.15

Figure 9.3.16 Figure 9.3.17 Figure 9.3.18

Figure 9.3.19

Figure 9.3.20

Figure 9.3.21

Figure 9.3.22

Figure 9.3.23

Figure 9.3.24

Figure 9.4.1

Figure 9.4.2

Figure 9.4.3

Figure 9.4.4

Figure 9.4.5

Figure 9.4.6

Figure 9.4.7
Depositional Environments for the Upper Cretaceous Austin Chalk Formation . . . . . . 66

Porosity Versus Depth of Burial . . . . . . . . . . . . . . . . . . . 67

Typical Log From Pearsall Field Well $\ldots \ldots \ldots \ldots \ldots \ldots \ldots \ldots \ldots \ldots \ldots \ldots \ldots \ldots$

Major Structural Features in Southwest Texas . . . . . . . . . . . . . . 69

Subsurface Stratigraphic Cross-Section . . . . . . . . . . . . . . . . 70

Schematic Illustrations of Structural Types and Associated Fractures . . . . . . . 71

Well A-1 Production Test Data . . . . . . . . . . . . . . . . . 72

Well A-2 Production Test Data . . . . . . . . . . . . . . . . . 73

Well B-1 Production Test Data . . . . . . . . . . . . . . . . . 74

Well B-2 Production Test Data . . . . . . . . . . . . . . . . . . 75

Well P-1 Production Test Data . . . . . . . . . . . . . . . . . . . 76

Horizontal Wells with Single-Well Solutions . . . . . . . . . . . . . . 77

Horizontal Depletion Model (Schematic) $\ldots \ldots \ldots \ldots \ldots \ldots \ldots \ldots \ldots$

Vertical Depletion Model (Schematic) . . . . . . . . . . . . . . 78

Horizontal Injection Model (Schematic) . . . . . . . . . . . . . . . . 79

Vertical Injection Model (Schematic) $\ldots \ldots \ldots \ldots \ldots \ldots \ldots \ldots$. . . . . . . 79

Schematic of Grid for Horizontal Depletion Model . . . . . . . . . . . . 80

Schematic of Grid for Horizontal Injection Model $\ldots \ldots \ldots \ldots \ldots \ldots \ldots$

Oil-Water Relative Permeability After Honarpour $\ldots \ldots \ldots \ldots \ldots \ldots \ldots . \ldots 2$

Gas-Oil Relative Permeability After Honarpour . . . . . . . . . . . . . . . 83

Capillary Pressure Versus Wetting Phase Saturation .............. 84

Reservoir Oil PVT Properties Versus Pressure $\ldots \ldots \ldots \ldots \ldots \ldots \ldots \ldots \ldots$

Reservoir Gas PVT Properties Versus Pressure . . . . . . . . . . . . . . 86

Depth of Completion (Horizontal Well) $\ldots \ldots \ldots \ldots \ldots \ldots \ldots \ldots \ldots$. . . . . 87

Number of Fracture Swarms (Horizontal Well) $\ldots \ldots \ldots \ldots \ldots \ldots \ldots \ldots 88$

Fracture Swarm OOIP Distribution (Horizontal Well) . . . . . . . . . . . . . 89

Total OOIP (Horizontal Well) $\ldots \ldots \ldots \ldots \ldots \ldots \ldots \ldots \ldots \ldots$. . . . . . . . 90

Kazemi Shape Factors (Horizontal Well) $\ldots \ldots \ldots \ldots \ldots \ldots \ldots \ldots \ldots$. . . . 91

Thomas Shape Factors (Horizontal Well) $\ldots \ldots \ldots \ldots \ldots \ldots \ldots \ldots \ldots \ldots$

Fracture Spacing (Horizontal Well) $\ldots \ldots \ldots \ldots \ldots \ldots \ldots \ldots \ldots \ldots \ldots . \ldots . \ldots 9$

Recovery Factor as a Function of Fracture Spacing . . . . . . . . . . . . . 94

Relative Conductivity, $\mathrm{k}_{\mathrm{f}}=10 \mathrm{mD}$ (Horizontal Well) ............. 95

Relative Conductivity, $k_{\mathrm{m}}=0.0001 \mathrm{mD}$ (Horizontal Well) . . . . . . . . 96

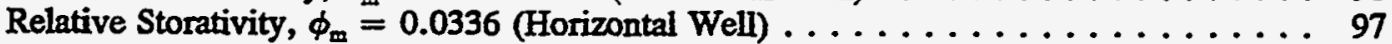

Relative Storativity, $\phi_{t}=0.000984$ (Horizontal Weil) $\ldots \ldots \ldots \ldots \ldots \ldots \ldots$. . . . 98

Fracture Capillary Pressure (Horizontal Well) . . . . . . . . . . . . . . . 99

Fracture Oil-Water Relative Permeability $-\left(S_{w i}, S_{\text {orwo }} p_{j}\right)=0.2$ Matrix Values ...... 100

Fracture Gas-Oil Relative Permeability - $\left(S_{w i}, S_{e r z}, p_{j}\right)=0.2$ Matrix Values . . . . . 101

Fracture Oil-Water Relative Permeability $-\left(S_{\text {wit }}, S_{\alpha w,} p_{c}\right)=0.5$ Matrix Values . . . . 102

Fracture Gas-Oil Relative Permeability $-\left(S_{w i}, S_{\alpha z}, p_{j}\right)=0.5$ Matrix Values ...... 103

Linear Fracture Relative Permeability (Horizontal Well) $\ldots \ldots \ldots \ldots \ldots \ldots \ldots \ldots$

Curved Fracture Relative Permeability (Horizontal Well) $\ldots \ldots \ldots \ldots \ldots \ldots \ldots \ldots$

Fracture Relative Permeability Shape, $s_{x f}=0.2 s_{\text {mat }}$ (Horizontal Well) $\ldots \ldots \ldots \ldots 106$

Fracture Relative Permeability Shape, $s_{\mathrm{rf}}=0.5 \mathrm{~s}_{\mathrm{m}}$ (Horizontal Well) $\ldots \ldots \ldots \ldots \ldots 107$

Oil-Water Capillary Pressure Versus Water Saturation . . . . . . . . . . . . 108

Gas-Oil Capillary Pressure Versus Gas Saturation . . . . . . . . . . . . . . . 109

Matrix Capillary Pressure, $p_{f f}=0$ (Horizontal Well) $\ldots \ldots \ldots \ldots \ldots \ldots \ldots \ldots \ldots$

Depth of Completion (Vertical Well) $\ldots \ldots \ldots \ldots \ldots \ldots \ldots \ldots \ldots \ldots \ldots \ldots$

Total OOIP (Vertical Well) . . . . . . . . . . . . . . . . . . 112

Kazemi Shape Factors (Vertical Well) . . . . . . . . . . . . . . . 113

Thomas Shape Factors (Vertical Well) $\ldots \ldots \ldots \ldots \ldots \ldots \ldots \ldots \ldots \ldots \ldots \ldots \ldots$

Fracture Spacing (Vertical Well) $\ldots \ldots \ldots \ldots \ldots \ldots \ldots \ldots \ldots \ldots \ldots \ldots$

Relative Conductivity, $\mathrm{k}_{\mathrm{f}}=10 \mathrm{mD}$ (Vertical Well) $\ldots \ldots \ldots \ldots \ldots \ldots \ldots \ldots$

Relative Conductivity, $k_{m}=0.0001 \mathrm{mD}$ (Vertical Well) $\ldots \ldots \ldots \ldots \ldots \ldots \ldots$ 


\section{LIST OF FIGURES (cont'd)}

Figure 9.4.8

Figure 9.4.9

Figure 9.4.10

Figure 9.4.11

Figure 9.4.12

Figure 9.4.13

Figure 9.4.14

Figure 9.6.1

Figure 9.6.2

Figure 9.6.3

Figure 9.6.4

Figure 9.6.5

Figure 9.6.6

Figure 9.6.7

Figure 9.6.8

Figure B.1

Figure B.2

Figure B.3

Figure B.4

Figure B.5

Figure B.6

Figure B.7

Figure B.8

Figure B.9
Relative Storativity, $\phi_{\mathrm{m}}=0.0336$ (Vertical Well) $\ldots \ldots \ldots \ldots \ldots \ldots \ldots \ldots \ldots$

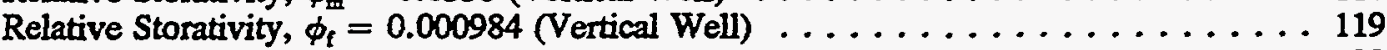

Fracture Capillary Pressure (Vertical Well) . . . . . . . . . . . . . . . 120

Linear Fracture Relative Permeability (Vertical Well) . . . . . . . . . . . . 121

Curved Fracture Relative Permeability (Vertical Well) . . . . . . . . . . . . . . . 122

Matrix Capillary Pressure, $p_{e f}=0$ (Vertical Well) $\ldots \ldots \ldots \ldots \ldots \ldots \ldots \ldots . \ldots \ldots$

Fracture Relative Permeability Shape, $s_{\mathrm{rf}}=0.5 \mathrm{~S}_{\mathrm{mm}}$ (Vertical Well) $\ldots \ldots \ldots \ldots 124$

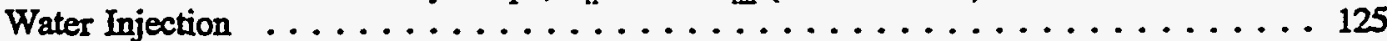

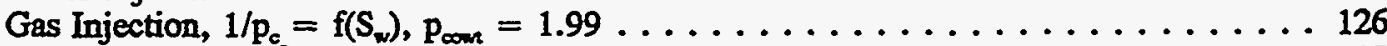

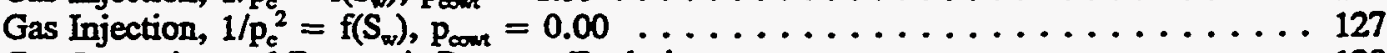

Gas Saturation and Reservoir Pressure Evolution . . . . . . . . . . . . . . 128

Gas \& Water Injection, $1 / p_{c}=f\left(S_{w}\right), p_{c o n}=1.99-G O R \ldots \ldots \ldots \ldots . . \ldots \ldots 129$

Gas \& Water Injection, $1 / \mathrm{p}_{\mathrm{c}}=\mathrm{f}\left(\mathrm{S}_{\mathrm{w}}\right), \mathrm{p}_{\text {com }}=1.99-$ Water Cut $\ldots \ldots \ldots \ldots \ldots \ldots 130$

Gas \& Water Injection, $1 / \mathrm{p}_{c}^{2}=\mathrm{f}\left(\mathrm{S}_{\mathrm{w}}\right), \mathrm{p}_{\mathrm{cown}}=0.00-\mathrm{GOR} \ldots \ldots \ldots \ldots \ldots \ldots \ldots$

Gas \& Water Injection, $1 / \mathrm{p}_{c}^{2}=\mathrm{f}\left(\mathrm{S}_{\mathrm{w}}\right), \mathrm{p}_{c \mathrm{wn}}=0.00-$ Water Cut $\ldots \ldots \ldots \ldots \ldots \ldots 132$

Ulimate Oil Recovery Per Well Versus Wellbore Orientation ........... B-2

Ultimate Oil Recovery Per Well For Horizontal Wells

Based On Prior Production From Vertical Well(s) On Same Lease ...... . B-3

Ultimate Oil Recovery Per Well For Horizontal Wells

Based On Multiple Well Lease Versus Single Well Lease . . . . . . . . . . B B-4

Ultimate Oil Recovery Per Well For Horizontal Wells

Based On Initial Production Method - Flowing or Pumping ........ B B

Wellbore Displacement in Pay Zone Versus Wellbore Orientation . . . . . . . . . B B-6

Ultimate Oil Recovery Per Displacement Versus Wellbore Orientation . . . . . . . . B B-7

Ultimate Oil Recovery Per Displacement

Based On Prior Production From Vertical Well(s) On Same Lease . . . . . . B B-8

Ultimate Oil Recovery Per Displacement

Based On Multiple Well Lease Versus Single Well Lease . . . . . . . . . . B-9

Ultimate Oil Recovery Per Displacement

Based On Initial Production Method - Flowing or Pumping $\ldots \ldots \ldots \ldots$ B-10

iii 


\section{LIST OF TABLES}

Table 8.1.1

Table 8.3.4

Table 9.2.1

Table 9.2.2

Table 9.3.1

Table 9.3.2

Table 9.3.3

Table 9.3.4

Table 9.3.5

Table 9.3.6

Table 9.3.7

Table 9.3.8

Table 9.3.9

Table 9.3.10

Table 9.3.11

Table 9.3.12

Table 9.3.13

Table 9.4.1

Table 9.4.2

Table 9.6.1

Table 9.6.2

Table 9.6.3

Table A.1
Sample Categories and Numbers of Wells $\ldots \ldots \ldots \ldots \ldots \ldots \ldots \ldots \ldots$

Results of $\chi^{2}$ Test for Ultimate Recovery . . . . . . . . . . . . . 18

Horizontal Depletion Model ....................... 22

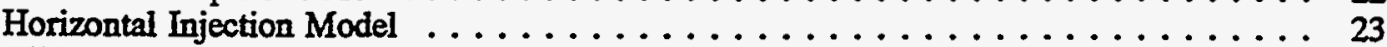

Oil Recovery Sensitivity to Depth of Completion . . . . . . . . . . . . 27

Oil Recovery Sensitivity to Number of Fracture Swarms . . . . . . . . . . . 28

Oil Recovery Sensitivity to Fracture Swarm OOIP Distribution . . . . . . . . . 29

Oil Recovery Sensitivity to Total OOIP . . . . . . . . . . . . . . . . . 29

Oil Recovery Sensitivity to Dual Porosity Shape Factor . . . . . . . . . . . . . 31

Oil Recovery Sensitivity to Fracture Spacing $\ldots \ldots \ldots \ldots \ldots \ldots \ldots \ldots \ldots \ldots$

Oil Recovery Sensitivity to Relative Conductivity $\ldots \ldots \ldots \ldots \ldots \ldots \ldots \ldots \ldots \ldots$

Oil Recovery Sensitivity to Relative Conductivity $\ldots \ldots \ldots \ldots \ldots \ldots \ldots \ldots$

Oil Recovery Sensitivity to Relative Storativity . . . . . . . . . . . . . . . 34

Oil Recovery Sensitivity to Relative Storativity ................. 35

Oil Recovery Sensitivity to Fracture Capillary Pressure . . . . . . . . . . . 36

Oil Recovery Sensitivity to Fracture Relative Permeability . . . . . . . . . . . . 37

Oil Recovery Sensitivity to Matrix Capillary Pressure . . . . . . . . . . . . . 38

Figure Number Cross-Reference for Horizontal and Vertical Models . . . . . . . . . . 39

Comparison of Oil Recovery Factors $\ldots \ldots \ldots \ldots \ldots \ldots \ldots \ldots \ldots \ldots \ldots$

Oil Recovery Sensitivity to Completion Interval and $p_{\infty} \ldots \ldots \ldots \ldots \ldots \ldots \ldots . \ldots 42$

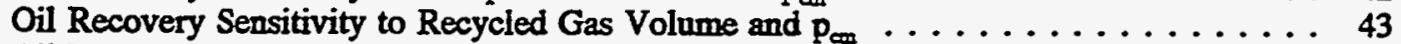

Oil Recovery Sensitivity to Recycled Gas Volume and $\mathrm{p}_{\mathrm{co}} \ldots \ldots \ldots \ldots \ldots \ldots$

Statistical Analysis Variables. ....................... A-1 


\begin{abstract}
The first of a three-year research program to evaiuate the effect of fracture closure on the recovery of oil and gas from naturally fractured reservoirs has been completed. The objectives of the study are to: (1) evaluate the reservoir conditions where fracture closure is significant, and (2) evaluate innovative fluid injection techniques capable of maintaining pressure within the reservoir.

Simulation studies were conducted with a dual porosity simulator capable of simulating the performance of vertical and horizontal wells. Each simulator was initialized using properties typical of the Austin Chalk reservoir in Pearsall Field, Texas. Simulations of both vertical and horizontal well performance were made assuming that fracture permeability was insensitive to pressure change. Sensitivity runs indicate that the simulator is predicting the effects of critical reservoir parameters in a logical and consistent manner. The resuits to-date confirm that horizontal wells can increase both oil recovery rate and total oil recovery from naturally fractured reservoirs.

The year one simulation results will provide the baseline for the ongoing study which will evaluate the performance degradation caused by the sensitivity of fracture permeability to pressure change, and investigate fluid injection pressure maintenance as a means to improve oil recovery performance. The study is likely to conclude that fracture closure decreases oil recovery and that pressure support achieved through fluid injection could be beneficial in improving recovery.
\end{abstract}




\section{EXECUTIVE SUMMARY}

\subsection{SUMMARY}

Fractured reservoirs contain a significant part of the remaining hydrocarbon reserves of the United States. Furthermore, oil production from fractured reservoirs is increasing due to the recently accelerated development drilling activity in such reservoirs.

The remarkable advances in horizontal drilling technology are of particular interest to operators with large holdings in known fractured reservoir trends, such as the Austin Chalk in Texas and the Bakken Shale in the Williston Basin. Horizontal wellbores offer a practical means to exploit these difficult reservoirs and others like them. In many instances, horizontal well completions offer the only economically feasible exploitation method.

This study is to investigate the pressure sensitivity of fractured reservoir systems and its impact on hydrocarbon recovery. The principal objective is to develop innovative techniques for counteracting the natural tendency of fractures to deform and reduce reservoir flow capacity as pressure is reduced by fluid withdrawals. The work is planned in three tasks, each of one-year duration. A brief description of each task follows:

Task 1: Select a candidate field, establish its reservoir properties, and initialize a mathematical simulator of a typical segment of the reservoir. Make performance forecasts assuming natural depletion and using both vertical and horizontal wellbores. Forecast secondary recovery performance with gas or water injection assuming vertical well exploitation. Make sufficient runs for each forecast mode to establish the sensitivity of the forecasts to key reservoir properties. For these simulations, the fractures are assumed to have no pressure sensitivity.

Task 2: The natural depletion and secondary recovery forecasts of Task 1 will be repeated, but assuming the fracture permeability to be stress dependent. The characterization of the permeability-stress relationship will be based on the most current published research findings.

Task 3: The production problems arising from fracture permeability reduction will be addressed. Those reservoir and operating conditions which manifest the most severe problems will be identified. Innovative approaches to resolving these problems with fluid injection and horizontal wells or combinations of vertical and horizontal wells will be evaluated.

Task 1 work has been completed and is reported in this document. The TRIAD reservoir simulator has been revised to allow description of fracture permeability as a function of pressure in a manner that is consistent with current research publications.

The Pearsall Field, Austin Chalk reservoir, has been selected as the prototype for this study. Prototype simulators of a typical segment of the reservoir have been initialized and Task 1 
simulations have been carried out. Sixty-eight simulations of natural depletion and secondary recovery have been made.

\subsection{CONCLUSIONS}

1. The permeability of fissures in naturally fractured reservoirs is most likely to exhibit some degree of pressure dependence.

2. The Austin Chaik reservoir in Pearsall Fieid is currently the best documented fractured reservoir in the petroleum literature, thus it has been selected as the prototypical reservoir for this study.

3. Horizontal well completions have proven to be particularly effective in Pearsall Field.

4. The Pearsall reservoir is horizontally compartmented by the tendency of the fractures to develop vertically in recurring bands or swarms. For this reason a long offset horizontal well can develop several fracture swarms. Development of the same reserves by vertical drilling would require appreciably more wells.

5. Task 1 simulations have demonstrated that certain reservoir parameters are more important in determining the performance of the prototype reservoir:

- Natural depletion recovery was very sensitive to the contrast of permeability between fractures and matrix: lowered by contrast reduction and raised by contrast increase.

- Natural depletion recovery was sensitive to the storage capacity of the fractures in relation to the matrix storage capacity: higher fracture capacity yielded better recovery efficiency.

- Naturai depletion recovery was highly dependent on dual permeability shape factor.

- Natural depletion recovery was adversely affected by fracture spacings closer than one foot for cubic matrix blocks.

- Natural depletion recovery was increased as fracture capillary pressure was increased.

- Water injection recovery was sensitive to capillary pressure but insensitive to producing well completion interval (top versus middle).

- Gas injection provided no recovery improvement for the base case reservoir description, e.g. closely spaced orthogonal fractures and cubic matrix blocks.

- Combined injection of gas and water offered no recovery advantage over water injection. 


\section{INTRODUCTION}

\subsection{BACKGROUND}

A significant fraction of the remaining domestic oil and gas reserves is contained in reservoirs wherein naturally occurring fractures provide the means of fluid flow. Increased attention is being given to such reservoirs because of the potential for improved productive capacity and ultimate recovery offered by the long horizontal wellbores made possible by recent advances in horizontal drilling technology. Examples of naturally fractured reservoirs in the United States include: Elk Basin in Montana and Wyoming, Bakken formation in the Williston Basin, Lisburne in Alaska, and Spraberry and the Austin Chalk trend in Texas.

The global fluid flow in a fractured reservoir takes place within a system of intersecting fissures in the reservoir rock. The volume of the fracture-related voids is, however, very small in comparison to the bulk volume of the reservoir, usually less than one percent and often much less. The greatest part of the reservoir storage volume is contained in the intervening porous rock, commonly referred to as the "matrix." The matrix is usually of very low permeability, often in the microdarcy range, but has more typical porous media porosity. Matrix porosity varies from a few percent up to a few tens of percent.

Reduction of void volume in conventional porous media due to the increased stresses induced by fluid withdrawals is a known phenomenon. It is usually accounted for in reservoir engineering calculations by the pore volume compressibility. It is generally acknowledged that similar reductions must also take place in the fissure void network. Since shrinkage of fissure voids would be expected to reduce their permeability, perhaps more drastically than for conventional porous media, this could have serious well productivity and reservoir flow mechanics implications.

There is a rather large body of writings in the technical literature; particularly in the field of rock mechanics, dealing with the assessment of fissure permeability and the tendency of this type of permeability to be stress sensitive. Researchers in this field have performed rather extensive studies of fracture systems, mainiy in the shallow subsurface and commonly related to large construction projects. These studies have included in situ measurements of principal rock stresses and fracture properties, such as fracture aperture, length, height and orientation, and the description of complex rock joint systems. Much of this research has been centered on the validity of the cubic law which states that fracture permeability varies as the cube of fracture aperture. Jones ${ }^{1}$ concluded in his study of fractured rocks and synthetic fractured media that the cubic law is valid for fracture apertures larger than 0.0253 inches. At smaller apertures the flow deviation can be characterized by experimentally determined friction factors, analogous to those commonly used for pipeflow calculations. Unlike pipeflow, the transition to turbulent fracture flow is smooth and dependent on surface roughness for smaller fracture apertures.

Although fissures are often referred to in terms implying that they are pianar features, they really are not. The fracture surface is commonly rough and undulating. The surface roughness can be characterized by the distribution of individual asperity heights. The stresses which cause the 
rock to fracture will commonly have a shear component which induces some displacement along the fracture surface. Even a slight displacement can be sufficient to juxtapose higher than average asperities, thus preventing the rock from mating and the fracture from closing. Larger displacements can lead to a situation where the waviness of the fracture will play a role in keeping the fracture surfaces from mating perfectly. Thus, it is common that fractures do not completely heal as stress is increased and measurable permeability can be observed to extremely high stress levels.

A fracture flow system, therefore, is seen to be a complex system of flattened flow channeis that, due to their tortuosity, intersect other channeis to form a complex network. In many respects, this network is not unlike a normal porous media, in that fracture permeability will be highly variable and flow will tend to be tortuous. It differs in the respect that the fractures do have a planar element that imparts a highly directional permeability to the reservoir.

The void spaces along the fracture surface between the points of contact will have a tendency to deform and reduce the aperture with increasing stress. The degree of deformation is dependent upon the mechanical properties of the rock and the equilibrium state stress conditions. In oil field operations, this equilibrium is disturbed by the withdrawal of reservoir fluids. As a consequence, the fluid pressure is reduced and the rock is subjected to increased stress.

\subsection{OBJECTIVES}

This study was proposed on the basis of two observations arising from prior research:

1. Horizontal wells improve oil recovery from reservoirs containing tectonic fractures. This improvement is due to the larger number of vertical fractures intersected by the wellbore.

2. Oil recovery in these reservoirs suffers because the fractures are inclined to close as reservoir pressure depletes, thus exacerbating the well productivity decline. The tendency of natural water encroachment or fluid injection is to retard or arrest reservoir pressure decline and fracture closure, thus reducing well productivity decline and offering the possibility of improved recovery.

Neither observation has been systematically quantified or evaluated. The primary purpose of this study is to rectify these shortcomings, thus the work has the following general objectives:

1. To evaluate the impact of fracture closure on hydrocarbon recovery from reservoirs having pressure sensitive, naturally occurring fractures.

2. To investigate innovative developmental and fluid injection methods for improving hydrocarbon recovery from such reservoirs.

The study will rely on state-of-the-art reservoir modelling techniques to provide reliable simulations of reservoir behavior. Analysis of these results is proposed as the basis for all observations and conclusions arising from this work. 


\section{DISCUSSION}

\subsection{LITERATURE REVIEW}

A review of the technical literature was undertaken to establish a basic core of reference materiai. The scope of the search was broadened as new information sources and subject titles were identified to minimize the possibility that any pertinent information was overlooked.

The primary reference indexes utilized were the following:

Petroleum Abstracts, 1965 through 1990

Society of Petroleum Engineers, 1961 through 1990

Association of Petroleum Geologists, 1961 through 1990

The search was conducted in three phases:

1. Preliminary Phase - Pertinent sections of each index were copied to provide a convenient way to scan and highlight titles requiring closer review. The subject list, as defined in the Petroleum Abstract index, was as follows:

fracture, extension

fracture geometry

fracture mapping

fracture porosity

fracture (rock)

fractured reservoir

fractured shale reservoir

fracture width

fracturing

2. Secondary Phase - Abstracts of candidate title documents were copied and reviewed to determine if they merited inclusion in the hard copy reference base.

3. Final Phase - The source documents for all interesting abstracts were looked up and copied. There were a few documents which could not be located in the available reference library. Approximately 200 documents were copied and filed for reference during the study. Each document was cataloged in a database.

In broad terms, the search attempted to identify and copy all documents dealing with some aspect of fractured reservoir/rock characteristics and their physical behavior. Of particular interest were naturally fractured hydrocarbon productive fields in the United States. A complete list of all documents located and copied as part of this search effort to date is provided in the bibliography. It is anticipated that new documents will be identified and added to the reference file as the study continues into the second and third years. The reference database will be kept current as new documents are added. 


\subsection{CANDIDATE RESERVOIR SELECTION}

An important consideration in the literature search was to identify a suitable fractured reservoir to use as a prototype for intitializing the simulators to be used in this study. It was recognized from the outset that the ideal candidate (a mature, fully documented, domestic reservoir producing from pressure sensitive fractures) was unlikely to be found. To be ideal, the documented data would have to include everything needed to initialize a modern dual porosity reservoir simulator, and sufficient diagnostic well production data, including some for horizontal wells, to provide a test case for the simulation approach. The test case simulations could be regarded as a form of history matching, even though history matching in the customary reservoir simulation sense was not intended in the scope of the present study.

Potential candidate fields included known fractured reservoirs like Bakken Shale, Elk Basin, Spraberry, Lisburne, Yates and the Austin Chalk. As the search progressed it became increasingly apparent that one of the Austin Chalk fields, Pearsall or Giddings, would have the most comprehensive set of published data. This was attributable to the current high level of horizontal drilling activity in these fields.

The Austin Chalk is an important reservoir rock in South Texas, the two most prolific oil producing areas being the Giddings and Pearsall Fields. Both fields have undergone several cycles of development, the most recent employing horizontal drilling.

The prototype reservoir chosen for the subject study was Pearsall. The main reason for this choice was that more published data was found for Pearsall than for Giddings. Secondary considerations favoring Pearsall were: fracture pervasiveness, horizontal well successes, and the performance data provided by a prominent field operator.

It was never intended that this study should necessarily simulate a particular field, nor indeed, that a single model would have to be used for all simulations. Thus, while Pearsall was the prototype for model initialization, the models would not be used to simulate its performance in the usual sense, Furthermore, some case requirements may dictate model reconfiguration. Nonetheless, the use of actual field data should impart a reasonable degree of reality to the simulations.

\subsection{RESERVOIR DESCRIPTION}

Production from the Pearsail Austin Chalk reservoir began in 1936. Development drilling in this first cycle of activity ended sometime in 1941 and resulted in the drilling of approximately 30 wells ${ }^{2}$. These wells were completed open hole and usually shot with nitroglycerin. The average per well oil recovery for this group of wells was about $85,000 \mathrm{STB}^{3}$.

A second cycie of development occurred between 1948 and 1956. These were also open hole completions and most wells were stimulated with acid. The average per well recovery was disappointing, about 30,000 STB. As a result, a few wells were hydraulically fractured. The fractured well recoveries approached that of the nitroglycerin-shot wells ${ }^{2}$. 
The third development cycle began in the latter part of 1974 , peaked in 1978 , and continued through 1980. During this period more than 1,000 wells were drilled in the field. The wells were cased through the Chalk and selectively perforated. Common stimulation treatments were large acid jobs and proppant fracturing jobs. Per well recoveries from this group of wells are difficult to ascertain as production in the public record is reported on a lease basis. By the end of 1985 , most of these wells had been abandoned and average per well production for the remaining active wells had fallen to $5 \mathrm{STB} /$ day.

The current development cycle with horizontal wells began in earnest in 1987 when ORYX Energy Company tested 338 STB/day from J.B. Baggett No. 9 through a redrilled 950-foot horizontal lateral. Drilling activity intensified significantly in 1989 after ORYX released information about their horizontal drilling experience.

\subsection{Geology}

Deposition of the Austin Chalk in the Pearsall vicinity was strongly influenced by the San Marcos Arch which created a shallow-marine environment ${ }^{4}$. The shallowest water occurred in the present day Austin-San Antonio vicinity. Water depths increased to the southeast, south, and southwest. This depositional setting is illustrated by Figure 7.1.1.

While deposition of chalks was common during the Cretaceous, the Austin Chalk differed with respect to the relative abundance of shallow-marine benthonic skeletal remains. These remains were deposited in the shallower waters on and surrounding the San Marcos Arch. Periodically, some of these remains were swept downdip into a deeper water marine setting, resulting in higher concentrations of metastable carbonates like high-magnesium calcite and aragonite. The presence of these minerais profoundly affected diagenesis. As a consequence, the Austin Chalk porosity in Pearsall Field has been reduced to the range of 3 percent to 7 percent, and permeability is usually less than 0.01 millidarcies.

Three diagenetic processes contributed to the porosity evolution: (1) early physical compaction, (2) cementation due to stabilization of metastable carbonates, and (3) pressure solution. The first two processes acted during burial and before the advent of pressure solution. In some cases the lithification associated with the stabilization of the aragonitic sediments was sufficient to resist the effects of pressure solution which is generally more dominant with increasing depth of burial. Thus, while there is a general trend of porosity decrease with depth, there are localized anomalies of better porosity development. Figure 7.1.2 illustrates the porosity variation with depth for the Austin Chalk in comparison to typical North Sea chalk reservoirs.

On the western flank of the San Marcos platform, the Austin Chalk thickens in a southwesterly direction as much as 700 feet in the Pearsall Field vicinity. Figure 7.1.3 is a representative well $\log$ illustrating the current field stratigraphic nomenclature and a possible correlation to outcrop studies in central Texas". The lower Chalk is comprised of the basal " $E$ " and overlying " $D$ " members. Two pyroclastic clay beds bracket the " $\mathrm{C}^{n}$ member of the middle Chalk. The upper " $B$ " and " $A$ " members are separated by a persistent bentonite bed. An uppermost marl unit occurs in the northwestern part of the field, thickening to as much as 90 feet. This stratigraphic sequence is capped by the Upson Clay. 
Within Pearsall Field, the lower Chalk thickens while the upper Chalk thins toward the Pearsall anticline and shows evidence of growth fault thickening into the Charlotte Graben. The structural features in this area are shown on Figure 7.1.4. Westward, into the Rio Grande Embayment, the upper Chalk thickens rapidly and becomes marly. These features are illustrated by stratigraphic section $X-Y$, Figure 7.1.5.

The role of fractures in controlling productivity and recoverable reserves of Chalk wells is undisputed. There is also general agreement that the fractures are of tensional origin, near vertical dip and strike parailel to the basin margin. The fractures more commonly dip steeply to the southeast, although northwestwardly dipping fractures are not uncommon. The trend of the fractures is NE-SW $\pm 15^{\circ}$ (approximate) but some variation with structure has been observed in some of the longer horizontal wells. Schafer ${ }^{6}$ reports that 33 fracture strike observations in 28 Pearsall wells ranged from $\mathrm{N} 13^{\circ} \mathrm{E}$ to $\mathrm{N} 57^{\circ} \mathrm{E}$ with a mean of $\mathrm{N} 39.5^{\circ} \mathrm{E}$, a mode of $\mathrm{N} 39^{\circ} \mathrm{E}$, and a standard deviation of $10.7^{\circ}$.

There is less agreement on the vertical and lateral extent of individual fractures and the spacing between fracture "swarms;" i.e., zones of intense fracturing separated by relatively non-fractured rock containing little or no oil saturation. These factors are of obvious importance for development planning and reserve assessment.

The spacing between fracture swarms varies widely from being almost continuous at frequencies up to several fractures per foot for several hundred lateral feet, to undetectable in dry holes. A periodicity of fracture development has been postulated ${ }^{7.8}$ on the basis of core, log, and drilling observations. These data suggest that the intra-swarm, non-fractured rock is practically devoid of hydrocarbons. This interpretation suggests that the hydrocarbons migrated into the Chalk along fracture planes, eventually saturating the low permeability matrix rock adjacent to the fractures. The Chalk and the underlying Eagleford Shale was a possible source rock.

The vertical continuity of fractures is also uncertain. Obviously, fractures do not always extend from top to base of the Chalk because development drilling has proven the existence of vertical isolation in some areas of the reservoir, at least. On the other hand, fractures in core and outcrop have been observed to cut across marly and shaley intervals. Also, marly intervals are prevalent in most productive intervals to the extent that the produced oil volumes could not be explained uniess the bulk of the interval was fractured.

There is also general agreement that there is no communication normal to the fracture trend (from swarm to swarm). The extent of communication along the fracture trend is obviously much better. The magnitude of oil recovery from many wells requires large (i.e., long) drainage areas. There is disagreement on how persistent communication is along a single fracture swarm. Production experience is reported ${ }^{8}$ to have shown very good communication along trend for a mile or more.

Fracture studies ${ }^{9}$ of the Austin Chalk outcrops have provided some important observations:

1. The pattern of fracture development suggests a very brittle deformation response. 
2. Closely spaced parallel fractures often pass and curve toward each other to join up at right angles to the fracture strike suggesting that fracturing took place at low differential stress, i.e., shallow burial depth.

3. Fractures tend to be contained by marly bed thicknesses exceeding four inches.

4. Fracture spacing averages three to four inches, normal to the local structural strike. This is about half the along-strike fracture spacing.

5. The distribution of fracture spacing is highly skewed towards low values (less than eight inches). The distributions are reasonably fitted by exponential functions of the type:

$$
y=a x^{-b}
$$

6. Many fractures are filled with sparry calcite, most probably precipitated at temperatures exceeding $150^{\circ} \mathrm{C}$.

7. The matrix rock is commonly diagenetically colored and banded parallel to each fracture, clearly indicating cross-flow from fracture to matrix.

The same study identified four structural styles which resulted in increased fracture intensity. Figure 7.1.6, reproduced from Corbett ${ }^{2}$, schematically depicts each fracture system type.

Plunging Anticlinal Fold - Two well-ordered and one poorly ordered fracture sets were observed. The major set was nearly vertical and parallel to the anticlinal axis with lengths up to 50 feet along strike and 15 feet downdip. The secondary set intersected the major set at $70^{\circ}$ with dips varying $30^{\circ}$ either side of vertical and averaging $10^{\circ}$ from vertical. Spacing of this set was less regular, varying from 4 to 60 inches (26-inch average). Their length along strike was limited by major set spacing to about 40 inches and dip lengths averaged 14 inches. The third fracture set lacked order, was highly variable in strike and dip length, and was only developed along the anticlinal crest.

Monoclinal Fold - These structures possess nearly horizontal upper and lower limbs and a gently dipping $\left(5^{\circ}\right.$ to $8^{\circ}$ ) intervening slope. They run parallel to and about one-half mile distant from northwest-dipping faults in the Balcones System. Four sets of fractures are observed in this structure type (Figure 7.1.6-b). The most dominant two form a steeply dipping conjugate pair, striking parallel to the fold axis, $\mathrm{N} 20^{\circ} \mathrm{E}$. Each dip at about $60^{\circ}$, but the northwest-dipping set is more abundant by a factor of two. These are actually small displacement faults of offsets ranging from 4 to 80 inches. They are localized by calcite and clay-filled veins and occur most abundantly in the slope and the synclinal axis. The remaining two sets have the same strike as the conjugate pair and one of these also develops into small faults dipping from $10^{\circ} \mathrm{NW}$ to $30^{\circ} \mathrm{SE}$ with shear displacements of up to a foot.

Listric Normal Faults - A system composed of a master fault accounting for most of the displacement and several small throw subsidiary faults in the foot and hanging walls. The foot wall subsidiary faults all strike parallel to and lie within 16 feet of the master fault with spacings 
of three to seven feet and are truncated by the master fault sole. The spacing of hanging wall subsidiary faults increases with distance from the master fault, continuing as far as 115 feet from the master fauit. The dip lengths of the master and foot wall subsidiary faults exceeded the outcrop exposure of 100 feet. The hanging wall subsidiary faults decreased in dip length with distance from the master fault from 40 feet to six feet. Extension fractures occur in both fault walls but are 1.5 times as frequent in the hanging wall. The hanging wall fractures have the same length trend as the faults. In the foot wall the fracture length is generally constrained to bed thickness.

Graben-In-Graben Normal Faults - Develop into orthogonal striking faults and related fracture sets. Conjugate faults of the Balcones system are the dominant set with the southeast dipping faults having the greater throws. Contained within and striking perpendicular to the dominant set are a second set of conjugate faults. This results in a keystone block within a Balcones graben having 1.5 times the fracture intensity of the remainder of the graben and 2.5 times that of the adjacent horsts.

On the basis of these observations and studies of core recovered from Austin Chalk wells, the authors conclude that most of the fracture mechanisms observed in the surface outcrops can be extrapolated to predict fracture occurrence in the subsurface. They concede, however, that subsurface fracture spacing may be wider by some unknown factor.

\subsection{Reservoir Properties}

The properties of the Austin Chalk reservoir rock and fluids are discussed in this section. This information provided the basis for the reservoir simulator initialization data described in Section 9.2.

Porosity and Permeability - The Pearsall Austin Chalk reservoir is conceptualized as a lateral series of vertical compartments of varying width formed by zones of intense fracture development ${ }^{7,10}$. The term "fracture swarm" is used to denote such a compartment. The swarms are parallel to each other and of uniform strike over long distances. Each swarm is separated from neighboring swarms by varying width intervals of impermeable, unfractured, and watersaturated or dense chalk.

Within each swarm, vertical fractures, paralleling the swarm strike are predominant. A secondary set of steeply dipping fractures are postulated to intersect the principal set at nearly right angles. Microfracturing is extensive within the fracture swarms but almost absent in the inter-swarm rock ${ }^{7}$. Fracture spacing as close as three per foot and maximum fracture porosity of 0.001 as a fraction of core bulk volume is reported by the same source. The presence of secondary fractures would increase the total fracture porosity to some degree. The spacing of the secondary fractures is unknown, but is thought to be wider than the principal set.

The chalk matrix within a fracture swarm is known to be oil-saturated from log response and limited core observations in horizontal wellbores. Conversely, the inter-swarm rock is known by these same means to be devoid of hydrocarbons. Although the core permeability of the chalk matrix is in the microdarcy range, it is probable that oil from the matrix is finding its way into 
the fractures through the microfractures observed in cores. It is extremely difficult to reconcile known recovered oil volumes unless some portion of the matrix hydrocarbon pore volume is regarded as effective and contributing to overall oil recovery.

The fractured chalk forms what is commonly referred to as a dual porosity reservoir system. The concept of dual porosity is a low pore volume, high transmissibility fracture network connecting discrete matrix blocks of higher pore volume and much lower permeability so that virtually all the reservoir flow takes place in the fractures while the matrix provides most of the reservoir storage capacity. The parameter ranges cited ${ }^{7}$ for the effective reservoir rock; i.e., in a fracture swarm, are given below:

$\begin{array}{llll}\text { matrix porosity, } \phi_{\mathrm{m}}, \text { fraction } & 0.02 & - & 0.05 \\ \text { fracture porosity, } \phi_{\mathrm{f}}, \text { fraction } & 0.0005 & - & 0.001 \\ & & & \\ \text { matrix permeability, } \mathrm{k}_{\mathrm{m}}, \text { microdarcies } & 0.01 & - & 0.1 \\ \text { fracture permeability, } \mathrm{k}_{\mathrm{f}}, \text { millidarcies } & 3.0 & - & 10.0\end{array}$

These parameters fit the concept of dual porosity, although the matrix values are uncommonly low.

Reservoir Thickness - The gross thickness of the Chalk varies from about 400 feet to more than 700 feet. Using a porosity cut-off of 3 percent to determine net pay and core data from a vertical well, ORYX has computed a net thickness to gross thickness ratio of 0.321 . The same source ${ }^{11}$ presents average porosity for the net rock of 3.90 percent using the same porosity cutoff and core data from two wells having an aggregate net porous thickness of just 203 feet. Since the average porosity of the net rock is so close to the cut-off, it is likely that the net thickness computation would be very sensitive to the cut-off chosen.

Fluid Properties - The gravity of the Austin Chalk oil varies over an extremely wide range, $21^{\circ}$ through $43^{\circ} \mathrm{API}$, and oils from adjacent wells can have very different gravities, viscosities, gas in solution and color ${ }^{12}$. In Pearsall Field, the range is somewhat narrower, from $29^{\circ}$ to $37^{\circ}$ API, but this is still unusually wide.

Schnerk ${ }^{7}$ has reported the results of one bottom-hole sample as follows: bubble point pressure $2350 \mathrm{psig}$, solution gas-oil ratio of $825 \mathrm{scf} / \mathrm{STB}$, oil formation volume factor 1.5, and oil viscosity of $0.6 \mathrm{cp}$. The author acknowledges that oil composition "varies from well to well," but most wells in his experience have producing gas-oil ratios in the 500-600 scf/STB range. In his view, this supports a lower bubble point value around 1650 psig compared to a virgin reservoir pressure of approximately 2600 psig. 
In their 1990 spacing unit submission to the Texas Railroad Commission ${ }^{11}$, ORYX Energy Company provided the following Pearsall Field fluid data:

$\begin{array}{lccc}\text { stock tank oil gravity, }{ }^{\circ} \mathrm{API} & 32 & - & 37 \\ \text { solution gas-oil ratio, scf/STB } & 280 & - & 615 \\ \text { separator gas specific gravity (air = 1) } & 0.93 & - & 0.95 \\ \text { oil formation volume factor, v/v } & 1.382 & - & 1.183 \\ \text { reservoir temperature, }{ }^{\circ} \mathrm{F} & 190 & & \end{array}$

Rock-Fluid Properties - Included in this category are capillary pressure, wettability, relative permeability, and pore volume compressibility. Pearsall data is almost completely lacking in the public data realm. Indeed, the only parameter found was an assumed value of matrix irreducible water saturation of 0.3 which was further assumed to be the initial water saturation ${ }^{7}$. This was contradictory to the 0.65 value used in the reserves computations found in the ORYX spacing unit submission ${ }^{11}$.

\subsection{Reservoir Performance Data}

Actual well performance data, (fluid production rates, bottom-hole measured pressures, wellhead pressures, etc.) were sought to provide a test case for the simulation approach proposed for this study. Data of this sort is available in the public record but is limited to monthly lease production and annual well tests. This does not provide a practical basis for allocating lease total production to individual wells in multi-well leases. Furthermore, reservoir pressure data are very limited. Recently, a field operator agreed to provide performance data on selected leases, a multi-well lease with both vertical and horizontal wells and three, single horizontal well leases.

The operator-supplied data are daily test rates of oil, gas, and water production and, during certain periods, measured bottom-hole pressures from wells equipped with surface readout devices. These data were only recently received and have not yet been fully analyzed or used for simulation test cases. The data for the horizontal wellbores are presented in Figure 7.3.1 through Figure 7.3.5. The wells designated B-1 and B-2 are from the same multi-well lease. The wells designated as A-1, A-2 and P-1 are all single well leases.

Analyses of these data and test case simulations are planned to be carried out in the early part of the second fiscal year of the project. The findings of that work will be discussed in the second fiscal year progress report.

\subsection{Examination of Vertical and horizontal Well Performance}

An examination of Pearsall Field, Austin Chalk, vertical well and horizontal well performance was undertaken to provide guidelines for the simulation studies. In this context, several items were investigated, i.e.:

- Distribution of ultimate recovery for vertical wells. 
- Distribution of ultimate recovery for horizontal wells.

- Distribution of the amount of displacement in pay for both vertical and horizontal wells.

- Nature of the relationship between ultimate recovery and its associated amount of displacement in pay.

These items were examined through analysis of historical performance data via engineering and statistical methods. This effort consisted of four steps: selection of a data sample, the determination of ultimate recoveries, statistical analysis of the data, and discussion of results.

\subsection{Sample Selection.}

The weil sample was chosen from Austin Chalk completions in Pearsall Field for consistency with the simulation study. All data were obtained from public records or from commercial sources which accumulate public sector data. Data in the public domain is limited, for most instances, to well completion information, initial well potential and monthly production reported by lease. In some instances, a lease contains either a single well or a single active well at any given time. A list of data item variable names with a brief description of each can be found in Appendix A.

Specific wells and leases were sought which would provide definitive production history trends for both horizontal and vertical well completions. Previous experience with horizontal completions indicated a minimum requirement of approximately 12 months of performance data. Thus, all leases containing at least one horizontal well completed prior to April, 1990 were selected. The leases found fell into two main groups: those with prior production from vertical wells and those with no prior vertical well production. Each lease was further categorized according to the number of horizontal completions it contained, as being either a single well lease or a multiple well lease. The first two columns of Table 8.1.1 show the number of wells in each category without regard to completion date and production data availability. These were the target group of wells. The final two columns show the numbers of wells on leases which satisfied the date and production data criteria.

The sample data are widely distributed across the field and do not represent a grouping of contiguous leases. The spatial distribution of the sample leases covers an area extending some 30 miles east, 20 miles west, 13 miles north and 10 miles south of the ORXY J.B. Baggett lease. 
Table 8.1.1

Sample Categories and Numbers of Wells

\begin{tabular}{|c|c|c|c|c|}
\hline \multirow[b]{2}{*}{ Category } & \multicolumn{2}{|c|}{ Original Search } & \multicolumn{2}{|c|}{ Final Search } \\
\hline & Horiz. & Vert. & Horiz. & Vert. \\
\hline \multicolumn{5}{|l|}{ Leavea Hiving Prior Vertical Production } \\
\hline Lesuce with single horizontul wells & 10 & 25 & 8 & 25 \\
\hline Levea with multiple horizontel welle & 34 & 33 & 7 & 31 \\
\hline \multicolumn{5}{|l|}{ Lewer Withom Prior Vertical Production } \\
\hline Leates with single horizontal wells & 53 & 0 & 35 & 0 \\
\hline Leaves with multiple borizontel wells & 51 & 0 & 24 & 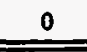 \\
\hline Totale & 148 & 58 & 74 & 56 \\
\hline
\end{tabular}

\subsection{Determination of Ultimate Recovery.}

The production data were analyzed to determine an ultimate oil recovery for each completion. All leases were extrapolated to a common ending rate which was arbitrarily applied to all leases with no regard for the number or type of producing wells. The selection of a single final rate, simplified the determination of lease uitimate recovery but it probably does not reflect the average economic limit for these leases. Ultimate recovery was the summation of cumulative production to the end of the historical period and the extrapolated estimate of remaining reserves. Ultimates obtained from the sample data set were divided into subsets according to well type in order to obtain and compare results among the respective types.

The analyses were made with the assistance of commercial software which facilitated both diagnostic plot generation (log rate versus time and $\log$ rate versus $\log$ time) and application of dimensionless type-curves. In most instances, data which could not be extrapolated by semi-log analysis were amenable to type curve analysis of the log-log plots.

Ultimate recoveries were determined for all leases with definitive production rate trends. Leases containing horizontal completions were examined to see if the ultimate recovery of individual wells could be ascertained. This proved to be possible for some wells. Otherwise, multi-well ultimates were determined.

Regardless of how determined, the ultimate recoveries were the only interpretative data to be included in the statistical analysis. All other data used for statistical analysis such as displacement in pay was regarded as fixed and not subject to interpretation.

\subsection{Statistical Analysis.}

The data described in Section 8.1 and the respective ultimate recoveries for a well or lease basis were processed through the use of SPSS/PC + statistical software. Descriptive statistics were 
performed on several items and a test for relationship between ultimate recovery and displacement in pay ${ }^{\dagger}$ was performed.

Descriptive statistics for ultimate recovery, displacement in pay, and ultimate recovery divided by displacement in pay were calculated for various well groupings. The values computed for each grouping included mean, the median, and the 5 percent trimmed mean. Outlier and extreme data points can distort the mean computation, whereas, the trimmed mean tends to discount extreme points giving a better representation of the mean. The following discussions summarize the analysis of each well grouping. A box plot and descriptive statistics details for each well grouping can be found in Appendix B.

Table 8.3.1 summarizes the statistical computations for eight different groupings of wells. The first and second differentiate on the basis of well type, either vertical or horizontal. The next two grouping pairs apply only to the horizontal well data: grouping 3 and 4 differentiate leases with and without prior vertical well production and grouping 5 and 6 separate leases having multiple well and single well solutions. The last two groupings apply to horizontal wells with single well solutions and differentiate on the basis of the ability to flow upon initial completion.

The vertical well grouping includes all ultimate recovery values attributable to vertical completions on both single and multiple well leases. Similarly, the horizontal well grouping comprises recoverable values ascribed to horizontal completions, including both single and multiple well solutions.

\footnotetext{
${ }^{\dagger}$ Borehole length within the gross pay interval.
} 
Table 8.3.1

Ultimate Recovery - Descriptive Summary

(Units are 1000 STB)

\begin{tabular}{|c|c|c|c|c|c|c|}
\hline Groupings & Wells & Men & Modien & $\underset{\text { Trimed }}{5 \%}$ & $\underset{\text { Malinime }}{\text { Value }}$ & 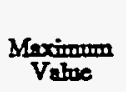 \\
\hline Vertical Well & 56 & 29.3 & 17.1 & 27.8 & 2.1 & 81.9 \\
\hline Horizonal Wells & 74 & 117.4 & 71.1 & 104.0 & 7.2 & 488.7 \\
\hline Well zubrotal & 130 & & & & & \\
\hline \multicolumn{7}{|c|}{ Horizontal Wells } \\
\hline Lenes - to prior vertical production & 59 & 127.9 & 77.2 & 114.5 & 7.2 & 488.7 \\
\hline Ieasea - prior vertical production & 15 & 76.3 & 43.3 & 72.2 & 19.4 & 207.0 \\
\hline Well zabtotal & 74 & & & & & \\
\hline \multicolumn{7}{|c|}{ Horizontal Wells } \\
\hline Leasca - mohi-well solutions & 25 & 152.6 & 114.4 & 141.2 & 22.2 & 488.7 \\
\hline Leave - singlo-well solutions & 49 & 99.5 & 69.0 & 90.3 & 7.2 & 372.4 \\
\hline Well Subtotel & 74 & & & & & \\
\hline \multicolumn{7}{|c|}{ Horizontal Wells on Leases With Single-Well Solutions } \\
\hline Flowing initial completion wells & 27 & 136.3 & 90.5 & 130.3 & 13.1 & 372.4 \\
\hline Non-flowing initial conpletion weils & 22 & 54.4 & 37.7 & 50.4 & 7.2 & 179.1 \\
\hline Well Subrotal & 49 & & & & & \\
\hline
\end{tabular}

Displacement in pay represents an estimate of the pay section contributing production to a given wellbore. For a vertical well, the displacement was taken to be the total perforated interval (top to bottom). For a horizontal well, the wellbore length within the reservoir interval was assumed. Table 8.3.2 summarizes the properties of the displacement in pay distribution.

Table 8.3.2

Displacement in Pay - Descriptive Summary

(Units are feet)

\begin{tabular}{|c|c|c|c|c|c|c|}
\hline & Well & Men & Modien & $\underset{\substack{5 \% \\
\text { Trimed }}}{\sin }$ & $\begin{array}{c}\text { Mrinimum } \\
\text { Vyboe }\end{array}$ & $\frac{\text { Maximom }}{\text { Valuo }}$ \\
\hline Vertical Well & 56 & 355.0 & 333.0 & 350,0 & 240.8 & 57.0 \\
\hline Horizontel Wells & 74 & 2272.0 & 2182.0 & 2255.0 & 502.0 & 4133.0 \\
\hline Well mabeotel & 130 & & & & & \\
\hline
\end{tabular}


The computed displacement values represent upper limits of effective thickness. The thickness that actually contributes the production, the net effective thickness, is expected to be somewhat lower. This would be particularly true of a horizontal well wherein effective pay is constrained to the fracture swarms, whereas displacement is taken as the entire borehole length within the reservoir section. Vertical wells on the other hand are cased and selectively perforated, presumably in the effective intervals, so the ratio of effective pay to displacement should be higher.

The displacements were paired with ultimate recovery for each well to determine values for recovery per foot of displacement. The mean values, grouped as presented in Table 8.3.1, are provided in Table 8.3.3. This variable was an attempt to normalize ultimate recovery to permit vertical and horizontal well comparison on a barrel per foot basis. The overstatement of displacement will tend towards understatement of the barrel per foot figures. For the reasons cited above, this understatement will tend to favor the vertical well values.

Table 8.3.3

Ultimate Recovery per Displacement in Pay - Descriptive Summary (Units are STB/foot)

\begin{tabular}{|c|c|c|c|c|c|c|}
\hline Groupings & Well & Mens & Moding & $\begin{array}{c}5 \% \\
\text { Trimened } \\
\text { Miend }\end{array}$ & $\begin{array}{l}\text { Minimingm } \\
\text { Vilue }\end{array}$ & $\begin{array}{l}\text { Maximum } \\
\text { Valbe }\end{array}$ \\
\hline Vertical Wells & 56 & 82.4 & 53.9 & 78.2 & 3.7 & 234.3 \\
\hline Horizontal Well & 74 & 58.9 & 32.8 & 53.6 & 3.4 & 245.3 \\
\hline Well mabtocal & 130 & & & & & \\
\hline \multicolumn{7}{|c|}{ Horizontal Wells } \\
\hline Leased - no prior vertical production & 59 & 59.0 & 36.7 & 53.2 & 3.4 & 245.3 \\
\hline Leases - prior vertical production & 15 & 58.2 & 21.3 & 56.2 & 7.6 & 145.7 \\
\hline Well rubtotal & 74 & & & & & \\
\hline \multicolumn{7}{|c|}{ Horizontal Wells } \\
\hline Leasea - multi-well sobrtions & 25 & 68.3 & 43.9 & 66.3 & 10.2 & 163.4 \\
\hline Leasea - single-well solution & 49 & 54.1 & 31.5 & 47.2 & 3.4 & 245.3 \\
\hline Well Subtotal & 74 & & & & & \\
\hline \multicolumn{7}{|c|}{ Horizontal Wells on Leases With Single-Well Solutions } \\
\hline Flowiog initial completion well & 27 & 77.1 & 54.7 & 71.8 & 6.7 & 245.3 \\
\hline Non-flowing initial conpletion weils & 22 & 25.7 & 19.1 & 23.6 & 3.4 & 88.6 \\
\hline Well Subtotal & 49 & & & & & \\
\hline
\end{tabular}

The ranges of values obtained, 3.7 to $234.4 \mathrm{STB} / \mathrm{ft}$ for vertical completions and 3.4 to $245.3 \mathrm{STB} / \mathrm{ft}$ for horizontal completions, suggest heterogeneity of the pay section across the area sampled. Wellbores which penetrate thick intervals of high fracture density should yield high 
values of ultimate recovery per displacement in pay. Wellbores which encounter infrequent fracturing would yield very low values. Although mapping of this variable might provide some indication of where fracturing is best developed, it was not attempted.

A statistical test for the existence of a relationship between ultimate recovery and displacement in pay was performed using the single horizontal well lease data. These data were chosen because they should possess the least possible degree of ambiguity due to other well interference. This does not preclude, however, interference from wells on offsetting leases. The selected data are crossplotted on Figure 8.3.1. If it is hypothecated that the variables are completely unrelated, the $\chi^{2}$ of the population would be zero. If this hypothesis can be disproved, it can be said that a relationship does indeed exist. If the hypothesis can not be disproved, it must be concluded that no relationship exists.

Table 8.3.4

Resuits of $\chi^{2}$ Test for Ultimate Recovery (STB) Versus Displacement (feet)

\begin{tabular}{|c|c|c|c|c|c|c|}
\hline \multirow[b]{2}{*}{ Cleser } & \multirow[b]{2}{*}{$\begin{array}{l}\text { Recovery } \\
\text { Min - Max }\end{array}$} & Cles & 1 & 2 & 3 & \multirow[b]{2}{*}{ Row Total } \\
\hline & & Displucement: Min. & $\begin{array}{c}0 \\
\text { through } \\
1.499\end{array}$ & $\begin{array}{l}1,500 \\
\text { throokt } \\
2,499\end{array}$ & $\begin{array}{c}2,500 \\
\text { through } \\
4.200\end{array}$ & \\
\hline 1 & $\begin{array}{l}0 \\
\text { barough } \\
49.999\end{array}$ & 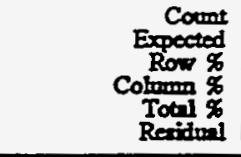 & $\begin{array}{r}4 \\
4.4 \\
22.2 \\
33.3 \\
8.2 \\
. .4\end{array}$ & $\begin{array}{r}10 \\
8.8 \\
55.6 \\
41.7 \\
20.4 \\
1.2\end{array}$ & $\begin{array}{r}4.8 \\
2.8 \\
30.8 \\
8.2 \\
-.8\end{array}$ & $\begin{array}{r}18 \\
36.7\end{array}$ \\
\hline 2 & $\begin{array}{l}50,000 \\
\text { through } \\
129,999\end{array}$ & 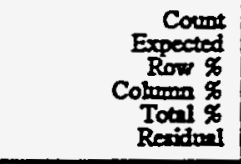 & $\begin{array}{r}4.7 \\
21.1 \\
21.1 \\
8.2 \\
. .7\end{array}$ & $\begin{array}{r}9.9 \\
47.3 \\
47.4 \\
37.5 \\
18.4 \\
-.3\end{array}$ & $\begin{array}{r}5.6 \\
31.6 \\
46.2 \\
12.2 \\
1.0\end{array}$ & $\begin{array}{r}19 \\
\vdots \\
38.8\end{array}$ \\
\hline 3 & $\begin{array}{l}130,000 \\
\text { through } \\
489,000\end{array}$ & 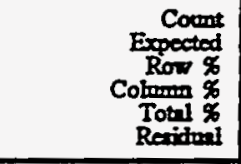 & $\begin{array}{r}24 \\
2.9 \\
33.3 \\
33.3 \\
8.2 \\
1.1 \\
\end{array}$ & $\begin{array}{r}5.5 \\
51.9 \\
41.7 \\
20.8 \\
10.2 \\
-.9\end{array}$ & $\begin{array}{r}3.3 \\
3.2 \\
25.0 \\
23.1 \\
6.1 \\
-.2 \\
\end{array}$ & $\begin{array}{r}12 \\
\\
24.5\end{array}$ \\
\hline & Colomm & $\underset{\text { Todel } \%}{\text { Count }}$ & $\begin{array}{r}12 \\
24.5\end{array}$ & $\begin{array}{r}24 \\
49.0\end{array}$ & $\begin{array}{r}13 \\
26.5\end{array}$ & $\begin{array}{r}49 \\
100 \\
\end{array}$ \\
\hline
\end{tabular}

\begin{tabular}{|c|c|}
\hline Strtintical Propenty & Vabee \\
\hline 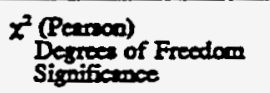 & $\begin{array}{l}1.13173 \\
4.88921\end{array}$ \\
\hline Phi & 0.15198 \\
\hline Cruner's V & 0.10746 \\
\hline Contingedey Coefficient & 0.15025 \\
\hline
\end{tabular}

To enable the $\chi^{2}$ calculation, each variable distribution was subdivided into three class intervals by visual examination. Thus, all ultimate recovery values in the range 0 to 49,999 STB were 
in reserves class one; values from 50,000 to 149,999 were class two; and values from 150,000 to 489,000 were class three. Similarly , displacement in pay values between 0 and 1,499 feet were displacement class one; 1,500 to 2,499 were class two; and 2,500 feet to 4,200 were class three. The class interval data and the $\chi^{2}$ calculation are summarized in Table 8.3.4.

The significance of a $\chi^{2}$ of 1.13173 is shown to be 0.88921 . This means that approximately 88.9 percent of the time, a sample will yield a $\chi^{2}$ of 1.13173 or larger from a population whose true $\chi^{2}$ is assumed to be zero. This probability is much too large to reject the assumption; therefore, it is concluded that the variables are quite probably unrelated.

\subsection{Discussion}

Comparison of the data presented in Table 8.3.1 through Table 8.3.3 allows several observations to be made. The results are compared on an average basis as represented by the $5 \%$ trimmed mean value. Comparisons are made for: (1) vertical versus horizontal completions, (2) horizontal wells on leases with prior vertical well production versus horizontal wells on single well leases, and (3) horizontal well completions which initially flowed versus those artificially lifted.

The $104.0 \mathrm{mSTB}$ average ultimate recovery for a horizontal completion is significantly larger than the vertical completion value of $27.8 \mathrm{mSTB}$ (Table 8.3.1). This difference seems to confirm the higher probability that horizontal wells encounter more fracture swarms than do vertical wells. Vertical wellbores are probably limited to a single fracture swarm, whereas, horizontal boreholes may penetrate several fracture swarms. Even for dissimilar ratios of productive section to total displacement in pay, a horizontal well may be drilled so that it encounters more reservoir quality rock than a vertical well.

The average vertical completion ultimate recovery per foot of displacement in pay of 78.2 STB is greater than the comparable average of $53.6 \mathrm{STB} / \mathrm{ft}$ for horizontal completions (Table 8.3.3). In this instance, the difference is most likely due to the overstatement of horizontal displacement as compared to the vertical displacement, as was explained in the discussion of Table 8.3.2. If the displacement values could be brought more in line with the net effective thickness contributing the reserves, it is considered likely that the comparison would be tipped in favor of the horizontal wells.

Referring again to Table 8.3.1, comparison of the $114.5 \mathrm{mSTB}$ average recovery from horizontal completions on undeveloped leases (no prior vertical well production) against the $72.2 \mathrm{mSTB}$ average for horizontal completions on leases with prior vertical production, appears to indicate that horizontal well recovery is reduced by prior vertical well production. This observation is not unexpected since the fracture swarms partially depleted by prior vertical well production will most likely be also penetrated by the horizontal borehole.

In contrast to the preceding observation, the corresponding per foot recoveries given in Table 8.3.3, 53.2 STB/ft versus 56.2 STB/ft, suggest that prior vertical production has little impact on ultimate recovery when it is related to horizontal displacement. This observation is probably incorrect or at best incomplete. The comparison of the median values supports the expected result that prior production does impact the recovery per foot. 
Distinguishing horizontal wells according to their ability to flow at initial completion (last two rows of Table 8.3.1) shows that flowing wells have an average ultimate recovery of $130.3 \mathrm{mSTB}$ as compared to $50.4 \mathrm{mSTB}$ for non-flowing completions. A similar comparison is provided by Table 8.3.3 in terms of recovery per foot of displacement in pay: $71.8 \mathrm{STB} / \mathrm{ft}$. for flowing completions and 23.6 STB/ft for non-flowing completions. Both observations are consistent with the expectation that higher reservoir energy environments, as evidenced by the flowing initial completions, should yield larger recovery values.

The $\chi^{2}$ test (Table 8.3.4) indicated that horizontal well ultimate recovery and displacement in pay are not correlated. The variability of the key unknowns, like fracture swarm frequency and oil in place per swarm may preclude such a simple relationship. Nonetheless, it seems highly likely that ultimate recovery is dependent on one or more variables which are somehow related to displacement length. No other explanation exists for the observation that the average ultimate recovery for a horizontal completion is larger than that for a vertical completion.

\subsection{RESERVOIR SIMULATION}

A mathematical model for single-phase flow in a dual porosity system was first solved by Barenblatt ${ }^{13}$ and later refined by Warren and Root $^{14}$. The Warren and Root model assumes that the fractures are orthogonal and parallel to one of the three permeability axes. The fractures subdivide the matrix rock into a regular array of identical homogeneous rectilinear blocks. Along each axis, the fractures are assumed to be evenly spaced and of constant aperture. Flow can occur between matrix and fracture, but matrix-matrix flow cannot occur. Matrix-fracture flow is governed by a shape factor which is a function of the matrix block geometry.

Other workers ${ }^{15-21}$ incorporated the Warren and Root model in existing black-oil reservoir simulators and extended the mathematics to describe three-phase flow. More recent workers have dealt with methods to more accurately treat gravity segregation and capillary imbibition.

The program used for the simulations described in this report is a modification of the TRIAD program, a state-of-the-art general purpose reservoir simulator which provides dual-porosity treatment as an option. The modifications allow implicit treatment of horizontal wells and deformation of the porous media; i.e., both porosity and permeability are functions of pore pressure. The revised program has been renamed TETRAD. A description of the features of TETRAD can be found in Appendix $C$.

The program was extensively tested following modification to ensure that it was performing correctly. The problems posed in the Sixth SPE Comparative Solution Project for dual-porosity simulators ${ }^{22}$ provided one source of test problems. The waterflood test problems published by Kazemi ${ }^{15}$ were also simulated. The TETRAD solutions agreed with the published solutions of Kazemi and compared very favorably with those of the Comparative Solution Project participants.

\subsection{Model Description}

The conceptual Austin Chalk model advocated by Schnerk ${ }^{7}$ and Lichtenberge ${ }^{10}$ and described in Section 7.2 was followed in setting up the simulation models used for Task 1 studies. 
The simulation case requirements of Task 1 required initialization of four models: (1) horizontal well natural depletion (horizontal depletion), (2) vertical well natural depletion (vertical depletion), (3) horizontal well secondary recovery (horizontal injection) and, (4) vertical well secondary recovery (vertical injection).

All four models consider a rectangular segment of the reservoir corresponding to a 640-acre well spacing unit. All fracture swarms are assumed to extend beyond the segment and to be of identical strike, paralleling the $Y$-axis (long axis) of the reservoir segment. Thus, a horizontal well drilled parallel to the $X$-axis of the segment would penetrate all fracture swarms. Conversely, a vertical well could only penetrate one fracture swarm.

The horizontal depletion model further assumes the presence of a single horizontal wellbore, drilled through the reservoir segment parallel to its X-axis (horizontal length; 3,733.5 feet). Communication between fracture swarms is non-existent in the reservoir but permissible through the wellbore. Figure 9.1.1 is a schematic representation of the spacing unit for the horizontal depletion model.

The vertical depletion model describes an individual fracture swarm within the basic reservoir segment. Thus, it has a reduced X-direction length equal to the width of one fracture swarm but the same Y-direction length as the horizontal model. This model is depicted in Figure 9.1.2.

The horizontal injection model additionally assumes the existence of a horizontal injection well along both Y-direction boundaries of the reservoir segment and equidistant from the centrally located producing well, as illustrated by Figure 9.1.3.

The vertical injection model is basically the vertical depletion model with the addition of a vertical injection well at each Y-direction boundary, as seen on Figure 9.1.4.

\subsection{Simulator Initialization}

The data used to initialize the simulators for these four models is discussed according to one of the four basic categories: grid definition, reservoir properties, reservoir fluids, initial conditions, and well data.

\subsubsection{Simulation Grid}

The simulators initialized for this study assume a 640-acre rectangular spacing unit with dimensions $3,733.52$ by $7,467.05$ feet. Wells, either vertical or horizontal, were assumed to be drilled along the short central axis of the unit, thus creating an axis of symmetry. The horizontal segment of a horizontal well is assumed to be properly oriented and of sufficient length to develop all fracture swarms occurring in the spacing unit. A vertical well, on the other hand, is assumed to develop only a single fracture swarm. Thus, a spacing unit having seven fracture swarms would be developed by a single horizontal well, while seven vertical wells would be required to develop the same reserves. 
The grid for the horizontal well natural depletion cases had dimensions: NX by NY by NZ of 21 by 9 by 5 . The grid was oriented with the $X$-axis perpendicular to the major fracture set strike and with the $\mathrm{Y}-\mathrm{Z}$ plane parallel to the fracture strike-dip plane.

The assumed gross thickness of the reservoir was a constant 544 feet. This total was equally distributed across the five model layers, making the layer thickness 108.8 feet in the $Z$ direction.

The model included seven identical fracture swarms, each 100 feet wide, but excluded the intervening dense rock. Thus, each fracture swarm was three grid blocks wide in X and each block was 33.33 feet long in $\mathrm{X}$ direction. The excluded dense rock was assumed to be equally distributed between swarms; i.e., 433.34 feet of dense rock between each swarm. The horizontal well flowing pressure gradient was adjusted to compensate for omission of the dense intervals. Communication between fracture swarms was prevented by explicitly setting the $X$ direction transmissibility of every third grid block to zero.

The $Y$ direction grid spacing varied logarithmically from 33.33 feet at the well cell to 1,491.91 feet at the spacing unit boundary. Table 9.2.1 lists the $Y$ direction grid block sizes.

Table 9.2.1

Horizontal Depletion Model

Y Direction Grid Sizes (feet)

\begin{tabular}{c|c}
$\mathrm{J}$ & $\Delta \mathrm{Y}$ \\
\hline 1 & 33.33 \\
2 & 43.72 \\
3 & 72.39 \\
4 & 119.87 \\
5 & 198.48 \\
6 & 328.64 \\
7 & 544.16 \\
8 & 901.02 \\
9 & $1,491.91$ \\
\hline \hline Total & $3,733.52$
\end{tabular}

The injection case horizontal well model dimensions in the $\mathrm{X}$ and $\mathrm{Z}$ directions were identical to the natural depletion model. However, the $\mathrm{Y}$ direction grid was refined at both ends (Table 9.2.2) to better define conditions in the vicinities of the production and injection wellbores. Thus, there are two axes of symmetry in this model, one through the center of producing well and another through the injection well center, making each well a half well. 
Table 9.2.2

Horizontal Injection Model

Y Direction Grid Sizes (feet)

\begin{tabular}{c|c}
$\mathrm{J}$ & $\Delta \mathrm{Y}$ \\
\hline 1 & 38.53 \\
2 & 96.13 \\
3 & 263.56 \\
4 & 722.59 \\
5 & $1,491.92$ \\
6 & 722.59 \\
7 & 263.56 \\
8 & 96.13 \\
9 & 38.53 \\
\hline \hline Total & $3,733.52$ \\
\hline
\end{tabular}

It is emphasized that both horizontal well models, the natural depletion model and the injection model, were identical in area and volume. Schematic representations of the two grids can be seen in Figure 9.2.1 and Figure 9.2.2.

\subsubsection{Grid Node Data}

The input data items described in this section apply to both horizontal and vertical modeis and both depletion and injection configurations.

Net Thickness - The assumed total net reservoir thickness of 174 feet was equally subdivided among the five model layers. Thus, the effective ratio of net thickness to gross thickness was 0.32 .

Depth - The depth of each grid node was computed assuming a monoclinal structure, dipping 88.3 feet/mile $\left(1^{\circ}\right)$ parallel to the $X$ axis. A minimum top of reservoir depth of 6,290 feet was assumed along the first column of grid blocks $(I=1, J=1, N Y$. The tops for columns $I=2$ through I $=21$ were computed from this depth, the dip angle, and the cumulative $\mathrm{X}$ departure, including the 433.34 feet of dense rock assumed to separate each fracture swarm (refer to Section 9.3.1).

Porosity - Uniform matrix and fracture porosities of 3.36 and 0.0984 percent were assumed for all grid blocks in the model. The fracture value was computed by assuming a constant fracture 
aperture of 0.1 millimeters and three intersecting fracture sets, dividing the matrix into one-foot cubic blocks.

Permeability - Matrix and fracture permeabilities were also assumed to be uniform and isotropic. The assumed values were 10 millidarcies for the fractures and 100 nanodarcies for the matrix.

\subsubsection{Rock-Fluid Properties}

The properties considered in this category are relative permeability, capillary pressure, and pore compressibility of the matrix and fracture systems.

Relative Permeability - Matrix relative permeability was developed from the empirical correlations of Honarpour ${ }^{23}$. These correlations define relative permeability as functions of porosity, permeability, wettability, lithology, and endpoint fluid saturations. The correlating parameters used to evaluate the correlations are given below:

Rock Type: Carbonate

Wettability: Water Wet

\begin{tabular}{ll}
\hline \hline Irreducible water saturation, $S_{\text {wi }}$ & 0.30 \\
Residual oil saturation, water, $S_{\text {orw }}$ & 0.28 \\
Water relative permeability @ $S_{\text {orw }}$ & 0.35 \\
Residual oil saturation, gas, $S_{\text {orz }}$ & 0.16 \\
Gas relative permeability, @ $S_{\text {org }}$ & 0.62
\end{tabular}

The resulting relative permeability curves are shown on Figure 9.2.3 for the oil-water system and by Figure 9.2.4 for the gas-oil system.

Fracture relative permeabilities were assumed to be linear functions of phase saturations with zero residual saturation values.

Capillary Pressure - Matrix capillary pressure was computed assuming capillary pressure endpoints of 1.99 psia when completely water saturated $\left(S_{w}=1.0\right)$ and 59.7 psia at irreducible water saturation, $S_{\mathrm{wi}}$ of 0.3 . Between these extremes it was assumed that the reciprocal of capillary pressure was a linear function of water saturation.

Gas-oil capillary pressure was computed from the oil-water capillary pressures using the familiar relationship:

$$
\mathrm{p}_{\text {cgo }}=\mathrm{p}_{\text {cow }} \sigma_{\mathrm{go}} / \sigma_{\text {ow }}
$$

Gas-oil interfacial tension in dynes $/ \mathrm{cm}, \sigma_{\mathrm{go}}$ was computed from the phase densities as suggested by the work of Van Dijk ${ }^{24}$ and Offeringa ${ }^{25}$ :

$$
\sigma_{g o}=43.36\left(\rho_{o}-\rho_{g}\right)^{4}
$$


Oil-water interfacial tension of 23.33 dynes/cm was assumed.

The computed oil-water and gas-oil capillary pressure functions are displayed on Figure 9.2.5. Each curve is also depicted on the relative permeability plots, Figure 9.2.3 for oil-water and Figure 9.2.4 for gas-oil.

\subsubsection{Initial Reservoir Conditions}

Initial values of reservoir temperature and pressure typical of virgin conditions in Pearsall Field were chosen to initialize the models. The values selected were $190^{\circ}$ Fahrenheit for temperature and 3,000 psi for reservoir pressure at datum depth (6,592 feet).

\subsubsection{Reservoir Fluid Properties}

The PVT properties of the reservoir gas and oil phases were computed from published correlations $^{26-29}$. The unknown parameter values, such as separator temperature, pressure, and produced gas gravity, were allowed to vary until known fluid properties were reasonably matched. Known values were: stock tank oil gravity, $37^{\circ}$ API, saturation pressure, $p_{b}$ of 2350 psig and solution gas-oil ratio, $R_{s}$ of $730 \mathrm{scf} / \mathrm{STB}$. The unknown parameters yielding the best agreement were as follows:

produced gas specific gravity, air $=1$

separator temperature, ${ }^{\circ} \mathrm{F}$

separator pressure, psig

250

The resulting PVT property functions are shown on Figure 9.2.6 and Figure 9.2.7. The data set depicted has the following additional properties:

oil formation factor, $B_{0} @ p_{b}$, psia

slope of $B_{o}$ above $p_{b}, 10^{-6} \mathrm{v} / \mathrm{v} / \mathrm{psia}$

oil viscosity @ $\mathrm{p}_{\mathrm{b}}, \mathrm{cp}$

slope of oil viscosity above $\mathrm{p}_{\mathrm{b}}, \mathrm{cp} \cdot 10^{-5} / \mathrm{psi}$

\subsubsection{Well Productivity and Injectivity}

Well productivity/injectivity parameters were defined using the Peaceman ${ }^{30.33}$ equivalent drainage radius concept, modified as suggested by the author for wells on the edge of the computing grid or wells near an upper or lower boundary. This was necessary since all model wells are edge wells and in some cases they are located near the top or bottom boundary. The method employs a model with finely subdivided grid to effectively isolate the well block. The author has demonstrated that the block can be regarded as isolated if it is centered in a uniform grid and surrounded by five empty grid nodes. This model satisfies the conditions for radial flow. Thus, for the isotropic permeability condition $\left(k_{x}=k_{y}=k_{z}=k\right)$, the following equations define flowing bottom-hole pressure, $p_{w f}$. For the vertical models the equations are: 


$$
p_{w f}=p_{0}-q \mu B_{o} \ln \left(r_{0} / r_{w}\right) / k_{r o}(2 \pi k \Delta z) \ldots \ldots \ldots \ldots \ldots
$$

where:

$$
I_{0}=0.14\left(\Delta x^{2}+\Delta y^{2}\right)^{1 / 2}
$$

and for horizontal models:

$$
\mathrm{p}_{\mathrm{wf}}=\mathrm{p}_{0}-\mathrm{q} \mu \mathrm{B}_{\mathrm{o}} \ln \left(\mathrm{r}_{\mathrm{o}} / \mathrm{r}_{\mathrm{w}}\right) / \mathrm{k}_{\mathrm{ro}}(2 \pi \mathrm{k} \Delta \mathrm{y}) \ldots \ldots \ldots \ldots \ldots \ldots
$$

where:

$$
I_{0}=0.14\left(\Delta x^{2}+\Delta z^{2}\right)^{1 / 2}
$$

Inspection of the equations reveals that the equivalent well block radius, $r_{0}$ is a function of the grid block dimensions, $\Delta x$ and $\Delta y$ or $\Delta x$ and $\Delta z$. Furthermore, the well block pressure, $p_{0}$ will be grid block size-dependent. Therefore, without correction, the bottom-hole pressures computed by the field scale models would be significantly different than that computed by the fine grid. To avoid this problem a correction factor, $f$, is applied in the coarser grid, field scale model so that the $p_{w f}$ equation becomes:

$$
p_{w f}=p_{0}-q \mu B_{o} / k_{x o}\left[\ln \left(f_{0} / r_{w}\right) /(2 \pi k \Delta z)\right] \ldots \ldots \ldots \ldots \ldots \ldots
$$

for the vertical well case and,

$$
\mathrm{p}_{\mathrm{wf}}=\mathrm{p}_{0}-\mathrm{q} \mu \mathrm{B}_{\mathrm{o}} / \mathrm{k}_{\mathrm{so}}\left[\ln \left(\mathrm{fr}_{\mathrm{o}} / \mathrm{r}_{\mathrm{w}}\right) /(2 \pi \mathrm{k} \Delta \mathrm{y})\right]
$$

for the horizontal well case.

Referring to Equation 9.7 and Equation 9.8, the terms enciosed in brackets are independent of pressure and saturation. In the TETRAD simulator this term is given the variable name PICIW. Thus, the problem reduces to defining a PICIW value for the field scale model which will yield the same $\mathrm{p}_{\mathrm{wf}}$ as the fine grid model. This can readily be done by making a field scale test run assuming $f=1$ to determine the uncorrected pressure drawdown, $p_{0}-p_{\text {wff }}$. Since the pressure drawdown is directly proportional to PICIW, the PICIW scaling factor is simply the ratio of this drawdown to the drawdown needed to match the fine grid $p_{w r}$.

\subsection{Primary Recovery Forecasts for a Horizontal Well}

The base case horizontal depletion model regarded the reservoir segment as seven identical fracture swarms, isolated from each other by transmissibility discontinuities. Most of the sensitivity runs were made with some variation of this model. Taking as an example the series of runs testing shape factor sensitivity, the base case (Case H1A) assumed one-foot cubic matrix blocks, Case $\mathrm{H} 6$ assumed one-foot square columnar blocks, and Case $\mathrm{H7}$ assumed one-foot wide tabular blocks. Each case had seven identical fracture swarms, but the fracture swarms of each 
case varied from the other two, due to the differing fracture orientations. The exceptions to the identical fracture swarm assumption were the cases set up to investigate variable fracture swarm oil-in-place effects.

Thirty-five sensitivity runs were made with the horizontal depletion model. All horizontal well cases were terminated when the oil-producing rate fell below $25 \mathrm{STB} /$ day. The ensuing discussion compares each sensitivity case grouping to the base case.

\subsubsection{Completion Layer}

The base case, Case H1A, assumed that the horizontal well would be located in the middle of the reservoir; i.e., in the third model layer. Case H2A considered the situation of a well completed near the base of the reservoir in model Layer 5, as it might be to take advantage of gravity segregation, for example. The final case in this series, Case H3A, positioned the well near the top of the reservoir in model Layer 1, perhaps to delay water production.

The results of these runs are compared to the base case in Figure 9.3.1 in terms of oil production rate in STB/day and gas-oil ratio in scf/STB versus cumulative oil production in STB. The comparison shows that the mid-point completion depth (Case H1A) gives the most favorable rate of recovery, while the bottom completion interval (Case H2A) provides the highest ultimate recovery. The top completion interval (Case H3A) yieids the least desirable results. The cases are compared in terms of cumulative oil produced and recovery as a fraction of oil initially in place in the simulated reservoir segment in the following table. These figures show that recovery is relatively insensitive to positioning of the completion interval.

Table 9.3.1

Oil Recovery Sensitivity to Depth of Completion Horizontal Depletion Model

\begin{tabular}{l|c|c}
\multicolumn{1}{c|}{ Case/Interval } & Cumuiative, mSTB & Fraction \\
\hline \hline H1A, middle & 235.1 & 0.164 \\
H2A, base & 236.9 & 0.166 \\
H3A, top & 230.1 & 0.160
\end{tabular}

\subsubsection{Number of Fracture Swarms}

The reservoir segment was assumed to contain seven fracture swarms in the base case model, H1A. The number was increased to nine for Case H4A and reduced to five for Case H5A. Figure 9.3.2 shows the comparison of results for this series of cases. Oil-in-place, initial production rate and cumulative recovery bear a relationship to each other that is similar, if not directly proportional to the number of fracture swarms. The numerical comparison, given below, reinforces this observation and shows that the fractional recovery is independent of the number of fracture swarms. 
Table 9.3.2

Oil Recovery Sensitivity to Number of Fracture Swarms

Horizontal Depletion Model

\begin{tabular}{l|c|c}
\multicolumn{1}{c|}{ Case/Swarms } & Cumulative, mSTB & Fraction \\
\hline \hline H1A, seven & 235.1 & 0.164 \\
H2A, nine & 302.9 & 0.164 \\
H3A, five & 167.2 & 0.163
\end{tabular}

\subsubsection{Distribution of Swarm Oil-In-Place}

The oil-in-place of a fracture swarm would have a probability distribution determined by the distributions of the volumetric parameters: porosity and oil saturation (matrix and fracture), swarm dimensions (width, length, height), net to gross ratio and formation volume factor. Using a combination of reported data and assumptions, the parameters were assigned either triangular or constant distributions and Monte Carlo simulations were made to define the oil-in-place distribution. The values of the first through seventh octiles provided the fracture swarm oil-inplace volumes in this series of cases. For the Case H18 model, these oil-in-place volumes were randomly assigned to the seven fracture swarms. The same volumes were assigned in ascending order to the fracture swarms of the Case H19 model and in descending order for the Case H2O model, the ordering being with reference to the wellbore beginning. Thus, all three models had the same total oil-in-place and the same statistical distribution but in differing arrangements. That total volume was uniformly distributed to the fracture swarms in the Case H1X model. The Case H1X and Case H1A models differ only in respect to oil-in-place: 1,546,154 STB for Case H1X and 1,435,502 STB for Case H1A.

The results of variable oil-in-place cases were very similar to each other and to the uniform distribution case, Case H1X. There were differences between the oil rate and gas-oil ratio profiles of these three and the uniform distribution, Case H1X, indicating some sensitivity in this respect. Figure 9.3.3 illustrates the maximum range of this difference using Cases H18 and H1X. As Table 9.3.3 shows, the total oil recovery of all four cases was practically identical, indicating no recovery sensitivity to ordering. 
Table 9.3.3

Oil Recovery Sensitivity to Fracture Swarm OOIP Distribution

Horizontal Depletion Model

\begin{tabular}{l|c|c}
\multicolumn{1}{c|}{ Case/Interval } & Cumulative, mSTB & Fraction \\
\hline \hline H18, random & 253.4 & 0.164 \\
H19, ascending & 253.4 & 0.164 \\
H20, descending & 253.3 & 0.164 \\
H1X, uniform & 254.0 & 0.164
\end{tabular}

The effect of total oil-in-place was tested by Case H21 and Case H22. Both had uniform distributions of oil-in-place like Case H1X, but the total was increased to conform to the upper quartile volume $(2,060,761 \mathrm{STB})$ for Case $\mathrm{H} 21$ and reduced to the lower quartile volume $(1,019,037$ STB) for Case H22. Figure 9.3.4 compares these two cases to Case H1X and shows that the oil rate and gas-oil ratio profiles are sensitive to oil-in-place, as one would expect. The recovery comparison in Table 9.3.4 shows a minor sensitivity of fractional recovery to oil-inplace.

Table 9.3.4

Oil Recovery Sensitivity to Total OOIP

Horizontal Depletion Model

\begin{tabular}{l|c|c}
\multicolumn{1}{c|}{ Case/Interval } & Cumulative, mSTB & Fraction \\
\hline \hline H21, upper quartile & 339.7 & 0.165 \\
H1X, median & 254.0 & 0.164 \\
H22, lower quartile & 165.8 & 0.163
\end{tabular}

\subsubsection{Shape Factor}

The dual porosity formulation uses a shape factor in the definition of the matrix-fracture fluid transfer term. Warren and Root ${ }^{14}$ originally defined the shape factor, $\sigma$ for the assumption of single-phase, quasi-steady state flow as,

$$
\sigma=4 \mathrm{~N}(\mathrm{~N}+2) / \mathrm{L}^{2}
$$

where:

$\mathrm{N}=$ number of sets of fractures

$\mathrm{L}=$ block dimension (fracture spacing) 
For cubic block cases, Equation 9.9 reduces to:

$$
\sigma=60 / \mathrm{L}^{2}
$$

Kazemi ${ }^{15}$, working with a multi-phase, unsteady state reservoir simulator revised the shape factor definition as follows:

$$
\sigma=4\left(1 / \mathrm{L}_{\mathrm{x}}{ }^{2}+1 / \mathrm{L}_{\mathrm{y}}{ }^{2}+1 / \mathrm{L}_{\mathrm{z}}{ }^{2}\right) \ldots \ldots \ldots \ldots \ldots \ldots \ldots
$$

where:

$\mathrm{L}_{\mathrm{x}}=$ block dimension in $\mathrm{X}$-direction

$\mathrm{L}_{\mathrm{y}}=$ block dimension in $\mathrm{Y}$-direction

$\mathrm{L}_{\mathrm{z}}=$ block dimension in Z-direction

Again, for the cubic block case, Equation 9.10 reduces to:

$$
\sigma=12 / \mathrm{L}^{2}
$$

Thomas ${ }^{16}$ re-defined the shape factor by adding the terms total fracture block face area, A and fracture block volume, $V_{b}$ as follows:

$$
\sigma=\mathrm{A} / \mathrm{L}_{\mathrm{f}} \mathrm{V}_{\mathrm{b}}
$$

where:

$L_{\mathrm{f}}=\mathrm{a}$ characteristic flow path length

Setting $L_{\mathrm{f}}$ to the distance from a block face to the centroid of the pyramid having the block face as its base and a volume, $\mathrm{L}^{3} / 6$, the author suggests a shape factor as follows:

$$
\begin{aligned}
& A=6 \mathrm{~L}^{2} \\
& V_{b}=\mathrm{L}^{3} \\
& L_{\mathrm{f}}=\mathrm{L} / 6.1 \\
& \text { therefore, } \\
& \sigma=36.6 / \mathrm{L}^{2}
\end{aligned}
$$

Taking the simple cubic block case $\left(\mathrm{L}_{f}=\mathrm{L}\right)$, the Thomas definition then becomes:

$$
\sigma=6 / \mathrm{L}^{2}
$$

The effect of varying shape factor was tested in a suite of six runs, three using the Kazemi definition (Equation 9.10) and three using the Thomas definition (Equation 9.11). All cases used 
a characteristic matrix block dimension of one foot. Table 9.3.5 compares the cumulative production and recovery fraction of these six cases.

Table 9.3.5

Oil Recovery Sensitivity to Dual Porosity Shape Factor

Horizontal Depletion Model

\begin{tabular}{l|c|c|c} 
Case/Shape & $\sigma, 1 / \mathrm{ft}^{2}$ & Cumulative, mSTB & Fraction \\
\hline \hline H1A, cube & 12.0 & 235.1 & 0.164 \\
H6K, column & 8.0 & 240.0 & 0.167 \\
H7K, slab & 4.0 & 245.4 & 0.171 \\
H1T, cube & 36.6 & 210.9 & 0.147 \\
H6T, column & 4.0 & 245.4 & 0.171 \\
H7T, slab & 2.0 & 248.5 & 0.173
\end{tabular}

The case names differentiate the block shape by number and shape factor calculation method by letter: $\mathrm{K}$ for the Kazemi method and $\mathrm{T}$ for the Thomas method, except for Case H1A, which did use the Kazemi shape factor definition. The results show a logical progression, in that recovery increases as the shape factor is reduced, under either method of computation. Further, the Thomas method yieids somewhat higher recoveries for the column and slab geometries. Finally, equal shape factors yield similar recoveries, irrespective of the assumed block geometry (Case H7K and Case H6T).

The recovery performance of the shape factor cases are compared in Figure 9.3.5 (Kazemi method) and Figure 9.3.6 (Thomas method). The visual impression gained from these plots agrees with the observations in the paragraph above.

\subsubsection{Fracture Spacing}

Fracture spacings of one-half, two, and four times the base case spacing were simulated in Case H8, Case H9, and Case H9A, respectively.

In all four cases, including the base case, Case H1A, three sets of fractures were assumed to subdivide the matrix rock into systems of cubic blocks of dimensions as given in the following table. 
Table 9.3.6

Oil Recovery Sensitivity to Fracture Spacing

Horizontal Depletion Model

\begin{tabular}{l|c|c} 
Case/Feet & Cumulative, mSTB & Fraction \\
\hline \hline H8, 0.5 & 216.4 & 0.145 \\
H1A, 1.0 & 235.1 & 0.164 \\
H9, 2.0 & 237.2 & 0.169 \\
H9A, 4.0 & 235.3 & 0.169
\end{tabular}

The cumulative oil productions seem to indicate that there is an optimum block sizet. Production rises rapidly at first as block size is increased, but eventually begins to level and then starts to drop slightly as the block size continues to increase past optimum. The fractional recovery, which considers the variation in oil-in-place caused by fracture porosity reduction as block size increases, reinforces the sharp drop off at the smailest block size. It also shows that the fraction continues to increase as block size is increased, but at a diminishing rate, implying that the recovery factor would asymptotically approach a value of about 0.17 as the block size is increased. To test the validity of this inference, the vertical depletion model was used to simulate the above spacings plus two additional fracture spacings: 10 feet and 0.75 feet. Figure 9.3.7 presents the recovery factor results for both models (horizontal well and vertical well) as a function of block size. The similarity of the horizontal and vertical well results strongly suggests that the Case. H9A result is a maximum.

The reduction of cumulative production for the 0.5 foot block (Case H8) is also clearly illustrated by the oil rate versus cumulative production plot (Figure 9.3.7) but the 1.0, 2.0 and 4.0 foot spacing cases (Case H1A, Case H9, and Case H9A) are very similar and difficult to distinguish until the final fourth of cumulative recovery.

\subsubsection{Relative Conductivity (matrix/fracture)}

Relative conductivity, the ratio of matrix permeability to fracture permeability, was $10^{-5}$ in the base case model. This series of runs looked at the recovery implications of increasing the ratio to $10^{-4}$, Case H12, and of reducing the ratio to $10^{-6}$, Case H13. These changes could be accomplished in one of two ways: keep the fracture permeability constant and change the matrix values as in Case H12 and Case H13, or keep matrix permeability constant and revise fracture permeability as was done for Case H1F and Case H1K.

The performance plot comparing the constant fracture permeability cases, $\mathrm{H} 12$ and $\mathrm{H} 13$, to Case H1A is Figure 9.3.9. It shows that an order of magnitude increase in the relative conductivity, as was done for Case H12, has a much greater effect on the cumulative oil recovery than does an order of magnitude reduction, as in Case H13. In other words, reducing the contrast between fracture and matrix permeability tends to reduce oil recovery more rapidly than

\footnotetext{
${ }^{t}$ The terms block size and fracture spacing are synonymous in the context of this report.
} 
increasing the contrast increases oil recovery. This observation is also evident from the ultimate recoveries shown in Table 9.3.7.

Table 9.3.7

Oil Recovery Sensitivity to Relative Conductivity Horizontal Depletion Model, Fracture Permeability Constant

\begin{tabular}{c|c|c|c|c} 
Case & $\mathrm{k}_{\mathrm{m}}, \mu \mathrm{D}$ & $\mathrm{k}_{\mathrm{m}} / \mathrm{k}_{\mathrm{f}}$ & Cumulative, mSTB & Fraction \\
\hline \hline H12 & 1.0 & $10^{-4}$ & 163.4 & 0.114 \\
$\mathrm{H} 1 \mathrm{~A}$ & 0.1 & $10^{-5}$ & 235.1 & 0.164 \\
$\mathrm{H} 13$ & 0.01 & $10^{-6}$ & 249.8 & 0.174
\end{tabular}

A parallel comparison is made for the constant matrix permeability alternative in Figure 9.3.10 and by Table 9.3.8. Looking at Figure 9.3.10, it is obvious that changing fracture permeability profoundly affects the rate of oil recovery; however, the ultimate recovery realized for a given $\mathrm{k}_{\mathrm{m}} / \mathrm{k}_{\mathrm{f}}$ ratio is about the same, as for the constant fracture permeability alternatives of Table 9.3.7. Thus, it would appear that ultimate recovery is dependent mainly on the ratio of matrix to fracture permeability, increasing as the ratio is reduced and reducing as the ratio is increased.

Table 9.3.8

Oil Recovery Sensitivity to Relative Conductivity Horizontal Depletion Model, Matrix Permeability Constant

\begin{tabular}{c|r|c|c|c} 
Case & $\mathrm{k}_{\mathrm{f}}, \mu \mathrm{D}$ & $\mathrm{k}_{\mathrm{m}} / \mathrm{k}_{\mathrm{f}}$ & Cumulative, mSTB & Fraction \\
\hline \hline H1F & 1.0 & $10^{-4}$ & 150.8 & 0.105 \\
H1B & 10.0 & $10^{-5}$ & 235.1 & 0.164 \\
H1K & 100.0 & $10^{-6}$ & 252.3 & 0.176
\end{tabular}

\subsubsection{Relative Storativity (fracture/matrix)}

The base case fracture porosity was computed assuming a uniform fracture aperture of $0.1 \mathrm{~mm}$ and one-foot cubic matrix blocks. This provided a fracture porosity of 0.000984 . In the series of cases discussed in this section, the ratio of fracture pore volume to matrix pore volume (relative storativity) was altered to either of one-half or four times the base case ratio of 0.0293 . Once again, there were two ways to accomplish this end: keep matrix porosity constant and change fracture porosity, or keep fracture porosity constant and change matrix porosity. Both means were explored.

Matrix porosity was kept constant and fracture porosity was changed to 0.000492 for Case H14 and to 0.003936 for Case H15. These values correspond to assuming cubic matrix blocks surrounded by constant aperture fractures of $0.05 \mathrm{~mm}$ and $0.4 \mathrm{~mm}$, respectively. While fracture aperture changes would be expected to change both fracture porosity and fracture permeability, only porosity was changed for these runs. 
For cubic blocks, the functional relationship of fracture porosity, $\phi_{\mathrm{f}}$ to fracture aperture, $w_{\mathrm{f}}$ and . block size, $L$ is:

$$
\phi_{\mathrm{f}}=\left[\left(\mathrm{L}+\mathrm{w}_{\mathrm{f}}\right)^{3}-\mathrm{L}^{3}\right] /\left(\mathrm{L}+\mathrm{w}_{\mathrm{f}}\right)^{3}
$$

Fracture aperture also enters into the computation of flow from one matrix block to the surrounding fractures in two ways. First in the computation of harmonic mean permeability, $\bar{k}$ :

$$
\bar{K}=\left(w_{f} k_{m}+L k_{f}\right)\left(L+w_{f}\right) / k_{f} k_{m} \ldots \ldots \ldots \ldots \ldots
$$

and the potential gradient

$$
\Delta \Phi / \Delta L=2\left(\Phi_{\mathrm{f}}+\Phi_{m}\right) /\left(L+w_{f}\right) \ldots \ldots \ldots \ldots \ldots
$$

where $\Phi_{f}$ and $\Phi_{m}$ refer to the potential of the fractures and matrix, respectively.

Equation 9.13 indicates that fracture aperture should have a negligible effect on $\bar{k}$ since the product, $w_{f} k_{m}$ approaches zero and fracture aperture is insignificant in relation to the block dimension. The latter reasoning applies to as well to Equation 9.14. Thus, it seems safe to conclude that the sensitivity shown by Case H14 and Case H15 in comparison to the base case, $\mathrm{H} 1 \mathrm{~A}$, is a valid reflection of the relative storativity effect.

Figure 9.3.11 shows that cumulative oil recovery is sensitive to the storativity of the fractures relative to matrix storativity. This, in part, is a reflection of the oil-in-place variation $(1,407,602$ for Case H14; 1,435,512 for Case H1A; and 1,608,337 for Case H15; all in STB) caused by the fracture pore volume change. Table 9.3.9 shows that both cumulative production and fractional recovery increase as the relative storativity of the fractures increases.

Table 9.3.9

Oil Recovery Sensitivity to Relative Storativity Horizontal Depletion Model, Matrix Porosity Constant

\begin{tabular}{c|c|c|c|c} 
Case & $\phi_{\mathrm{f}}$, fraction & $\phi_{\mathrm{f}} / \phi_{\mathrm{m}}$ & Cumulative, mSTB & Fraction \\
\hline \hline H14 & .000492 & .01464 & 226.7 & 0.160 \\
H1A & .000984 & .02929 & 235.1 & 0.164 \\
H15 & .003927 & .11714 & 280.9 & 0.175
\end{tabular}

The relative storativities of Case H1P and Case H1M were the same as those of Case H14 and Case H15, respectively, but the ratios were achieved by changing matrix porosity while keeping fracture porosity constant. As this change alone would have resulted in unacceptably large oil-inplace changes, net thickness was adjusted so that oil-in-place was effectively constant. The modification of net thickness required a reciprocal modification of permeability to retain the same transmissibility from case to case. 
The results of Case H1M, Case H1P, and Case H1A are compared on Figure 9.3.12 in terms of oil production rate and gas-oil ratio versus cumulative. The production rate declines of these cases are similar to the constant matrix porosity cases (Figure 9.3.11) but differ with respect to decline rate and ending cumulative (comparing Case H1M to Case H15 and Case H1P to Case H14). These differences are attributed to the modest oil-in-place departures permitted for the constant matrix porosity cases, i.e. 1,406,620 STB for Case H14 and 1,608,337 STB for Case H15 as compared to 1,435,512 STB for Case H1A; whereas, oil-in-place was not allowed to depart from the Case H1A value for the constant fracture porosity series (Case H1M and Case H1P).

Comparing fractional recovery numbers for Case H1P and Case H1M (Table 9.3.10) to those for Case H14 and Case H15 (Table 9.3.9), the numbers are seen to be similar for comparable storativity ratios. It is concluded, therefore, that relative storativity does control the recovery sensitivity exhibited by this series of runs.

Table 9.3.10

Oil Recovery Sensitivity to Relative Storativity Horizontal Depletion Model, Fracture Porosity Constant

\begin{tabular}{c|c|c|c|c} 
Case & $\phi_{\mathrm{m}}$, fraction & $\phi_{\mathrm{f}} \phi_{\mathrm{m}}$ & Cumulative, mSTB & Fraction \\
\hline \hline H1P & .0672 & .01464 & 230.4 & 0.161 \\
H1A & .0336 & .02929 & 235.1 & 0.164 \\
H1M & .0084 & .11714 & 250.8 & 0.175
\end{tabular}

\subsubsection{Fracture Capillary Pressure}

Capillary pressure was assumed to be nonexistent in the fractures of the base case model. Case H16 and Case H17 considered the effects of nonzero fracture capillary pressures. Fracture oil-water and gas-oil capillary pressure were assumed to be simpie fractions of matrix capillary pressure values: one-haif for Case H16 and two-tenths for Case H17. The same fractions were applied to irreducible water saturation, reducing the Case H16 value to 0.15 and Case $\mathrm{H17}$ to 0.06 .

Figure 9.3.13 displays oil rate and gas-oil ratio for these cases in comparison to Case H1A. The results clearly show that oil recovery is increased as fracture capillary pressure is increased. A numerical comparison of cumulative and fractional recovery is given in Table 9.3.11. 
Table 9.3.11

Oil Recovery Sensitivity to Fracture Capillary Pressure

Horizontal Depletion Model

\begin{tabular}{c|c|c|c} 
Case & $\mathrm{P}_{\mathrm{ce}} \mathrm{P}_{\mathrm{cm}}$ & Cumulative, mSTB & Fraction \\
\hline \hline H16 & 0.5 & 252.8 & 0.177 \\
$\mathrm{H} 17$ & 0.2 & 242.2 & 0.169 \\
$\mathrm{H} 1 \mathrm{~A}$ & 0.0 & 235.1 & 0.164
\end{tabular}

\subsubsection{Fracture Relative Permeability}

A series of four runs was made to test the base case assumptions of linear relative permeability and zero or unity endpoint values for the fracture system. The Case H30 model used linear relative permeabilities, but with endpoints of two-tenths of the corresponding matrix values. This introduced an irreducible water saturation of 0.06 and residual oil saturations of 0.032 (gas displacement) and 0.056 (water displacement) to the fracture system. Fracture capillary pressure was as described in the preceding section, commensurate with irreducible water saturation. Linear relative permeabilities were also used in Case H31, but the ratio of fracture to matrix endpoints was increased to one-half. Case $\mathrm{H} 32$ and Case $\mathrm{H} 33$ used curvilinear relative permeabilities and endpoints as for Case $\mathrm{H} 30$ and Case H31, respectively. The curvature was simply introduced by equating relative permeability to the square of the normalized saturation of the flowing phase. Thus, for the oil-water, two-phase system:

$$
k_{n}=\left(S_{w}\right)^{2}
$$

where:

$$
S_{w}^{*}=\left(S_{w}-S_{w i}\right) /\left(1-S_{w i}\right) \quad \ldots \ldots \ldots \ldots \ldots \ldots \ldots \ldots
$$

and

$$
k_{\text {row }}=\left(S_{\text {ow }}\right)^{2}
$$

where:

$$
S_{o w}{ }^{*}=\left(S_{0}-S_{o m m}\right) /\left(1-S_{w i}-S_{o w w}\right) \ldots \ldots \ldots \ldots \ldots \ldots \ldots \ldots
$$

and for the gas-oil system

$$
k_{z z}=\left(S_{z}\right)^{2}
$$

where:

$$
S_{g}^{*}=\left(S_{g}-S_{g c}\right) /\left(1-S_{w i}-S_{g c}\right) \ldots \ldots \ldots \ldots \ldots \ldots \ldots \ldots
$$

and

$$
k_{\text {rog }}=\left(S_{o g}\right)^{2}
$$

where: 


$$
S_{o g}=\left(S_{o}-S_{o r g}\right) /\left(1-S_{w i}-S_{o r g}\right) \ldots \ldots \ldots \ldots \ldots \ldots \ldots \ldots
$$

The fracture-relative permeabilities and capillary pressures corresponding to the 0.2 endpoint assumption, Case $\mathrm{H} 30$ (linear) and Case $\mathrm{H} 32$ (curvilinear), are displayed in Figure 9.3 .14 (oilwater) and Figure 9.3.15 (gas-oil). Figure 9.3.16 (oil-water) and Figure 9.3.17 (gas-oil) depict the 0.5 endpoint assumption data as used for Case H31 (linear) and Case H32 (curvilinear).

The results of Case $\mathrm{H} 30$ and Case $\mathrm{H} 31$ are compared to the Case H1A, the base case on Figure 9.3.18. All three cases used linear fracture relative permeability but with differing endpoint assumptions. Both oil production rate and gas-oil ratio show increasingly more favorable trends as the endpoint level is increased. This observation is borne out by the trend of fractional recoveries shown in Table 9.3.12.

Table 9.3.12

Oil Recovery Sensitivity to Fracture Relative Permeability Horizontal Depletion Model

\begin{tabular}{l|c|c} 
Case/shape & Cumulative, mSTB & Fraction \\
\hline \hline H1A, lin. 0.0 & 235.1 & 0.164 \\
H30, lin. 0.2 & 238.7 & 0.167 \\
H31, lin. 0.5 & 243.4 & 0.171 \\
H32, curve 0.2 & 233.0 & 0.163 \\
H33, curve 0.5 & 237.7 & 0.165
\end{tabular}

Figure 9.3.19 compares the curvilinear Case H32 and Case $\mathrm{H} 33$ to the base case which used linear fracture relative permeability. The oil production rates of both curvilinear cases are less favorable, in terms of the rate of recovery, than the base case. The final cumulative oil production of all three cases is similar, however.

The next two illustrations compare linear and curvilinear cases having the same endpoint values, Figure 9.3.20 showing the cases for which the fracture endpoints are two-tenths of the matrix rock values and Figure 9.3.21 offering a similar comparison for the fracture endpoints increased to one-half of matrix leveis. Both clearly show that linear relative permeabilities yield more optimistic results in terms of rate of recovery and slightly more favorable cumulative productions. The fractional recovery comparison given in the preceding table shows that the curvilinear case recoveries are about one-half percent lower than the linear relative permeability cases.

\subsubsection{Matrix Capillary Pressure}

The base case matrix capillary pressure data assumed threshold capillary pressures (at 100 percent wetting phase saturation) of 1.99 psia for oil-water and 0.154 psia for gas-oil systems. 
These thresholds were removed for Case H1Q to see how sensitive the recovery performance was to this parameter.

The shape of the assumed capillary pressure curves was altered for Case H1R to the more " $L$ shaped" curves shown in Figure 9.3.22 and Figure 9.3.23. The oil-water curve was developed by assuming that the reciprocal of the square of capillary pressure was a linear function of water saturation between the points $\left(S_{w}, p_{\text {cow }}\right)(0.3,59.7$ psia) and $(1.0,0.0)$, whereas the Case H1A curve assumed that the reciprocal of capillary pressure was a linear function of $S_{\mathrm{v}}$ between the points $(0.3,59.7$ psia) and $(1.0,1.99$ psia). The Case H1R gas-oil capillary pressure function was computed from the oil-water function in proportion to ratio of interfacial tensions (Equation 9.1), as explained in Section 9.2.2.

Figure 9.3.24 shows the recovery performance improvement that occurs when the matrix capillary pressure threshold is removed, as in Case H1Q, and the further improvement when a more uniform pore size distribution is approximated, as in Case H1R. All cases have essentially the same behavior for the first half of the oil recovery. The numerical comparison of cumulative oil production and fractional recovery, provided in Table 9.3.13, show modest, roughly equal increments of oil recovery as capillary pressure is reduced.

Table 9.3.13

Oil Recovery Sensitivity to Matrix Capillary Pressure

Horizontal Depletion Model

\begin{tabular}{c|c|c|c|c|c} 
Case & $\mathrm{p}_{\text {cog }}$ & $\mathrm{p}_{\text {cowt }}$ & Function & Cumulative, mSTB & Fraction \\
\hline \hline H1A & 0.154 & 1.99 & $1 / \mathrm{p}_{c}=\mathrm{f}\left(\mathrm{S}_{\mathrm{w}}\right)$ & 235.1 & 0.164 \\
$\mathrm{H} 1 \mathrm{Q}$ & 0.000 & 0.00 & $1 / \mathrm{p}_{c}=\mathrm{f}\left(\mathrm{S}_{\mathrm{w}}\right)$ & 243.2 & 0.169 \\
$\mathrm{H} 1 \mathrm{R}$ & 0.000 & 0.00 & $1 / \mathrm{p}_{c}^{2}=\mathrm{f}\left(\mathrm{S}_{\mathrm{w}}\right)$ & 250.2 & 0.174
\end{tabular}

\subsection{Primary Recovery Forecasts for a Vertical Well}

Most of the sensitivity runs described for the horizontal natural depletion model were also run on the vertical natural depletion model with the minimum rate constraint reduced to $10 \mathrm{STB} /$ day. These cases have the same case identification numbers as the horizontal model runs, but with the prefix "V" substituted for " $\mathrm{H}$." The cases dealing with the number of fracture swarms and the oil-in-place variation from swarm to swarm were not run, since the vertical model included only a single fracture swarm.

The results obtained from the vertical model simulations are not individually discussed in this report because their characteristics were so similar to the horizontal model results. Detailed discussion of each case, or even groups of cases would have been completely redundant.

The vertical model simulation results are, however, displayed in Figure 9.4.1 through Figure 9.4.13 in the same format as used for the horizontal model presentations. By appropriate pairing of figures, the vertical model oil production rates and gas-oil ratios can be seen to have 
the same general characteristics as those of the corresponding horizontal model results. Table 9.4.1 provides a useful Figure number cross-reference for this purpose.

Table 9.4.1

Figure Number Cross-Reference for Horizontal and Vertical Models

\begin{tabular}{c|c|c} 
Vertical & Horizontal & Case Number \\
\hline \hline 9.4 .1 & 9.3 .1 & $1 \mathrm{~A}, 2 \mathrm{~A}, 3 \mathrm{~A}$ \\
9.4 .2 & 9.3 .4 & $1 \mathrm{X}, 21,22$ \\
9.4 .3 & 9.3 .5 & $1 \mathrm{~A}, 6 \mathrm{~K}, 7 \mathrm{~K}$ \\
& & \\
9.4 .4 & 9.3 .6 & $1 \mathrm{~T}, 6 \mathrm{~T}, \mathrm{TT}$ \\
9.4 .5 & 9.3 .7 & $1 \mathrm{~A}, 8,9,9 \mathrm{~A}$ \\
9.4 .6 & 9.3 .9 & $1 \mathrm{~A}, 12,13$ \\
& & \\
9.4 .7 & 9.3 .10 & $1 \mathrm{~A}, 1 \mathrm{~F}, 1 \mathrm{~K}$ \\
9.4 .8 & 9.3 .11 & $1 \mathrm{~A}, 14,15$ \\
9.4 .9 & 9.3 .12 & $1 \mathrm{~A}, 1 \mathrm{P}, 1 \mathrm{M}$ \\
& & \\
9.4 .10 & 9.3 .13 & $1 \mathrm{~A}, 16,17$ \\
9.4 .11 & 9.3 .18 & $1 \mathrm{~A}, 30,31$ \\
9.4 .12 & 9.3 .19 & $1 \mathrm{~A}, 32,33$ \\
9.4 .13 & 9.3 .21 & 31,33 \\
9.4 .14 & 9.3 .24 & $1 \mathrm{~A}, 1 \mathrm{Q}, 1 \mathrm{R}$ \\
& &
\end{tabular}

Table 9.4.2 displays the oil recovery factors obtained from the vertical model cases versus the comparable horizontal model numbers. The recovery factors realized by the vertical model cases are seen, for the most part, to vary no more than 0.7 percent (fractional recovery basis) from the horizontal model values. The only exception, Case V1F, was found to have been prematurely truncated by the minimum rate constraint of $10 \mathrm{STB} /$ day (compare Figure 9.4.7 to Figure 9.3.10). By lowering the minimum rate to $1 \mathrm{STB} /$ day, the recovery of this case was increased to 0.118 percent, or within 0.5 percent of Case H1F. 
Table 9.4.2

Comparison of Oil Recovery Factors

For Horizontal and Vertical Model Cases

\begin{tabular}{|c|c|c|c|}
\hline $\begin{array}{c}\text { Vertical } \\
\text { Case }\end{array}$ & $\begin{array}{c}\text { Vertical } \\
\text { Oil } \\
\text { Recovery } \\
\text { (frac OIP) }\end{array}$ & $\begin{array}{c}\text { Horizontal } \\
\text { Oil } \\
\text { Recovery } \\
\text { (frac OIP) }\end{array}$ & $\begin{array}{l}\text { Horizontal } \\
\text { Case }\end{array}$ \\
\hline $\begin{array}{l}\text { V1A } \\
\text { V2A } \\
\text { V3A }\end{array}$ & $\begin{array}{l}0.161 \\
0.162 \\
0.156\end{array}$ & $\begin{array}{l}0.164 \\
0.165 \\
0.160\end{array}$ & $\begin{array}{l}\mathrm{H1A} \\
\mathrm{F} 2 \mathrm{~A} \\
\mathrm{~F} 3 \mathrm{~A}\end{array}$ \\
\hline $\begin{array}{l}\text { v1x } \\
\text { v21 } \\
\text { v22 }\end{array}$ & $\begin{array}{l}0.161 \\
0.162 \\
0.160\end{array}$ & $\begin{array}{l}0.164 \\
0.165 \\
0.163\end{array}$ & $\begin{array}{l}\mathrm{HIX} \\
\mathrm{H21} \\
\mathrm{H} 22\end{array}$ \\
\hline $\begin{array}{l}\text { vGK } \\
\text { vTR }\end{array}$ & $\begin{array}{l}0.164 \\
0.167\end{array}$ & $\begin{array}{l}0.167 \\
0.171\end{array}$ & $\begin{array}{l}\text { EGK } \\
\text { H7R }\end{array}$ \\
\hline $\begin{array}{l}\text { V1T } \\
\text { VGT } \\
\text { VTr }\end{array}$ & $\begin{array}{l}0.145 \\
0.167 \\
0.169\end{array}$ & $\begin{array}{l}0.147 \\
0.171 \\
0.173\end{array}$ & $\begin{array}{l}\text { HIT } \\
\text { HGT } \\
\text { HTT }\end{array}$ \\
\hline $\begin{array}{c}\text { V8 } \\
\text { V9 } \\
\text { V9A }\end{array}$ & $\begin{array}{l}0.143 \\
0.165 \\
0.165\end{array}$ & $\begin{array}{l}0.145 \\
0.169 \\
0.169\end{array}$ & $\begin{array}{c}\text { H8 } \\
\text { H9 } \\
\text { H9A }\end{array}$ \\
\hline $\begin{array}{l}\text { V12 } \\
\text { V13 }\end{array}$ & $\begin{array}{l}0.114 \\
0.169\end{array}$ & $\begin{array}{l}0.114 \\
0.174\end{array}$ & $\begin{array}{l}\mathrm{H12} \\
\mathrm{H13}\end{array}$ \\
\hline $\begin{array}{l}\text { VIF } \\
\text { VIR }\end{array}$ & $\begin{array}{l}0.092^{t} \\
0.174\end{array}$ & $\begin{array}{l}0.113 \\
0.174\end{array}$ & $\begin{array}{l}\text { HIF } \\
\text { HIX }\end{array}$ \\
\hline $\begin{array}{l}\text { V14 } \\
\text { V15 }\end{array}$ & $\begin{array}{l}0.158 \\
0.170\end{array}$ & $\begin{array}{l}0.160 \\
0.175\end{array}$ & $\begin{array}{l}\text { H14 } \\
\text { H15 }\end{array}$ \\
\hline $\begin{array}{l}\text { VIP } \\
\text { VIM }\end{array}$ & $\begin{array}{l}0.158 \\
0.170\end{array}$ & $\begin{array}{l}0.161 \\
0.175\end{array}$ & $\begin{array}{l}\text { HIP } \\
\text { HIM }\end{array}$ \\
\hline $\begin{array}{l}\text { V16 } \\
\text { V17 }\end{array}$ & $\begin{array}{l}0.170 \\
0.165\end{array}$ & $\begin{array}{l}0.177 \\
0.169\end{array}$ & $\begin{array}{l}\mathrm{H16} \\
\mathrm{E17}\end{array}$ \\
\hline $\begin{array}{l}\text { v30 } \\
\text { v31 } \\
\text { v32 } \\
\text { v33 }\end{array}$ & $\begin{array}{l}0.163 \\
0.166 \\
0.158 \\
0.161\end{array}$ & $\begin{array}{l}0.167 \\
0.171 \\
0.163 \\
0.165\end{array}$ & $\begin{array}{l}E 330 \\
E 31 \\
\text { E32 } \\
\text { E33 }\end{array}$ \\
\hline $\begin{array}{l}\text { V1Q } \\
\text { V1R }\end{array}$ & $\begin{array}{l}0.166 \\
0.169\end{array}$ & $\begin{array}{l}0.169 \\
0.174\end{array}$ & $\begin{array}{l}\text { HIQ } \\
\text { HIR }\end{array}$ \\
\hline
\end{tabular}

'Increases to 0.118 when constraint is reduced to 1 STB/day. 


\subsection{Secondary Recovery Forecasts for a Horizontal Well}

This part of the study is programmed for year two of the project. Current fiscal year efforts in this regard were restricted to initializing the horizontal model as is described in Section 9.1 and making some test case runs with water injection to verify that it was performing satisfactorily.

\subsection{Secondary Recovery Forecasts for a Vertical Well}

The vertical injection model, configured as described in Section 9.1, was used for the simulations discussed in this section. Three types of secondary recovery were investigated: water injection, gas injection and combined injection of gas and water. In each instance the objective was to use the injected fluids to supplement the natural energy and increase oil recovery.

\subsubsection{Water Injection}

The possibility of improved oil recovery with a line drive waterflood was tested in the vertical injection model. Two cases, differing with respect to the completion layer of the producing well, were run. Case IV1 had the producing well completed in the middle layer of the model, or Layer 3, whereas Case IV3 had the producing well completed in the uppermost layer of the model, Layer 1. In both cases, the injection well was located at the opposite boundary of the model and was completed in the fifth, or bottom model layer. The results of these cases are compared to the most favorable natural depletion case, Case V2A, in Table 9.6.1.

Water injection cases would be expected to be sensitive to many of the same parameters investigated with the depletion models, and indeed it is planned that the more significant parameters will be investigated in the second contract year. One parameter that has been investigated is matrix capillary pressure. The capillary pressure data described in Section 9.3.10 for Case HIR was selected since it contrasted most strongly to the base case data used for Case IV1 and Case IV3. Both sets of data are depicted on Figure 9.3.22 and Figure 9.3.23. The cases using the revised data are Case RV1 and Case RV3. In all other respects, most notably layer of completion, these cases are identical to Case IV1 and Case IV3, respectively.

Table 9.6.1 shows that completing the producing well in the uppermost layer (Case IV3) as opposed to the middle layer (Case IV1) has little affect on ultimate oil recovery. Much the same impression is gained from the graph of oil producing rate and watercut versus cumulative oil production shown in Figure 9.6.1. The rate of oil recovery is initially slightly higher with the Case IV1 completion, but after about one-third of the cumulative recovery the Case IV3 completion is more advantageous. The water cut comparison is the most significant difference between the two completions. It shows that the higher completion Case IV3 delays the breakthrough of water and results in lower water cuts throughout, although the difference diminishes and eventually the two cases come to the same terminal water cut. 
Comparing the lower capillary pressure cases, Case RV1 and Case RV3, against the comparable completion interval Case IV1 and Case IV3 reveals that the lower capillary pressures used for Case RV1 and Case RV3 had a significantly adverse effect on waterflood oil recovery. All four cases have been plotted on Figure 9.6.1 to facilitate comparison of compietion interval effects; e.g., Case IV1 versus Case IV3 and comparisons of capillary pressure sensitivity; e.g., Case IV1 versus Case RV1.

Table 9.6.1

Oil Recovery Sensitivity to Completion Interval and $p_{c m}$ Vertical Injection Model - Water Injection

\begin{tabular}{c|c|c|c|c} 
Case & Comp. Layer & $\mathrm{p}_{\mathrm{cm}}$ Func. & Cumulative, STB & Fraction \\
\hline \hline IV1 & middle (3) & $1 / \mathrm{p}_{\mathrm{c}}=\mathrm{f}\left(\mathbf{S}_{\mathrm{w}}\right)$ & 92370 & 0.450 \\
IV3 & upper (1) & $1 / \mathrm{p}_{\mathrm{c}}=\mathrm{f}\left(\mathrm{S}_{\mathrm{w}}\right)$ & 92898 & 0.453 \\
& & & & \\
RV1 & middle (3) & $1 / \mathrm{p}_{\mathrm{c}}{ }^{2}=\mathrm{f}\left(\mathbf{S}_{\mathrm{w}}\right)$ & 79278 & 0.387 \\
RV3 & upper (1) & $1 / \mathrm{p}_{\mathrm{c}}{ }^{2}=\mathrm{f}\left(\mathrm{S}_{\mathrm{w}}\right)$ & 79800 & 0.389
\end{tabular}

\subsubsection{Gas Injection}

A fraction of the produced gas was reinjected into an injection well completed in the top model layer for Case eV2, Case fV2, and Case gV2. In all three cases, the producing well was compieted in the lowermost layer of the model, Layer 5 . The fractions of gas reinjected were 1.0 for Case eV2, 0.75 for Case fV2, and 0.66 for Case gV2. Figure 9.6.2 offers a comparison of these cases against Case V2A, the best of the natural depletion cases. The figure clearly shows that gas reinjection, at best, offers no real recovery benefit over natural depletion, and if all of the produced gas is recycled the recovery is actually reduced. This observation is borne out by the cumulative recovery and fractional recovery results given in Table 9.6.2.

The same series of recycling rates was repeated but using the lower capillary pressure data described for Case H1R (Section 9.3.10). This was analogous to what was done for the water injection cases. The revised capillary pressure gas injection runs were Case hV2, Case iV2, and Case jV2. For comparison, the best natural depletion alternative was rerun with the revised capillary pressures as Case V2R. The performance of these cases is compared to each other in Figure 9.6.3. The basic pattern is the same, that is, gas recycling is no better than natural depletion from a recovery point of view; however, the more favorable capillary pressures do yield a small recovery improvement. The impact of capillary pressure on recovery can be quantified from Table 9.6.2 by differencing comparable rates of gas recycling; e.g., iV2 and fV2. 
Table 9.6.2

Oil Recovery Sensitivity to Recycled Gas Volume and $p_{\mathrm{cm}}$ Vertical Injection Model - Gas Injection

\begin{tabular}{l|c|c|c|c} 
Case & Gas Recycle & $\mathrm{p}_{\mathrm{cm}}$ Func. & Cumulative, STB & Fraction \\
\hline \hline V2A & none & $1 / \mathrm{p}_{\mathrm{c}}=\mathrm{f}\left(\mathrm{S}_{\mathrm{w}}\right)$ & 33204 & 0.162 \\
eV2 & $0.66^{*} \mathrm{Gp}$ & $1 / \mathrm{p}_{\mathrm{c}}=\mathrm{f}\left(\mathrm{S}_{\mathrm{w}}\right)$ & 33716 & 0.164 \\
$\mathrm{fV} 2$ & $0.80^{*} \mathrm{Gp}$ & $1 / \mathrm{p}_{\mathrm{c}}=\mathrm{f}\left(\mathrm{S}_{\mathrm{w}}\right)$ & 33470 & 0.163 \\
$\mathrm{gV2}$ & $1.00 * \mathrm{Gp}$ & $1 / \mathrm{p}_{\mathrm{c}}=\mathrm{f}\left(\mathrm{S}_{\mathrm{w}}\right)$ & 21778 & 0.106 \\
& & & & \\
V2R & none & $1 / \mathrm{p}_{\mathrm{c}}{ }^{2}=\mathrm{f}\left(\mathrm{S}_{\mathrm{w}}\right)$ & 35137 & 0.172 \\
$\mathrm{hV2}$ & $0.66^{*} \mathrm{Gp}$ & $1 / \mathrm{p}_{\mathrm{c}}{ }^{2}=\mathrm{f}\left(\mathrm{S}_{\mathrm{w}}\right)$ & 36243 & 0.177 \\
$\mathrm{iV2}$ & $0.80 * \mathrm{Gp}$ & $1 / \mathrm{p}_{\mathrm{c}}{ }^{2}=\mathrm{f}\left(\mathrm{S}_{\mathrm{w}}\right)$ & 36364 & 0.177 \\
$\mathrm{jV2}$ & $1.00 * \mathrm{Gp}$ & $1 / \mathrm{p}_{\mathrm{c}}{ }^{2}=\mathrm{f}\left(\mathrm{S}_{\mathrm{w}}\right)$ & 23252 & 0.113
\end{tabular}

The disappointing performance of the injection case against the natural depletion case is attributed to the lack of potential for injection gas to enter the matrix. That is to say, the gravity potential for oil to drain from, and gas to enter into the matrix is insufficient to overcome the capillary and viscous forces. Furthermore, the reinjection of gas is sufficient to maintain the matrix pressure above bubble point in much of the reservoir, thus preventing the evolution of dissolved gas and the consequential expulsion of oil into the fractures. Evidently, this loss of matrix oil expulsion can be compensated for by the reduced shrinkage loss of the fracture oil, since the ultimate recoveries of injection Case eV2 and Case fV2 are very similar to the depletion case, V2A. Figure 9.6.4 which compares the evolution of average matrix values of gas saturation and pressure for injection Case eV2 to depletion Case V2A, adds credibility to this reasoning.

\subsubsection{Combined Injection of Gas and Water}

The possibility of recovery improvement with gas injection into the top model layer, water injection into the bottom model layer, and production from the middle model layer was investigated in a series of six runs: three with the base case capillary pressure functions and three using the reduced capillary pressure data set introduced for Case H1R. Each set of three cases varied with respect to the volume of recycied gas. These levels were 90 percent, 72 percent, and 59.4 percent. These levels were 90 percent of the levels assumed for the gas injection only cases discussed in the preceding section. The balance of voidage replacement needed to maintain reservoir pressure was provided by water injection.

Two illustrations were prepared for each set of runs, one showing oil rate and gas-oil ratio versus cumulative oil production and a second with oil production rate and water cut as functions of cumulative oil production. Figure 9.6.5 and Figure 9.6.6 present the basic capillary pressure cases: cV1, dV1 and eV1 while Figure 9.6.7 and Figure 9.6.8 present the lower capillary pressure cases: fV1, gV1 and hV1. 
Table 9.6.3 summarizes the oil recovery data for these cases and provides a convenient reference for the recycle fraction and capillary pressure assumption.

Following an initial decline, the first three cases (cV1, dV1, eV1) all show a levelling of production rate which continues until about one-third of the oil has been recovered (Figure 9.6.5). During this period, the gas-oil ratio, after an initial build-up which mirrors the production decline, also flattens at a gas-oil ratio level dependent on the recycle fraction. Case dV1 and Case eV1 maintain the gas-oil ratio plateau for the duration of the cases while the Case cV1 values tend to increase slowly. Figure 9.6.6 reveals that water breakthrough occurs at 25 percent of uitimate recovery and that the oil production rate plateau extends until the water cut reaches about 10 percent. Thereafter, the production rate begins an almost log-linear decline against cumulative and the water cut continues to increase, eventually exceeding 90 percent.

Figure 9.6.7 shows that the second group of cases (fV1, gV1, hV1) have oil rate and gas-oil ratio patterns similar to the first three, but the oil rate levels only briefly and the total oil recovery is about 15 percent less. Figure 9.6 .8 shows that water breakthrough occurs at a lower recovery (about 15 percent of ultimate) and builds more rapidly. The performance of these cases is less favorable.

The recovery observations made in the preceding discussions are quantified in Table 9.6.3. The recoveries for the lower recycling rates are comparable to, but no better than, the waterflood recoveries discussed in Section 9.6.1.

Table 9.6.3

Oil Recovery Sensitivity to Recycled Gas Volume and $p_{c m}$ Vertical Injection Model - Gas and Water Injection

\begin{tabular}{c|c|c|c|c} 
Case & Gas Recycle & $\mathrm{p}_{\mathrm{cm}}$ Func. & Cumulative, STB & Fraction \\
\hline \hline $\mathrm{cV} 1$ & $0.900 * \mathrm{Gp}$ & $1 / \mathrm{p}_{\mathrm{c}}=\mathrm{f}\left(\mathrm{S}_{\mathrm{w}}\right)$ & 91979 & 0.448 \\
$\mathrm{dV} 1$ & $0.720 * \mathrm{Gp}$ & $1 / \mathrm{p}_{\mathrm{c}}=\mathrm{f}\left(\mathrm{S}_{\mathrm{w}}\right)$ & 92677 & 0.452 \\
$\mathrm{eV} 1$ & $0.594 * \mathrm{Gp}$ & $1 / \mathrm{p}_{\mathrm{c}}=\mathrm{f}\left(\mathrm{S}_{\mathrm{w}}\right)$ & 92618 & 0.452 \\
& & & \\
$\mathrm{fV} 1$ & $0.900 * \mathrm{Gp}$ & $1 / \mathrm{p}_{\mathrm{c}}{ }^{2}=\mathrm{f}\left(\mathrm{S}_{\mathrm{w}}\right)$ & 54931 & 0.268 \\
$\mathrm{gV} 1$ & $0.720 * \mathrm{Gp}$ & $1 / \mathrm{p}_{\mathrm{c}}=\mathrm{f}\left(\mathrm{S}_{\mathrm{w}}\right)$ & 79180 & 0.386 \\
$\mathrm{hV} 1$ & $0.594 * \mathrm{Gp}$ & $1 / \mathrm{p}_{\mathrm{c}}{ }^{2}=\mathrm{f}\left(\mathrm{S}_{\mathrm{w}}\right)$ & 79412 & 0.387
\end{tabular}




\section{NOMENCLATURE}

\begin{tabular}{|c|c|}
\hline $\begin{array}{l}\mathrm{A} \\
{ }^{\mathrm{o}} \mathrm{API}\end{array}$ & $\begin{array}{l}\text { - Block face area } \\
\text { - Oil gravity }\end{array}$ \\
\hline B & - Formation volume factor \\
\hline $\mathrm{cp}$ & - Centipoise \\
\hline${ }^{\circ} \mathrm{F}$ & - Temperature, degrees Fahrenheit \\
\hline $\mathrm{f}$ & - Well block radius correction factor \\
\hline Gp & - Gas produced \\
\hline $\mathrm{k}$ & - Permeability \\
\hline K & - Harmonic mean permeability \\
\hline $\mathrm{k}_{\mathrm{T}}$ & - Relative permeability \\
\hline L & - Block dimension (fracture spacing) \\
\hline $\mathrm{L}_{\mathrm{f}}$ & - Characteristic flow path length \\
\hline $\mathrm{mSTB}$ & - Thousand stock tank barreis \\
\hline $\mathrm{N}$ & - Number of sets of fractures \\
\hline $\mathrm{NX}, \mathrm{NY}, \mathrm{NZ}$ & - Number of grid blocks along given axis \\
\hline & - Oil-in-place \\
\hline OOIP & - Original oil-in-place \\
\hline $\mathrm{p}$ & - Pressure \\
\hline $\mathrm{p}_{\mathrm{b}}$ & - Saturation pressure \\
\hline $\mathrm{p}_{c}$ & - Capillary pressure \\
\hline $\mathrm{p}_{0}$ & - Initial well block pressure \\
\hline $\mathrm{p}_{\mathrm{wf}}$ & - Flowing bottom-hole pressure \\
\hline psi & - Pounds per square inch \\
\hline $\mathrm{q}$ & - Volume rate, production or injection \\
\hline $\begin{array}{l}\text { S } \\
S^{*}\end{array}$ & - Phase saturation \\
\hline$S^{*}$ & - Normalized saturation \\
\hline STB & - Stock tank barrel(s) \\
\hline $\operatorname{scf}$ & - Standard cubic feet \\
\hline $\mathrm{R}_{\mathbf{r}}$ & - Solution gas-oil ratio \\
\hline$r_{0}$ & - Well block radius \\
\hline$r_{w}$ & - Wellbore radius \\
\hline$\tilde{V}_{b}$ & - Fracture block volume \\
\hline$w_{f}$ & - Fracture aperture \\
\hline$\Delta$ & - Difference operator \\
\hline$\mu$ & - Phase viscosity \\
\hline$\pi$ & $-3.14159 \ldots$ \\
\hline$\rho$ & - Phase density \\
\hline$\sigma$ & - Shape factor \\
\hline$\sigma_{\mathrm{go}}$ & - Gas-oil interfacial tension \\
\hline$\sigma_{\text {ow }}$ & - Oil-water interfacial tension \\
\hline$\phi$ & - Porosity \\
\hline & - Phase potential \\
\hline
\end{tabular}




\section{NOMENCLATURE（cont'd)}

\section{SUBSCRIPTS}

$\begin{array}{ll}\mathrm{f} & \text { - Fracture } \\ \mathrm{g} & \text { - Gas phase } \\ \mathrm{i} & \text { - Irreducible } \\ \mathrm{m} & \text { - Matrix } \\ \mathrm{o} & \text { - Oil phase } \\ \mathrm{I} & \text { - Residual } \\ \mathrm{t} & \text { - Threshold } \\ \mathrm{w} & \text { - Water phase } \\ \mathrm{x}, \mathrm{y}, \mathrm{z} & \text { - Reference to given reservoir axis }\end{array}$




\section{REFERENCES}

1. Jones, T.A., Wooten, S.O., and Kaluza, T.J.: Single-Phase Flow Through Natural Fractures," paper SPE 18175, presented at the SPE Fall Meeting, Houston, Texas, October 2-5, 1988.

2. Dees, T.G., Freet, T.G. and Hollabaugh, G.S.: "Horizontal Well Stimulation Results in the Austin Chalk Formation, Pearsall Field, Texas," paper SPE 20683, presented at the SPE Fall Meeting, New Orleans, Louisiana, September 1990.

3. Scott, R.J.: "The Austin Chalk-Buda Trend of South Texas, " Trans. Vol. XXVII GCAGS, 1977, pp. 164-178.

4. Dravis, J.J.: "Regional Depositional Setting and Porosity Evolution of the Austin Chalk Formation, South Texas, " Proc. STGS Austin Chalk Exploration Symposium, San Antonio, Texas, February 24-26, 1991, pp. 17-24.

5. Durham, C.O., Jr. and Burnett Hall, S.: "The Austin Chalk Bed by Bed Through Central Texas," Proc. STGS Austin Chalk Exploration Symposium, San Antonio, Texas, February 24-26, 1991, pp. 25-40.

6. Schafer, J.N.: "A Practical Method of Well Evaluation and Acreage Development for the Naturally Fractured Austin Chalk Formation, "Proc. SPWLA Twentieth Annual Logging Symposium, June 3-6, 1979.

7. Schnerk, G.C. and Madeen, C.N.: "The Austin Chalk: Simulation of Horizontal Wells in a Heterogeneous Formation," paper SPE 20716, presented at the SPE Fall Meeting, New Orleans, Louisiana, September 1990.

8. Fett, T.: "Fracture Evaluation in the Austin Chalk," Proc. STGS Austin Chalk Exploration Symposium, San Antonio, Texas, February 24-26, 1991, pp. 41-49.

9. Corbett, K.P., Friedman, M., Wiltschko, D.V. and Humg, J.: "Characteristics of Natural Fractures in the Austin Chalk Outcrop Trend, "Proc. STGS Austin Chalk Exploration Symposium, San Antonio, Texas, February 24-26, 1991, pp. 3-11.

10. Lichtenberger, G.L.: "Pressure Buildup Test Results From Horizontal Wells in the Pearsall Field of the Austin Chalk, " paper SPE 20606, presented at the SPE Fall Meeting, New Orleans, Louisiana, September 1990.

11. ORYX Energy Co.: Spacing Unit Submission to Texas RRC, Docket 1-94.685, July 10, 1990.

12. Hill, O. F., Ward A.J. and Clement, C.C.: "Austin Chalk Fracturing Design Using a Crosslinked Natural Polymer as a Diverting Agent, " JPT, December 1978, pp. 1795-1804. 
13. Barenblatt, G.E., Zheltov, I.P. and Kochina, I.N.: "Basic Concepts in the Theory of Seepage of Homogeneous Liquids in Fissured Rocks," PMM USSR, 1960, Vol. 24, No. 5, p. 852.

14. Warren, J.E., Root, P.J.: "The Behavior of Naturally Fractured Reservoirs," SPEJ, September 1963, pp. 245-255.

15. Kazemi, H., Merrill, L.S., Porterfield, K.L., and Zeman, P.R., "Numerical Simulation of Water-Oil Flow in Naturally Fractured Reservoirs, " SPEJ, December 1976, pp. 317-26.

16. Thomas, L.K., Dixon, T.N. and Pierson, R.G.: "Fractured Reservoir Simulation, " SPEJ, February 1983, pp. 42-54.

17. Gilman, J.R. and Kazemi, H.: "Improvements in Simulation of Naturally Fractured Reservoirs, " SPEJ, August 1983, pp. 695-707.

18. Litvak, B.L.: "Simulation and Characterization of Naturally Fractured Reservoirs," Proc., Reservoir Characterization Technical Conference, Dallas, Texas, Academic Press, New York City, New York, 1985.

19. Gilman, J.R.: "An Efficient Finite-Difference Method for Simulating Phase Segregation in Fractured Reservoir Simulation," SPERE, July 1986, pp. 403-13.

20. Gilman, J.R. and Kazemi, H.: "Improved Calculations for Viscous and Gravity Displacement in Matrix Blocks in Dual Porosity Simulators," JPT, January 1988, pp. 6070.

21. Rossen, R. H. and Shen, E.I.C., "Simulation of Gas/Oil Drainage and Water/Oil Imbibition in Naturally Fractured Reservoirs, "SPERE, November 1989, pp. 464-470.

22. Firoozabadi, A. and Thomas, K.L.: "Sixth Comparative Solution Project: Dual Porosity Simulators," JPT, June 1990, pp. 710-715.

23. Honarpour, M., Koederitz, L.F., and Harvey, A.H.: "Empirical Equations for Estimating Two-Phase Relative Permeability in Consolidated Rock, "JPT, December 1982, pp. 290508.

24. Van Dijk, C.: "Agha Jari Gas/Oil Interfacial Tension Measurements," IOEPC, Tech. Memo T-636, June 1965.

25. Offeringa, J.: "Evaluation of Agha Jari Reservoir Performance, " IOEPC, Service Report S41, October 1961.

26. Dranchuk, P.M., Purvis, R.A., and Robinson, D.B.: "Computer Calculations of Natural Gas Compressibility Factors Using The Standing and Katz Correlation," Institute of Petroleum, Technical Series, No. IP74-008, 1974. 
27. Lee, A.L, Gonzalez, M.H., and Eakin, B.E.: "The Viscosity of Natural Gases," JPT, August 1966, pp. 997-1000.

28. Standing, M.B., Volumetric and Phase Behavior of Oil Field Hydrocarbon Systems, 1977, pp.26, 122.

29. Vasquez, M., and Beggs, H.D.: "Correlations for Fluid Physical Property Predictions," JPT, June 1980, pp. 968-970.

30. Peaceman. D.W.: "Interpretation of Well-Block Pressures in Numerical Reservoir Simulation, " SPEJ, June 1978, pp. 183-94.

31. Peaceman. D.W.: "Interpretation of Well-Block Pressures in Numerical Reservoir Simulation with Nonsquare Grid Blocks and Anisotropic Permeability, " SPEJ, June 1983, pp. 531-43.

32. Peaceman. D.W.: "Interpretation of Well-Block Pressures in Numerical Reservoir Simulation - Part 3: Some Additional Well Geometries," paper SPE 16976 presented at SPE Annual Conference and Exhibition, Dallas, Texas, September 27-30.

33. Peaceman. D.W.: "Representation of a Horizontal Well Numerical Reservoir Simulation," paper SPE 21217 presented at Eleventh SPE Symposium on Reservoir Simulation, Anaheim, California, February 17-20. 


\section{BIBLIOGRAPHY}

Aguilera, R., "Determination of Subsurface Distance Between Vertical Parallel Natural Fractures Based on Core Data," AAPG Bull., Vol. 72, No. 7, July 1988, pp. 845-851.

Aguilera, R., "Relative Permeability Concepts for Predicting Performance of Naturally Fractured Reservoirs," 32nd Annu. Petrol. Soc. of CIM Tech. Mtg. \& 83rd Annu. CIM Gen. Mtg., Calgary, 1981, Preprints, Pap. No. 81-21-22.

Aguilera, R., "Unsteady State Water Influx in Naturally Fractured Reservoirs," 39th Annu. CIM Petrol. Soc. Tech. Mtg. \& Can. Gas Processors Assoc. 2nd Quart. Mtg., Calgary, 1988, Preprints, Vol. 2, Pap. No. 88-39-64.

Al-Bemani, A.S. and Ershaghi, I., "Gas-Cap Effects in Pressure Transient Response of Naturally Fractured Reservoirs," 65th Annu. SPE Tech. Conf. Proc., New Orleans, 1990, pp. 47-56, SPE Pap. No. 20565.

Al-Naqib, F.M., Al-Debouni, R.M., Al-Irhayim, T.A. and Morris, D.M., "Water Drive Performance of the Fractured Kirkuk Field of Northern Iraq," 46th Annu. SPE of AIME Fall Mtg., New Orleans, 1971, SPE Pap. No. 3437.

Ayatollahi, M.S., Noorishad, J. and Witherspoon, P.A., "Stress-Fluid Flow Analysis of Fractured Rocks," J. Eng. Mech. Amer. Soc. Civil Eng., Vol. 109, No. 1, Feb. 1983, pp. 1-13.

Baker, R. and Gregor, V., "Fracture Characterization of the Wainwright Pool, "39th Annu. CIM Petrol. Soc. Tech. Mtg. \& Can. Gas Processors Assoc. 2nd Quart. Mtg., Calgary, 1988, Preprints, Vol. 2, Pap. No. 88-39-45.

Bakhtar, K., Rakop, K., Jones, A.H. and Barton, N.R., "Modeling Fracture Permeability Around a Well During Depletion, " 55th Annu. SPE of AIME Calif. Reg. Mtg. Proc., Bakersfield, CA, 1985, pp. 837-842, SPE Pap. No. 13671.

Balint, V., Ban, A. and Pach, F., "Increasing Depletion From Mixed Porosity Type Petroleum Reservoirs With Active Water Pressure by the Injection of Gaseous Media," 2nd Assoc. Rech. Tech. Exploit. Petrol. Enhanced Oil Recovery Europe. Symp. Proc., Paris, 1982, pp. 463-476.

Bandis, S.C., Lumsden, A.C. and Barton, N.R., "Fundamentals of Rock Joint Deformation," Int. J. Rock Mech. Sci. and Geomech. Abstr., Vol. 20, No. 6, 1983, pp. 249-268.

Barenblatt, G.E., Zheitov, I.P. and Kochina, I.N., "Basic Concepts in the Theory of Seepage of Homogeneous Liquids in Fissured Rocks," PMM USSR, Vol. 24, No. 5, 1960, p. 852. 
Bawden, W.F., Curran, J.H. and Roegiers, J.C., "Influence of Fracture Deformation on Secondary Permeability - A Numerical Approach," Int. J. Rock Mech. Mining Sci. Geomech. Abstr., Vol. 17, No. 5, Oct. 1980, pp. 265-279.

Bebout, D.G., "Ellenburger Fractured Dolomite," Atlas of Major Texas Oil Reservoirs, Texas Univ. Bur. Econ. Geol., Austin, 1983, pp. 89-93.

Belfield, W.C., "Characterization of a Naturally Fractured Carbonate Reservoir: Lisburne Field,

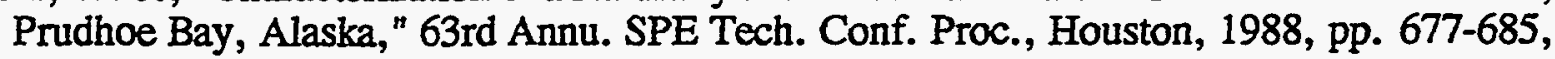
SPE Pap. No. 18174.

Beliveau, D., "Pressure Transients Characterize Fractured Midale Unit," J. Petrol. Technol., Vol. 41, No. 12, Dec. 1989, pp. 1354-1362, SPE Pap. No. 20015.

Berkowitz, B., "Boundary Conditions Along Permeable Fracture Walls: Influence on Flow and Conductivity," Water Resources Res., Vol. 25, No. 8, Aug. 1989, pp. 1919-1922.

Bourdarot, G. and Daviau, F., "Vertical Permeability: Field Cases," 64th Annu. SPE Tech. Conf. Proc., San Antonio, 1989, pp. 53-68, SPE Pap. No. 19777

Brown, S.R., "Fluid Flow Through Rock Joints: The Effect of Surface Roughness," J. Geophys. Res., Vol. 92, No. B2, Feb. 10, 1987, pp. 1337-1347.

Brown, S.R., Kranz, R.L. and Bonner, B.P., "Correlation Between the Surfaces of Natural Rock Joints," Geophys. Res. Lett., Vol. 13, No. 13, Dec. 1986, pp. 1430-1433.

Brown, S.R. and Scholz, C.H., "Broad Bandwith Study of the Topography of Natural Rock Surfaces," J. Geophys. Res., Vol. 90, No. B14, Dec. 10, 1985, pp. 12575-14582.

Brown, S.R. and Scholz, C.H., "Closure of Random Elastic Surfaces in Contact," J. Geophys. Res., Vol. 90, No. B7, June 10, 1985, pp. 5531-5545.

Brown, S.R. and Scholz, C.H., "Closure of Rock Joints," J. Geophys. Res., Vol. 91, No. B5, April 10, 1986, pp. 4939-4948.

Brown, S.R. and Scholz, C.H., "Experiments Confirm Rock-Fracture Theory," Geotimes, Vol. 29, No. 12, Dec. 1984, pp. 12-14.

Butler, M., Phelan, M.J. and Wight, A.W.R., "Buchan Field: Evaluation of a Fractured Sandstone Reservoir," Log Anal., Vol. 18, No. 2, March-April 1977, pp. 23-31.

Camacho-V, R.G. and Raghavan, R., "Well Test Analysis in Solution Gas Drive Systems for Naturally Fractured Reservoirs, " 65th Annu. SPE Tech. Conf. Proc., New Orleans, 1990, pp. 357-370, SPE Pap. No. 20564. 
Carlson, E.S. and Mercer, J.C., "Devonian Shale Gas Production: Mechanisms and Simple Models," SPE East. Reg. Conf. Proc., Morgantown, WV., 1989, pp. 45-54, SPE Pap. No. 19311.

Cason, L.D., "Waterflooding Increases Gas Recovery," J. Petrol. Technol., Vol. 41, No. 10, Oct. 1989, pp. 1102-1106, SPE Pap. No. 12041.

Chase, Jr., C.A. and Dietrich, J.K., "Compaction Within the South Belridge Diatomite," SPE Reservoir Eng., Nov. 1989, pp. 422-428, SPE Pap. No. 17415.

Chen, H.-Y., Poston, S.W. and Raghavan, R., "The Well Response in a Naturally Fractured Reservoir: Arbitrary Fracture Connectivity and Unsteady Fluid Transfer, "65th Annu. SPE Tech. Conf. Proc., New Orleans, 1990, pp. 371-382, SPE Pap. No. 20566.

Chen, Z.X., "Transient Flow of Slightly Compressible Fluids Through Double-Porosity, Double-Permeability Systems - A State-of-the-Art Review, " Transp. Porous Media, Vol. 4, No. 2, April 1989, pp. 147-184.

Corbett, K.P., Friedman, M. and Spang, J., "Fracture Development and Mechanical Stratigraphy of Austin Chalk, Texas," AAPG Bull., Vol. 71, No. 1, 1987, pp. 17-28.

Corbett, K.P., Friedman, M., Wiltschko, D.V. and Humg, J., "Characteristics of Natural Fractures in the Austin Chalk Outcrop Trend," Sou. Texas Geol. Soc. Austin Chalk Exploration Symp. Proc., San Antonio, 1991, pp. 3-11.

Corre, B., "Characterization of Fracture Networks From Well Tests Using a New Analytical Solution," 65th Annu. SPE Tech. Conf. Proc., New Orleans, 1990, pp. 383-398, SPE Pap. No. 20533.

Currie, J.B., "Significant Geologic Processes in Development of Fracture Porosity," AAPG Bull., Vol. 61, No. 7, July 1977, pp. 1086-1089.

Currier, B.H., "Lisburne Reservoir Limited-Drainage Test: A Pilot Test Case History," SPE Formation Evaluation, Dec. 1990, pp. 337-343, SPE Pap. No. 18277.

da Silva, F.V., "Primary and Enhanced Recovery of Ekofisk Field: A Single- and Double-Porosity Numerical Simulation Study," 64th Annu. SPE Tech. Conf. Proc., San Antonio, 1989, pp. 715-730, SPE Pap. No. 19840.

da Silva, F.V. and Belery, P., "Molecular Diffusion in Naturally Fractured Reservoirs: A Decisive Recovery Mechanism," 64th Annu. SPE Tech. Conf. Proc., San Antonio, 1989, pp. 429-442, SPE Pap. No. 19672.

Davidson, D.A. and Snowden, D.M., "Beaver River Middle Devonian Carbonate: Performance Review of a High-Relief, Fractured Gas Reservoir With Water Influx, "52nd Annu. SPE of AIME Fall Tech. Conf., Denver, 1977, SPE Pap. No. 6830. 
de Swaan, A., "A Three-Phase Model for Fractured Reservoirs Presenting Fluid Segregation," 6th SPE of AIME Reservoir Simulation Symp. Proc., New Orleans, 1989, pp. 285-292, SPE Pap. No. 10510.

de Swaan, A. and Ramirez-Villa, M., "Functions of Flow From Porous Rock Blocks," SPE Pap. No. 20173, Feb. 1990.

Dean, R.H. and Lo, L.L., "Development of a Natural Fracture Simulator and Examples of Its Use," SPE Petrol. Eng. Int. Mitg. Proc., Beining, China, 1986, Vol. 2, pp. 33-46, SPE Pap. No. 14110.

Dees, T.G., Freet, T.G. and Hollabaugh, G.S., "Horizontal Well Stimulation Results in the Austin Chalk Formation, Pearsall Field, Texas, "65th Annu. SPE Tech. Conf. Proc., New Orleans, 1990, pp. 665-676, SPE Pap. No. 20683.

Dennis, B., Standen, E., Georgi, D.T. and Callow, G.O., "Fracture Identification and Productivity Predictions in a Carbonate Reef Complex," 62rd Annu. SPE Tech. Conf. Proc., Dallas, 1987, pp. 579-588, SPE Pap. No. 16808.

Dikken, B.J., "Pressure Drop in Horizontal Wells and Its Effect on Production Performance," J. Petrol. Technol., Vol. 42, No. 11, Nov. 1990, pp. 1426-1433, SPE Pap. No. 19824.

Doe, T.W., Kindred, J.S., Dershowitz, W.S. and Uchida, M., "Simulation of Dual-Porosity Flow in Discrete Fracture Networks," CIM Petrol. Soc./SPE Int. Tech. Mtg., Calgary, Can, 1990, Preprints, Vol. 3, Pap No. CIM/SPE-90-120.

Dranchuk, P.M., Purvis, R.A., and Robinson, D.B., "Computer Calculations of Natural Gas Compressibility Factors Using The Standing and Katz Correlation, " Institute of Petroleum, Technical Series, No. IP74-008, 1974.

Dravis, J.J., "Regional depositional Setting and Porosity Evolution of the Austin Chalk Formation, South Texas," Sou. Texas Geol. Soc. Austin Chalk Exploration Symp. Proc., San Antonio, 1991, pp. 17-24.

Durham, Jr., C.O. and Burnett Hall, S., "The Austin Chalk Bed by Bed Through Central Texas," Sou. Texas Geol. Soc. Austin Chalk Exploration Symp. Proc., San Antonio, 1991, pp. 25-40.

Eica, M.S. and Ershaghi, I., "Modeling of Gas Injection in Fractured Reservoirs," SPE of AIME Golden Gate Sect. Calif. Reg. Mtg. Proc., San Francisco, 1982, pp. 3939-412, SPE Pap. No. 10758.

El Hadidi, A., "Review of the Drainage Policy After Study of the Earlier Water Break Through Eocene Reservoir Baker North America Area," 7th Arab Petrol. Congr., Kuwait, 1970, Preprint No. 83 (B-1). 
Festoy, S. and Van Golf-Racht, T.D., "Gas Gravity Drainage in Fractured Reservoirs Through New Dual-Continuum Approach," SPE Reservoir Eng., Aug. 1989, pp. 271-278, SPE Pap. No. 16980.

Fett, T., "Fracture Evaluation in the Austin Chalk," Sou. Texas Geol. Soc. Austin Chalk Exploration Symp. Proc., San Antonio, 1991, pp. 41-49.

Firoozabadi, A. and Hauge, J., "Capillary Pressure in Fractured Porous Media," J. Petrol. Technol., Vol. 42, No. 6, June 1990, pp. 784-791, SPE Pap. No. 18747.

Firoozabadi, A. and Thomas, L.K., "Sixth SPE Comparative Solution Project: Dual-Porosity Simulators, " J. Petrol. Technol., Vol. 42, No. 6, June 1990, pp. 710-715, 762-763, SPE Pap. No. 18741.

Fraim, M.L. and Lee, W.J., "Determination of Formation Properties From Long-Term Gas Well Production Affected by Non-Darcy Flow," 62rd Annu. SPE Tech. Conf. Proc., Dallas, 1987, SPE Pap. No. 16934.

Franco, A., "'Hot Play' Gets Hotter in the Austin Chalk, " Drilling Contractor, June/July 1990, pp. 52-56.

Frank, R.W. and Simonson, R.B., "Identification and Interpretation of Naturally Fractured Reservoirs in North Texas, " Exploration in a Mature Area, Annu. AAPG SW Sect. Et Al. Mtg. Proc., Abilene, 1983, pp. 20,143-167.

Fung, L.S.K., "Simulation of Block-to-Block Processes in Naturally Fractured Reservoirs," 60th Annu. SPE Calif. Reg. Mtg. Proc., Ventura, CA, 1990, pp. 51-66, SPE Pap. No. 20019.

Fung, L.S.K. and Collins, D.A., "An Evaluation of the Improved Dual Porosity Model for the Simulation of Gravity Effects in Naturally Fractured Reservoirs, " 39th Annu. CIM Petrol. Soc. Tech. Mtg. \& Can. Gas Processors Assoc. 2nd Quart. Mtg., Calgary, Can, 1988, Preprints, Vol. 2, Pap No. 88-39-05.

Gale, J.E., Taylor, R.L., Witherspoon, P.A. and Ayatollahi, M.S., "Flow in Rocks With Deformable Fractures," Finite Element Methods in Flow Problems, UAH Press, Huntsville, Ala., 1974, pp. 583-598.

Galloway, W.E., "Spraberry / Dean Sandstone," Atlas of Major Texas Oil Reservoirs, Texas Univ. Bur. Econ. Geol., Austin, 1983, pp. 83-85.

Gilman, J.R., "An Efficient Finite-Difference Method for Simulating Phase Segregation in Fractured Reservoir Simulation, " SPE Reservoir Eng., July 1986, pp. 403-413, SPE Pap. No. 12271 . 
Gilman, J.R. and Kazemi, H., "Improved Calculations for Viscous and Gravity Displacement in Matrix Blocks in Dual-Porosity Simulators," J. Petrol. Technol., Vol. 40, No. 1, Jan. 1988, pp. 60-70, SPE Pap. No. 16010.

Gilman, J.R. and Kazemi, H., "Improvements in Simulation of Naturally Fractured Reservoirs," Soc. Petrol. Eng. J., Vol. 23, Aug. 1983, pp. 695-707, SPE Pap. No. 10511.

Haas, R.C. and Stokley, C.O., "Drilling and Completing a Horizontal Well in Fractured Carbonate," World Oil, Oct. 1989, pp. 39-45.

Hale, F.V. and Tsang, C.F., "A Code to Compute Borehole Fluid Conductivity Profiles With Multiple Feed Points," Rep. No. LBL-24928, Calif. Univ. Berkeley, March 1988.

Hallenbeck, L.D., Sylte, J.E., Ebbs, D.J. and Thomas, L.K., "Implementation of the Ekofisk Waterflood," 64th Annu. SPE Tech. Conf. Proc., San Antonio, 1989, pp. 687-698, SPE Pap. No. 19838.

Harper, T.R. and Last, N.C., "Response of Fractured Rock Subject to Fluid Injection: Part 1: Development of a Numerical Model," Tectonophysics, Vol. 172, Nos. 1-2, Jan. 10, 1990, pp. 1-31.

Harper, T.R. and Last, N.C., "Response of Fractured Rock Subject to Fluid Injection: Part 2: Characteristic Behavior," Tectonophysics, Vol. 172, Nos. 1-2, Jan. 10, 1990, pp. 33-51.

Harper, T.R. and Last, N.C., "Response of Fractured Rock Subject to Fluid Injection: Part 3: Practical Application," Tectonophysics, Vol. 172, Nos. 1-2, Jan. 10, 1990, pp. 53-65.

Hensel, Jr., W.M., "A Perspective Look at Fracture Porosity, "SPE Formation Evaluation, Dec. 1989, pp. 531-534, SPE Pap. No. 16806.

Hill, O. F., Ward A.J. and Clement, C.C., "Austin Chalk Fracturing Design Using a Crosslinked Natural Polymer as a Diverting Agent," J. Petrol. Tech., Vol. 30, No. 12, Dec. 1978, pp. 1795-1804, SPE Pap. No. 6869.

Honarpour,M., Koederitz, L.F., and Harvey, A.H., "Empirical Equations for Estimating Two-Phase Relative Permeability in Consolidated Rock," J. Petrol. Tech., Vol. 34, No. 12 , Dec. 1982, pp. 2905-2908.

Horie, T., Firoozabadi, A. and Ishimoto, K., "Laboratory Studies of Capillary Interaction in Fracture/Matrix Systems, " SPE Reservoir Eng., Vol. 5, No. 3, Aug. 1990, pp. 353-360, SPE Pap. No. 18282.

Howard, J.H. and Nolen-Hoeksema, R.C., "Description of Natural Fracture Systems for Quantitive Use in Petroleum Geology," AAPG Bull., Vol. 74, No. 2, Feb. 1990, pp. 151-162. 
Jacquin, C., Legait, B., Martin, J.M., Nectoux, A., Anterion, F. and Rioche, M., "Gravity Drainage in a Fissured Reservoir With Fluids Not in Equilibrium," J. Petrol. Sci. Eng., Vol. 2, Nos. 2-3, April 1989, pp. 127-224.

Janot, P., "Determination of the Elementary Matrix Block in a Fissured Reservoir, Application on the Eschau Field, Alsace, France," J. Petrol. Technol., Vol. 25, No. 3, May 1973, pp. 523-530, SPE Pap. No. 3638.

Johns, R.T. and Jalali-Yazdi, Y., "Comparison of Pressure Transient Response in Intensely and Sparsely Fractured Reservoirs," 59th Annu. SPE Calif. Reg. Mtg. Proc., Bakersfield, CA, 1989, pp. 545-551, SPE Pap. No. 18800.

Johnson, B., "Permeability of a Simulated-Fracture as a Function of Normal Stress, "24th Texas A\&M Univ. Et Al. U.S. Rock Mech. Symp. Proc., College Station, TX, 1983, pp. 519-523.

Jones, Jr., F.O., "A Laboratory Study of the Effects of Confining Pressure on Fracture Flow and Storage Capacity in Carbonate Rocks," J. Petrol. Technol., Vol. 27, Jan. 1975, pp. 21-27, SPE Pap. No. 4569.

Jones, S.C., "Two-Point Determinations of Permeability and PV vs. Net Confining Stress," SPE Formation Evaluation, March 1988, pp. 235-241, SPE Pap. No. 15380.

Jones, T.A., Wooten, S.O. and Kaluza, T.J., "Single-Phase Flow Through Natural Fractures," 63rd Annu. SPE Tech. Conf. Proc., Houston, 1988, pp. 687-696, SPE Pap. No. 18175.

Karasaki, K., Witherspoon, P.A. and Long, J.C.S., "A New Analytical Model for Fracture-Dominated Reservoirs, "60th Annu. SPE of AIME Tech. Conf. Proc., Las Vegas, 1985, SPE Pap. No. 14171.

Karcz, I. and Dickman, S.R., "Determination of Fracture Intensity, " Tectonophysics, Vol. 56, Nos. 3-4, July 20,1979 , pp. T1-T7.

Kazemi, H., Gilman, J.R. and El-Sharkaway, A.M., "Analytical and Numerical Solution of Oil Recovery From Fractured Reservoirs Using Empirical Transfer Functions," 64th Annu. SPE Tech. Conf. Proc., San Antonio, 1989, pp. 827-842, SPE Pap. No. 19849.

Kazemi, H., Merrill, Jr., L.S., Porterfield, K.L. and Zeman, P.R., "Numerical Simulation of Water-Oil Flow in Naturally Fractured Reservoirs," Soc. Petrol. Eng. J., Vol. 16, Dec. 1976, pp. 317-326.

Kempthorne, R.H. and Irish, J.P.R., "Norman Wells - A New Look at One of Canada's Largest Oil Fields," J. Petrol. Technol., Vol. 33, No. 6, June 1981, pp. 985-991. 
Komar, C.A., Shuck, L.Z., Overbey, W.K. and Anderson, T.O., "Delineating a Subsurface Fracture System in a Petroleum Reservoir - An Experiment, " J. Petrol. Technol., Vol. 25, No. 3, May 1973, pp. 531-537.

Krizek, R.J., Karadi, G.M. and Socias, E., "Dispersion of a Contaminant in Fissured Rock," Int. Soc. Rock Mech. \& Int. Assoc. Eng. Geol. Percolation Through Fissured Rock Symp. Proc., Stuttgart, 1972, Pap. No. T3-C.

Kyte, J.R., "A Centrifuge Method to Predict Matrix-Block Recovery in Fractured Reservoirs," Soc. Petrol. Eng. J., Vol. 10, No. 2, June 1970, pp. 164-170.

Labastie, A., "Capillary Continuity Between Blocks of a Fractured Reservoir," 65th Annu. SPE Tech. Conf. Proc., New Orleans, 1990, pp. 423-432, SPE Pap. No. 20515.

Ladeira, F.L. and Price, N.J., "Relationship Between Fracture Spacing and Bed Thickness," J. Struct. Geol., Vol. 3, No. 2, 1981, pp. 179-183.

Lamb, C. and Haig, P., "Evaluating the Contributions of Fractures to Reservoir Performance," 11th Can. Well Logging Soc. Formation Evaluation Symp. Trans., Vol. 1, Calgary, Can, 1987, Pap. No. E, 1987.

Lee, A.L, Gonzalez, M.H., and Eakin, B.E., "The Viscosity of Natural Gases," J. Petrol. Tech., Vol. 18, No. 8, Aug. 1966, pp. 997-1000, SPE Pap. No. 1340.

Leung, W.F., "A Fast Convolution Method for Implementing Single-Porosity Finite/Infinite Aquifer Models for Water-Influx Calculations, " SPE Reservoir Eng., Vol. 1, No. 5, Sept. 1986, pp. 490-510, SPE Pap. No. 12276.

Leung, W.F., "A General Purpose Single-Phase Naturally Fractured (Carbonate) Reservoir Simulator With Rigorous Treatment of Rock-Stress/Fluid-Pressure Interactions and Interporosity Flow, " 8th SPE of AIME Reservoir Simulation Symp. Proc., Dallas, 1985, pp. 307-330, SPE Pap. No. 13528.

Leung, W.F., "A New Pseudosteady-State Model for Dual-Porosity/Dual-Permeability Aquifers and Two Interconnected Single-Porosity Aquifers," SPE Reservoir Eng., Vol. 1, No. 5, Sept. 1986, pp. 511-520, SPE Pap. No. 12277.

Leung, W.F., "A Tensor Model for Anisotropic and Heterogeneous Reservoirs With Variable Directional Permeabilities," 56th Annu SPE Calif. Reg. Mtg., Oakland, 1986, SPE Pap. No. 15134.

Lichtenberger, G.J., "Pressure Buildup Test Results From Horizontal Wells in the Pearsall Field of the Austin Chalk," 65th Annu. SPE Tech. Conf. Proc., New Orleans, 1990, pp. 835-850, SPE Pap. No. 20609. 
Litvak, B.L., "Simulation and Characterization of Naturally Fractured Reservoirs," NIPER Reservoir Characterization Tech. Conf. Proc., Dallas, 1985, pp. 561-584.

Litvak, B.L., Satter, A. and Etebar, S., "An Analysis of Naturally Fractured Reservoir Performance Using a Novel Fractured Reservoir Simulator, "SPE Petrol. Eng. Int. Mtg. Proc., Tianjin, China, 1988, pp. 679-688, SPE Pap. No. 17615.

Long, J.C.S. and Witherspoon, P.A., "The Relationship of the Degree of Interconnection to Permeability in Fracture Networks, " J. Geophys. Res., Vol. 90, No. B4, March 10, 1985, pp. 3087-3098.

Long, M., "Austin Chalk Play Spreads Far to Northeast in Texas," Oil Gas J., Vol. 74, No. 36, Sept. 6, 1976, pp. 60-64.

Lorenz, J.C., Warpinski, N.R., Branagan, P.T. and Sattler, A.R., "Fracture Characteristics and Reservoir Behavior of Stress-Sensitive Fracture Systems in Flat-Lying Lenticular Formations," J. Petrol. Technol., Vol. 41, No. 6, June 1989, pp. 615-622, SPE Pap. No. 15244.

Louis, C. and Maini, Y.N., "Determination of In-Situ Hydraulic Parameters in Jointed Rock," 2nd Int. Soc. Rock Mech. Congr. Proc., Vol. 1, Beograd, Yugo., 1970, pp. 235-245.

Mannon, R.W. and Chilingar, G.V., "Experiments on Effect of Water Injection Rate on Imbibition Rate in Fractured Reservoirs," 47th Annu. SPE of AIME Fall Mtg., San Antonio, 1972, SPE Pap. No. 4101.

McKee, C.R., Bumb, A.C. and Koenig, R.A., "Stress-Dependent Permeability and Porosity of Coal and Other Geologic Formations, " SPE Formation Evaluation, March 1988, pp. 81-91, SPE Pap. No. 12858.

McQuillan, H., "Fracture-Controlled Production From the Ogligo-Miocene Asmari Formation in Gachsaran and Bibi Hakimeh Fields, Southwest Iran, "Carbonate Petrol. Reservoirs, Springer-Verlag, New York, 1985, pp. 511, 513-523.

McQuillan, H., "Fracture Patterns on Kuh-E Asmari Anticline, Southwest Iran," AAPG Bull., Vol. 58, No. 2, Feb. 1974, pp. 236-246.

McQuillan, H., "Small-Scale Fracture Density in Asmari Formation of Southwest Iran and Its Relation to Bed Thickness and Structural Setting," AAPG Bull., Vol. 57, No. 12, Dec. 1973, pp. 2367-2385.

Mead, H.N., "Using Finite-System Buildup Analysis to Investigate Fractured, Vugular, Stimulated, and Horizontal Wells," J. Petrol. Technol., Vol. 40, No. 10, Oct. 1988, pp. 1361-1371, SPE Pap. No. 16379.

Moore, S.D., "Oryx Develops Horizontal Play," Petrol. Eng. Int., April 1990, pp. 16, 20-22. 
Morel, D.D., Bourbiaux, B., Latil, M. and Thiebot, B., "Diffusion Effects in Gas-Flooded Light Oil Fractured Reservoirs," 65th Annu. SPE Tech. Conf. Proc., New Orleans, 1990, pp. 433-446, SPE Pap. No. 20516.

Morgenstern, N.R. and Guther, H., "Seepage Into an Excavation in a Medium Possessing Stress-Dependent Permeability," Int. Soc. Rock Mech. \& Int. Assoc. Eng. Geol. Percolation Through Fissured Rock Symp. Proc., Stuttgart, 1972, Pap. No. T2-C.

Morita, N., Whitfill, D.L., Nygaard, O. and Bale, A., "A Quick Method to Determine Subsidence, Reservoir Compaction, and in-Situ Stress Induced by Reservoir Depletion," J. Petrol. Technol., Vol. 41, No. 1, Jan. 1989, pp. 71-79, SPE Pap. No. 17150.

Morrow, N.R., Brower, K.R., Ma, S. and Buckley, J.S., "Fluid Flow in Healed Tectonic Fractures," J. Petrol. Technol., Vol. 42, No. 10, Oct. 1990, pp. 1310-1318, SPE Pap. No. 19096.

Nelson, R.A., "An Experimental Study of Fracture Permeability in Porous Rock," 17th Utah Univ. Rock Mech. U.S. Symp. Proc., Snowbird, Utah, 1976, pp. 2A6-1 - 2A6-8.

Nelson, R.A., "Fractured Reservoirs: Turning Knowledge into Practice," J. Petrol. Technol., Vol. 39, No. 4, April 1987, pp. 407-414, SPE Pap. No. 16470.

Neuzil, C.E. and Tracy, J.V., "Flow Through Fractures," Water Resources Res., Vol. 17, No. 1, Feb. 1981, pp. 191-199.

Noorishad, J., Ayatollahi, M.S. and Witherspoon, P.A., "A Finite-Element Method for Coupled Stress and Fluid Flow Analysis in Fractured Rock Masses, "Int. J. Rock Mech. Sci. and Geomech. Abstr., Vol. 19, 1982, pp. 185-193.

Noorishad, J. and Doe, T.W., "Numerical Simulation of Fluid Injection into Deformable Fractures," 23rd Calif. Univ. Berkeley, Et Al. Rock Mech. Symp. Proc., Berkeley, 1982, Society of Mining Engineers, NY, 1982, pp. 645-654.

Noorishad, J., Tsang, C.F. and Witherspoon, P.A., "Coupled Thermal-Hydraulic-Mechanical Phenomena in Saturated Fractured Porous Rocks: Numerical Approach, " J. Geophys. Res., Vol. 89, No. B12, Nov. 10, 1984, pp. 10365-10373.

Norman, D.K. and Garrett, C.H., "Advances in Fractured Reservoir Characterization," 39th Annu. CIM Petrol. Soc. Tech. Mtg. \& Can. Gas Processors Assoc. 2nd Quart. Mtg., Calgary, Can, 1988, Preprints, Vol. 3, 1988, Pap No. 88-39-111.

Northrop, D.A. and Frohne, K.H., "The Multiweil Experiment - A Field Laboratory in Tight Gas Sandstone Reservoirs," J. Petrol. Technol., Vol. 42, No. 6, June 1990, pp. 772-779, SPE Pap. No. 18286. 
Oen, P.M., Engell-Jensen, M. and Barendregt, A.A., "Skjold Field, Danish North Sea: Early Evaluations of Oil Recovery Through Water Imbibition in a Fractured Reservoir," SPE Reservoir Eng., Vol. 3, No. 1, Feb. 1988, pp. 17-22, SPE Pap. No. 15569.

Offeringa, J., "Carbon-Dioxide-Assisted Production From Extensiveiy Fractured Reservoirs," U.S. Pat. $4,042,029$, c. $8 / 16 / 77$, f. $1 / 9 / 76$.

Offeringa, J., "Evaluation of Agha Jari Reservoir Performance," Iranian Oil Explor. Prod. Co., Service Report S41, Oct. 1961.

Olarewaju, J.S. and Lee, W.J., "New Pressure-Transient Analysis Model for Dual-Porosity Reservoirs," SPE Formation Evaluation, Sept. 1989, pp. 384-390, SPE Pap. No. 15634.

Oryx Energy Co., Spacing Unit Submission to Texas RRC, Docket 1-94.685, July 10, 1990.

Owusu, L.A. and Ershaghi, I., "Relative Permeability of Naturally Fractured Reservoirs From Field Performance Data, "59th Annu. SPE Calif. Reg. Mtg. Proc., Bakersfield, CA, 1989, pp. 33-40, SPE Pap. No. 18748.

Paige, K.T. and Dayton, J.S., "Development of the Lisburne Reservoir," 62rd Annu. SPE Tech. Conf. Proc., Dallas, 1987, pp. 107-112, SPE Pap. No. 16845.

Parsons, R.W., "Permeability of Idealized Fractured Rock, " Soc. Petrol. Eng. J., Vol. 6, June. 1966, pp. 126-136.

Pavone, D., Bruzzi, P. and Verre, R., "Gravity Drainage at Low Interfacial Tension," 5th Hung. Hydrocarbon Inst. Impr. Oil Recovery Europe. Symp. Proc., Budapest, Hungary, 1989, pp. 165-174.

Peaceman, D.W., "Convection in Fractured Reservoirs - The Effect of Matrix-Fissure Transfer on the Instability of a Density Inversion in a Vertical Fissure," 50th Annu. SPE of AIME Fall Mtg., Dallas, 1975, SPE Pap. No. 5523.

Peaceman, D.W., "Convection in Fractured Reservoirs - Numerical Calculation of Convection in a Vertical Fissure, Including the Effect of Matrix-Fissure Transfer," 51st Annu. SPE of AIME Fall Mtg., New Orleans, 1976, SPE Pap. No. 5959.

Peaceman. D.W., "Interpretation of Well-Block Pressures in Numerical Reservoir Simulation," Soc. Petrol. Eng. J., Vol. 18, June 1978, pp. 183-194, SPE Pap. No. 6893.

Peaceman. D.W., "Interpretation of Well-Block Pressures in Numerical Reservoir Simulation with Nonsquare Grid Blocks and Anisotropic Permeability," Soc. Petrol. Eng. J., Vol. 23, June 1983, pp. 531-543, SPE Pap. No. 10528. 
Peaceman. D.W., "Interpretation of Well-Block Pressures in Numerical Reservoir Simulation Part 3: Some Additional Well Geometries, " 62nd Annu. SPE Tech. Conf. Proc., Dallas, 1987, SPE Pap. No. 16976.

Peaceman. D.W., "Representation of a Horizontal Well Numerical Reservoir Simulation." 11th SPE of AIME Reservoir Simulation Symp. Proc., Anaheim, 1991, SPE Pap. No. 21217.

Peng, C.P., Singh, P.K., Halvorsen, H. and York, S.D., "Fractured Reservoir Characterization Through Injection Falloff and Flowback Tests," 65th Annu. SPE Tech. Conf. Proc., New Orleans, 1990, pp. 399-410, SPE Pap. No. 20567.

Peng, C.P. and Yanosik, J.L., "Pressure Pulsing Waterflooding in Dual Porosity Naturally Fractured Reservoirs," SPE Petrol. Eng. Int. Mtg. Proc., Tianjin, China, 1988, pp. 389-400, SPE Pap. No. 17587.

Pope, C.D. and Handren, P.J., "Completion Techniques for Horizontal Wells in the Pearsall Austin Chalk," 65th Annu. SPE Tech. Conf. Proc., New Orleans, 1990, pp. 657-664, SPE Pap. No. 20682.

Por, G.J., Boerrigter, P., Maas, J.F. and de Vries, A., "A Fractured Reservoir Simulator Capable of Modeling Block-Block Interaction," 64th Annu. SPE Tech. Conf. Proc., San Antonio, 1989, pp. 373-381, SPE Pap. No. 19807.

Pruess, K. and Narasimhan, T.N., "A Practical Method for Modeling Fluid and Heat Flow in Fractured Porous Media," Soc. Petrol. Eng. J., Vol. 25, Feb. 1985, pp. 14-26, SPE Pap. No. 10509.

Raven, K.G. and Gale, J.E., "Water Flow in a Natural Rock Fracture as a Function of Stress and Sample Size," Int. J. Rock Mech. Sci. and Geomech. Abstr., Vol. 22, No. 4, 1985, pp. 251-261.

Roehl, P.O. and Weinbrandt, R.M., "Geology and Production Characteristics of Fractured Reservoirs in the Miocene Monterey Formation, West Cat Canyon Oilfield, Santa Maria Valley," Carbonate Petrol. Reservoirs, Springer-Verlag, NY, 1985, pp. 525,527-545.

Rossen, R.H. and Shen, E.I.C., "Simulation of Gas/Oil Drainage and Water/Oil Imbibition in Naturally Fractured Reservoirs," SPE Reservoir Eng., Nov. 1989, pp. 464-470, SPE Pap. No. 16982.

Sagar, F. and Runchal, A., "Permeability of Fractured Rock: Effect of Fracture Size and Data Uncertainties," Water Resources Res., Vol. 18, No. 2, April 1982, pp. 266-274.

Sahuquet, B.C., Spreux, A.M., Corre, B. and Guittard, M.P., "Steam Injection in a Low-Permeability Reservoir Through a Horizontal Well in Lacq Superieur Field," 65th Annu. SPE Tech. Conf. Proc., New Orleans, 1990, pp. 559-568, SPE Pap. No. 20526. 
Saidi, A.M., "Effect of Gas Pressure Maintenance on the Recovery of the Iranian Fractured Limestone Reservoirs," 9th World Energy Conf. Trans., Detroit, 1974, Vol. 4, pp. 224-236.

Saidi, A.M., "Mathematical Simulation Model Describing Iranian Fractured Reservoirs and Its Application to Haft Kel Field, "9th World Petrol. Congr., Panel Discussion, Tokyo, 1975, Preprint No. 13(3).

Saidi, A.M., Tehrani, D.H. and Wit, K., "Mathematical Simulation of Fractured Reservoir Performance, Based on Physical Model Experiments," 10th World Petrol. Congr. Proc., Bucharest, 1979, Vol. 3, pp. 225-233.

Samaniego-V., F. and Cinco-Ley, H., "Pressure-Transient Analysis for Naturally Fractured Gas Reservoirs: Field Cases, " SPE Formation Evaluation, Sept. 1989, pp. 445-453, SPE Pap. No. 12010.

Sampson, L.E. and Marcou, J.A., "Interference Test in a Fractured Carbonate: A Lisburne Case History," 63rd Annu. SPE Tech. Conf. Proc., Houston, 1988, pp. 303-317, SPE Pap. No. 18138.

Schafer, J.N., "A Practical Method of Well Evaluation and Acreage Development for the Naturally Fractured Austin Chalk Formation," Soc. Prof. Well Log Anal. Twentieth Annual Logging Symp. Proc., 1979.

Schnerk, G.C. and Madeen, C.N., "The Austin Chalk: Simulation of Horizontal Wells in a Heterogeneous Formation," 65th Annu. SPE Tech. Conf. Proc., New Orleans, 1990, pp. 25-36, SPE Pap. No. 20716.

Schrauf, T.W. and Evans, D.D., "Laboratory Studies of Gas Flow Through a Single Natural Fracture," Water Resources Res., Vol. 22, No. 7, July 1986, pp. 1038-1050.

Scott, R.J., "The Austin Chalk-Buda Trend of South Texas," Gulf Coast Assoc. Geol. Soc. Trans., Vol. 27, 1977, pp. 164-178.

Sener, I., "Methodology Used in Estimating the Raman Reservoir Fracture System Data for Simulation," 62rd Annu. SPE Tech. Conf. Proc., Dallas, 1987, pp. 483-494, SPE Pap. No. 19978.

Sener, I., "Relative Diffusion Flux: A Practical Concept for Characterizing Fracture to Matrix Gas Transfer - Application to Fractured Reservoir Model, "61st Annu. SPE Tech. Conf. Proc., New Orleans, 1986, SPE Pap. No. 15522.

Sharp, J.C. and Maini, Y.N.T., "Fundamental Considerations on the Hydraulic Characteristics of Joints in Rock," Int. Soc. Rock Mech. \& Int. Assoc. Eng. Geol. Percolation Through Fissured Rock Symp. Proc., Stuttgart, 1972, Pap. No. T1-F. 
Singh, B.B., "Analysis of Pressure Buildup Tests in Naturally Fractured Reservoirs: Field Cases," 6th SPE Middle East Oil Show Proc., Manama, Bahrain, 1989, pp. 433-448, SPE Pap. No. 17971.

Snow, D.T., "Fracture Deformation and Change of Permeability and Storage Upon Changes of Fluid Pressures," Quart. of the Colorado School of Mines, Vol. 63, No. 1, Jan. 1968, pp. 201-244.

Snow, D.T., "The Frequency and Apertures of Fractures in Rock, "Int. J. Rock Mech. Mining Sci., Vol. 7, No. 1, Jan. 1970, pp. 23-40.

Snow, D.T., "Rock Fracture Spacings, Openings, and Porosities," J. Soil Mech. \& Foundations Div., ASCE, Vol. 94, No. SM1, Jan. 1968, pp. 73-91, Pap. No 5736.

Snyder, R.H. and Craft, M., "Evaluation of Austin and Buda Formations From Core and Fracture Analysis," Gulf Coast Assoc. Geol. Soc. Trans., Vol. 27, 1977, pp. 376-385.

Soeder, D.J., "Porosity and Permeability of Eastern Devonian Gas Shale," SPE Formation Evaluation; March 1988, pp. 116-124, SPE Pap. No. 15213.

Standing, M.B., "Volumetric and Phase Behavior of Oil Field Hydrocarbon Systems," 1977, pp. 26,122 .

Stang, C.W., "Alternative Electronic Logging Technique Locates Fractures in Austin Chalk Horizontal Well," Oil Gas J., Vol. 87, No. 45, Nov. 6, 1989, pp 42-45.

Stapp, W.L., "The Geology of the Fractured Austin and Buda Formations in the Subsurface of South Texas," Gulf Coast Assoc. Geol. Soc. Trans., Vol. 27, 1977, pp. 208-229.

Stayton, R.J. and Peach, S.R., "Long Radius Well Taps Vertical Fractures, " Drilling Contractor, June/July 1990, pp. 57-59.

Stewart, G. and Ascharsobbi, F., "Well Test Interpretation for Naturally Fractured Reservoirs," 63rd Annu. SPE Tech. Conf. Proc., Houston, 1988, pp. 661-676, SPE Pap. No. 18173.

Stewart-Gordon, T.J., "High Oil Prices, Technology Support Austin Chalk Boom," World Oil, Oct. 1976 , pp. $123,125-126$.

Sulak, R.M. and Danielsen, J., "Reservoir Aspects of Ekofisk Subsidence," J. Petrol. Technol., Vol. 41, No. 7, July 1989, pp. 709-716, SPE Pap. No. 17852.

Sulak, R.M., Thomas, L.K. and Boade, R.R., "Rigorous Treatment of Compaction Drive in a 3-D Reservoir Simulator: A Case Study of Ekofisk Field," 64th Annu. SPE Tech. Conf. Proc., San Antonio, 1989, pp. 313-326, SPE Pap. No. 19802. 
Teufel, L.W., "In-Situ Stress and Natural Fracture Distribution at Depth in the Piceance Basin, Colorado: Implications to Stimulation and Production of Flow, "27th Soc. Mining Eng. Rock Mech. U.S. Symp. Proc., "Rock Mechanics: Key to Energy Production," Tuscaioosa, AL, 1986, pp. 702-708.

Thomas, L.K., Dixon, T.N. and Pierson, R.G., "Fractured Reservoir Simulation, "Soc. Petrol. Eng. J., Vol. 23, Feb. 1983, pp. 42-54, SPE Pap. No. 9305.

Thomas, L.K., Dixon, T.N., Pierson, R.G. and Hermansen, H., "Ekofisk Nitrogen Injection," SPE Formation Evaluation, June 1991, pp. 151-160, SPE Pap. No. 19839.

Trantham, J.C., Threlkeld, C.B. and Peterson, H.L., "Reservoir Description for a Surfactant/Polymer Pilot in a Fractured, Oil-Wet Reservoir - North Burbank Unit Tract 97," 54th Annu. SPE of AIME Tech. Conf., Las Vegas, 1979, SPE Pap. No. 8432.

Tsang, Y.W., "The Effect of Tortuosity on Fluid Flow Through a Single Fracture," Water Resources Res., Vol. 20, No. 9, Sept. 1984, pp. 1209-1215.

Tsang, Y.W. and Tsang, C.F., "Channel Model of Flow Through Fractured Media," Water Resources Res., Vol. 23, No. 3, March 1987, pp. 467-479.

Tsang, Y.W. and Witherspoon, P.A., "Correlations Between Fracture Roughness Characteristics and Fracture Mechanical and Fluid Flow Properties," 23rd Calif. Univ. Berkeley Et Al. Rock Mech. Symp. Proc., "Issues in Rock Mechanics," Berkeley, CA, Soc. of Mining Eng., NY, 19820, pp. 560-567.

Tsang, Y.W. and Witherspoon, P.A., "The Dependence of Fracture Mechanical and Fluid Flow Properties on Fracture Roughness and Sample Size," J. Geophys. Res., Vol. 88, No. B3, March 1983, pp. 2359-2366.

Tsang, Y.W. and Witherspoon, P.A., "Hydromechanical Behavior of a Deformable Rock Fracture Subject to Normal Stress, " J. Geophys. Res., Vol. 86, No. BBB, Oct. 10, 1981, pp. 9287-9298.

Ueda, Y., Watanabe, Y., Funatsu, K. and Murata, S., "Investigation of the Shape Factor Used in the Dual-Porosity Reservoir Simulator," SPE Asia-Pacific Conf. Proc., Sydney, Australia, 1989, pp. 35-44, SPE Pap. No. 19469.

van Bloemen Waanders, B.G. and Litvak, B.L., "Simulation of a Naturally Fractured Reservoir, Point Arguello Field, Offshore California," 59th Annu. SPE Calif. Reg. Mtg. Proc., Bakersfield, CA, 1989, pp. 9-22, SPE Pap. No. 18745.

Van Dijk, C., "Agha Jari Gas/Oil Interfacial Tension Measurements," Iranian Oil Explor. Prod. Co., Tech. Memo T-636, June 1965. 
Vasquez, M., and Beggs, H.D., "Correlations for Fluid Physical Property Predictions," J. Petrol. Tech., Vol. 32, No. 6., June 1980, pp. 968-970, SPE Pap. No. 6719.

Wagner, F.C. and Engler, R., "Differences in the Mechanical Behavior of Cracks and Joints in Rock Samples," ACTA Geophys. Pol., Vol. 35, No. 2, 1987, pp. 183-186.

Walsh, J.B., "Effect of Pore Pressure and Confining Pressure on Fracture Permeability," Int. J. Rock Mech. Mining Sci. Geomech. Abstr., Vol. 18, No. 5, Oct. 1981, pp. 429-435.

Wang, J.S.Y., Tsang, C.F. and Sterbentz, R.A., "The State of the Art of Numerical Modeling of Thermohydrologic Flow in Fractured Rock Masses, " Environ. Geol., Vol. 4, Nos. 3-4, 1982-1983, pp. 133-199.

Warren, J.E. and Root, P.J., "The Behavior of Naturally Fractured Reservoirs, "Soc. Petrol. Eng. J., Vol. 8, Sept. 1968, pp. 245-255.

Williams, E.T. and Kikani, J., "Pressure Transient Analysis of Horizontal Wells in a Naturally Fractured Reservoir," 65th Annu. SPE Tech. Conf. Proc., New Orleans, 1990, pp. 877-891, SPE Pap. No. 20612.

Witherspoon, P.A. and Long, J.C.S., "Some Recent Developments in Understanding the Hydrology of Fractured Rocks," Rep. No. LBL-23464, Calif. Univ. Berkeley, April 1987.

Witherspoon, P.A., Tsang, Y.W., Long, J.C.S. and Noorishad, J., "New Approaches to Problems of Fluid Flow in Fractured Rock Masses," 22nd Mass. Inst. Technol. Et Al. U.S. Rock Mech. Symp. Proc., "Rock Mechanics From Research to Application," Cambridge, MS, 1981, pp. 3-22.

Witherspoon, P.A., Wang, J.S.Y., Iwai, K. and Gale, J.E., "Validity of Cubic Law for Fluid Flow in a Deformable Rock Fracture, "Water Resources Res., Vol. 16, No. 6, Dec. 1980, pp. 1016-1024.

Withjack, E.M., "Analysis of Naturally Fractured Reservoirs With Bottom-Water Drive: Nido A and B Fields, Offshore NW Palawan, Philippines," 58th Annu. SPE of AIME Tech. Conf. Proc., San Francisco, 1983, SPE Pap. No. 12019.

Wooten, S.O. and Jones, T.A., "Graphical Method to Determine Deviation From the Cubic Law for Single-Phase Flow Through Natural Fractures," SPE Pap. No. 20163, Jan. 1990.

Wu, Y.S. and Pruess, K., "A Multiple-Porosity Method for Simulation of Naturally Fractured Petroleum Reservoirs," 56th Annu. SPE Calif. Reg. Mtg. Proc., Oakland, 1986, Vol. 2, pp. 335-350, SPE Pap. No. 15129. 


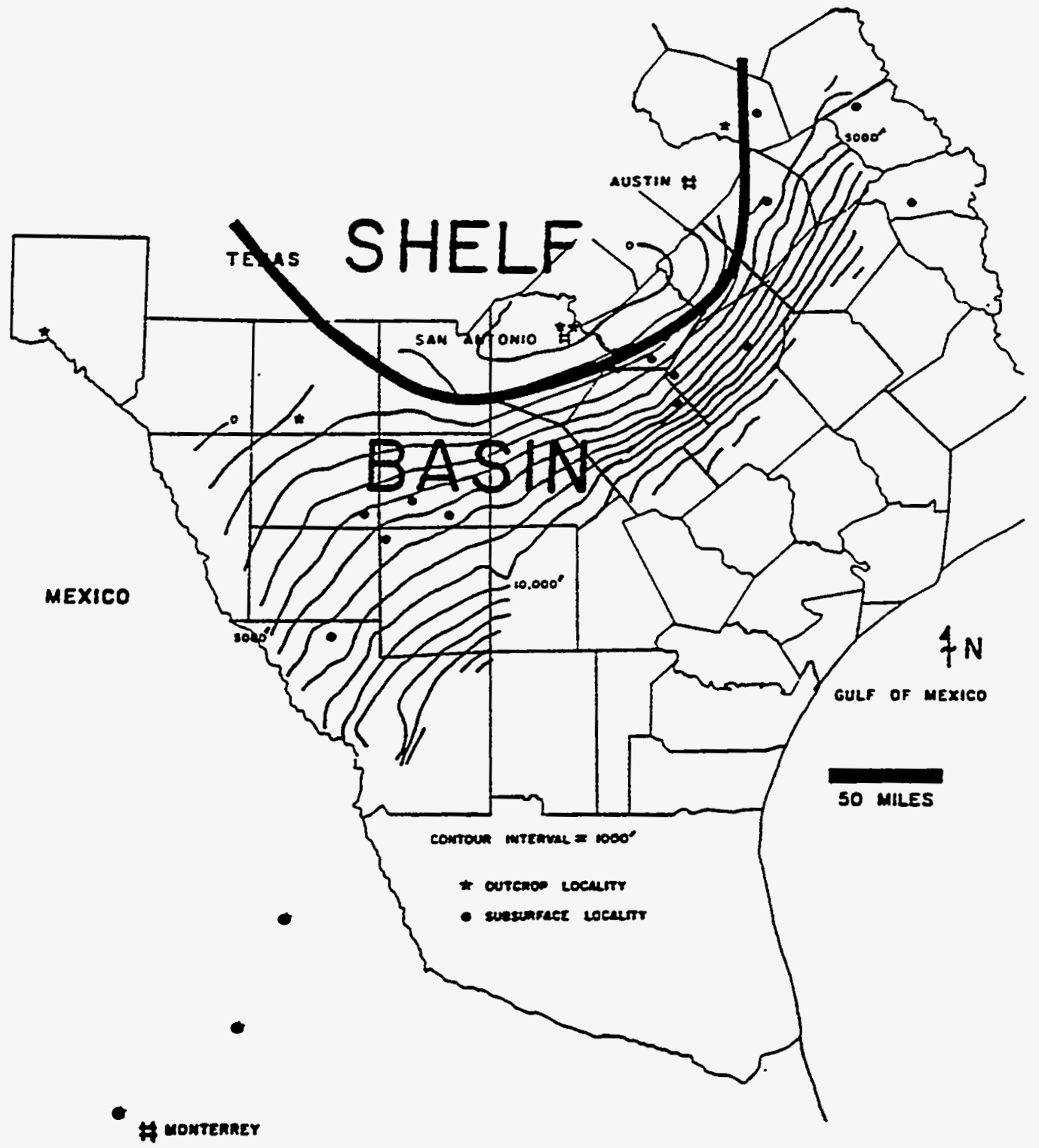

Figure 7.1.1

Depositional Environments for the Upper Cretaceous Austin Chalk Formation ${ }^{4}$ 


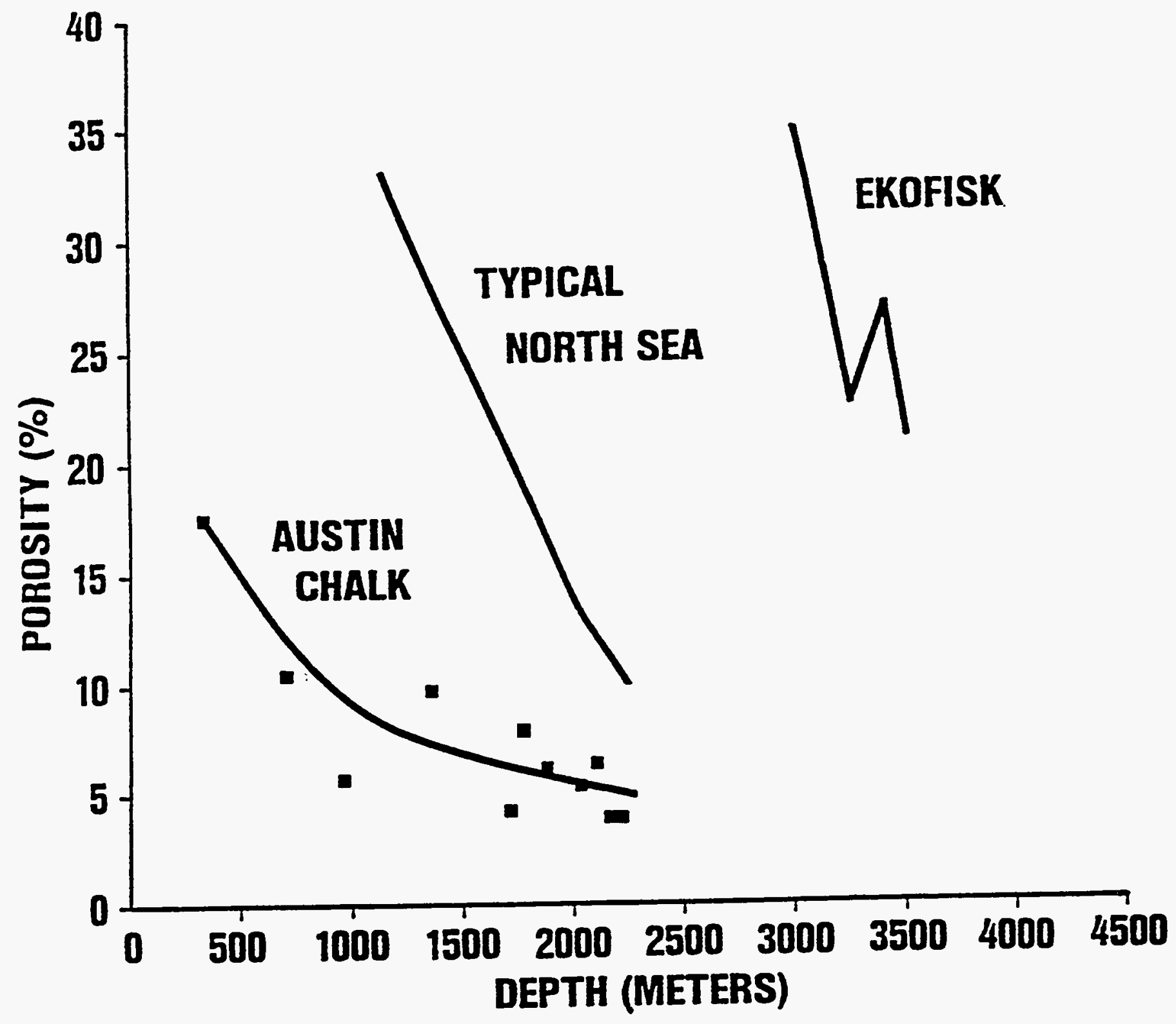

Figure 7.1.2

Porosity versus Depth of Burial ${ }^{4}$ 

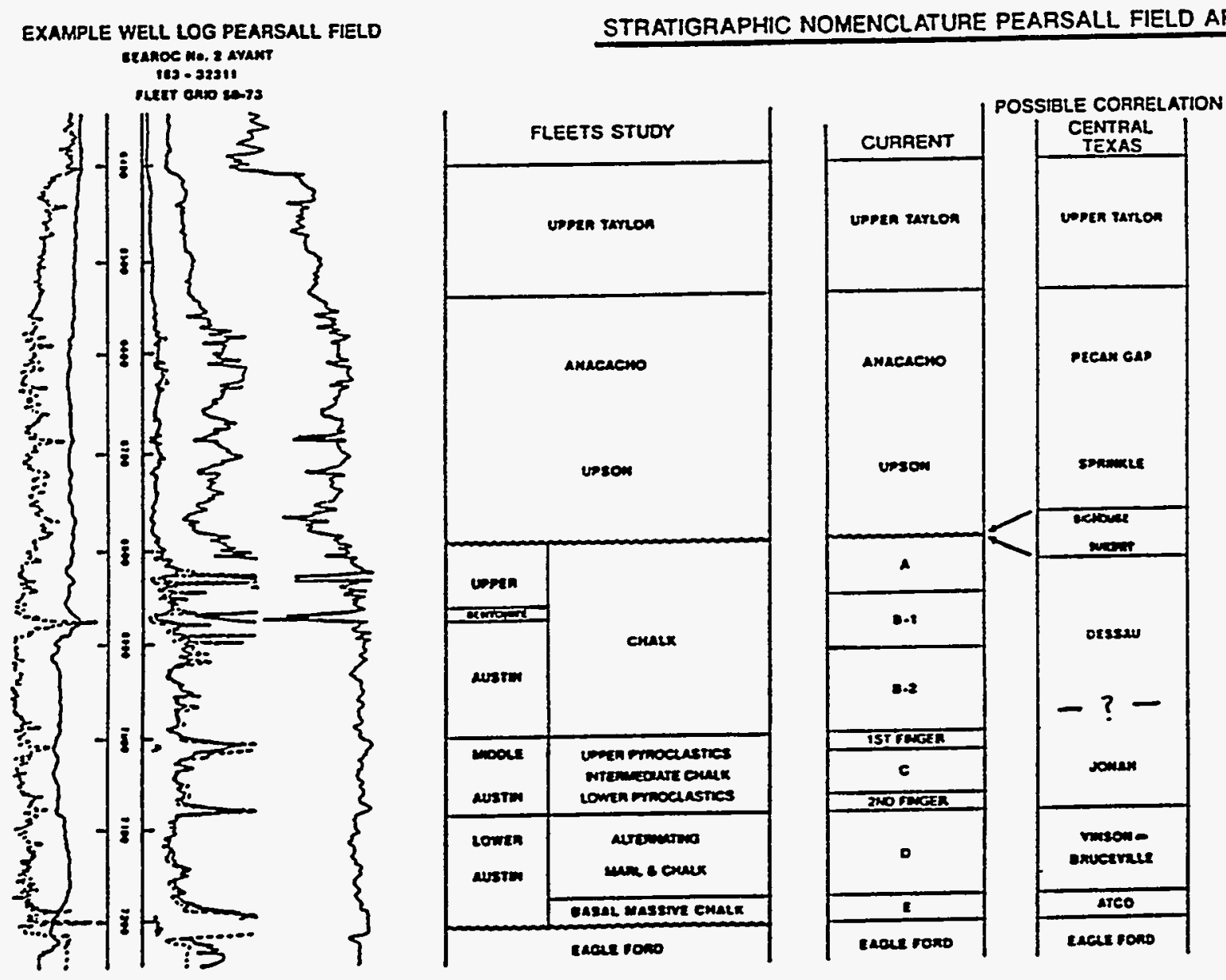

Figure 7.1.3

Typical Log From Pearsall Field Well ${ }^{5}$ 


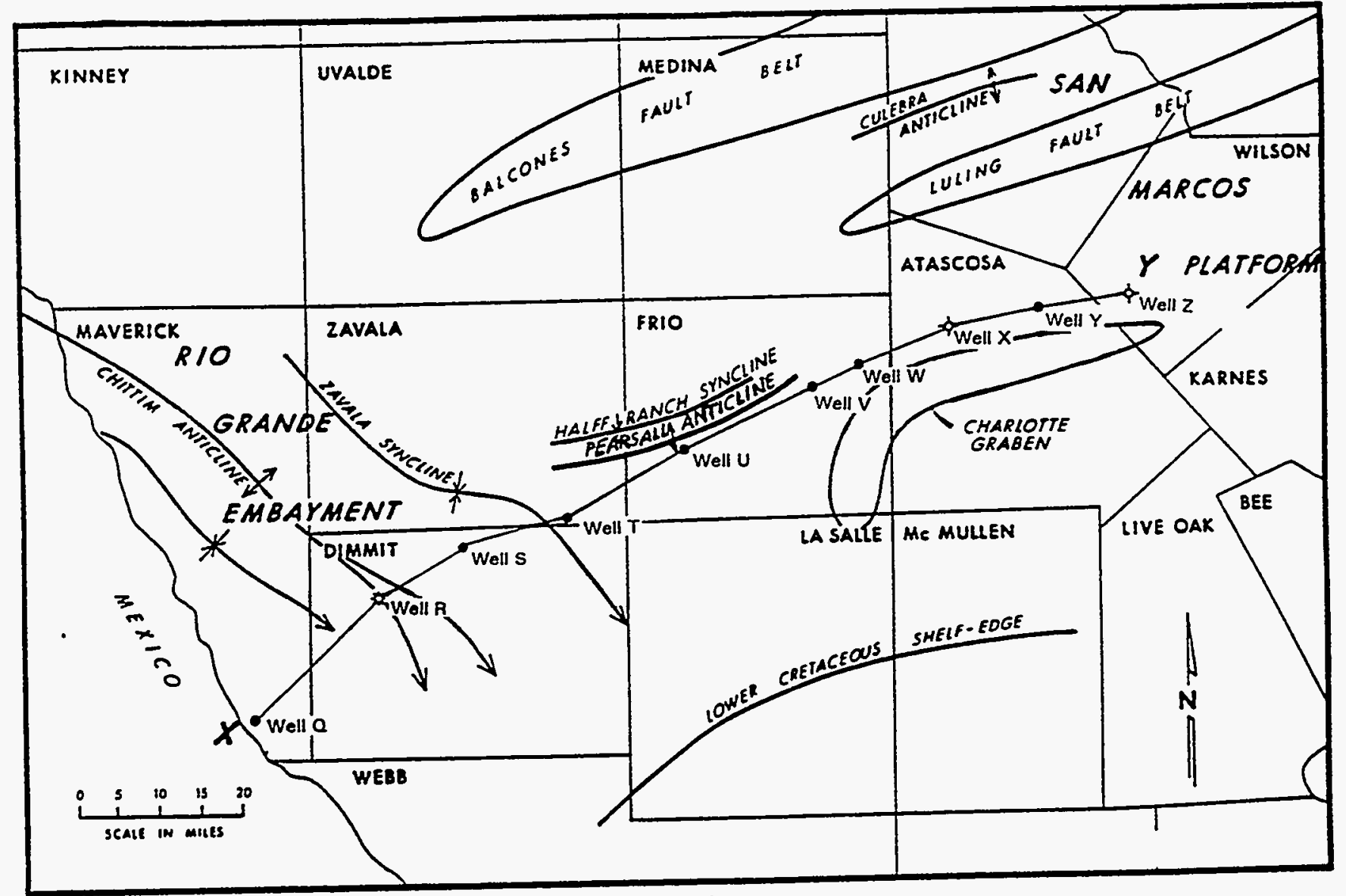

Figure 7.1.4

Major Structural Features in Southwest Texas 


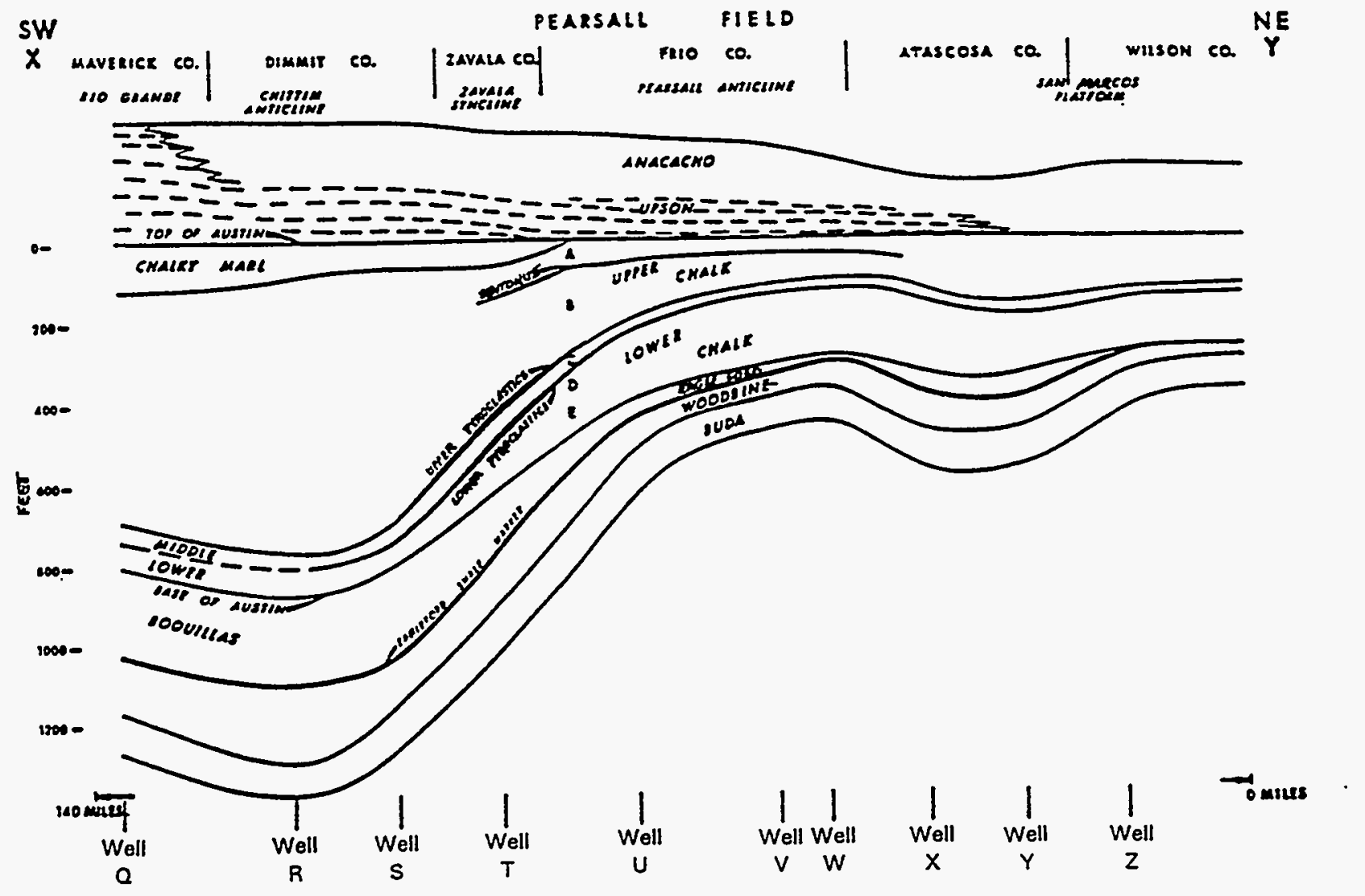

Figure 7.1.5

Subsurface Stratigraphic Cross-Section ${ }^{5}$ 

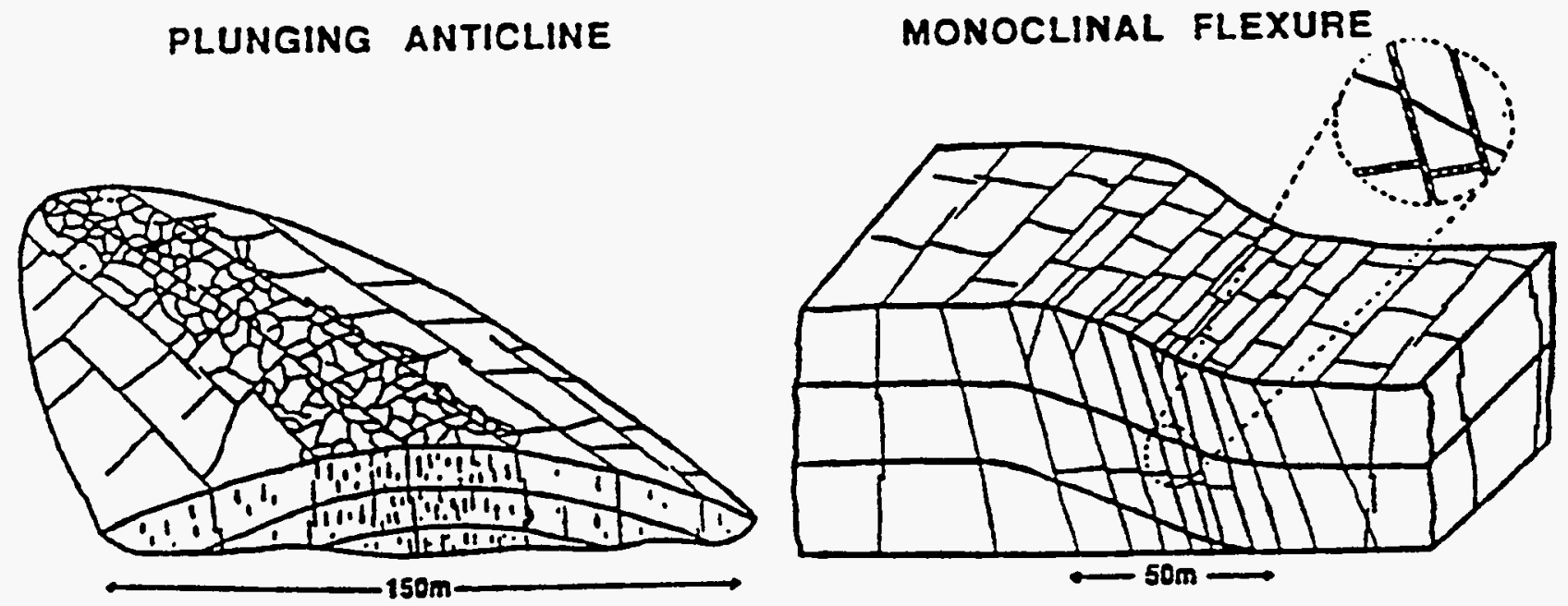

a.

b.

LISTRIC NORMAL FAULT

GRABEN-IN-GRABEN NORMAL FAULTS

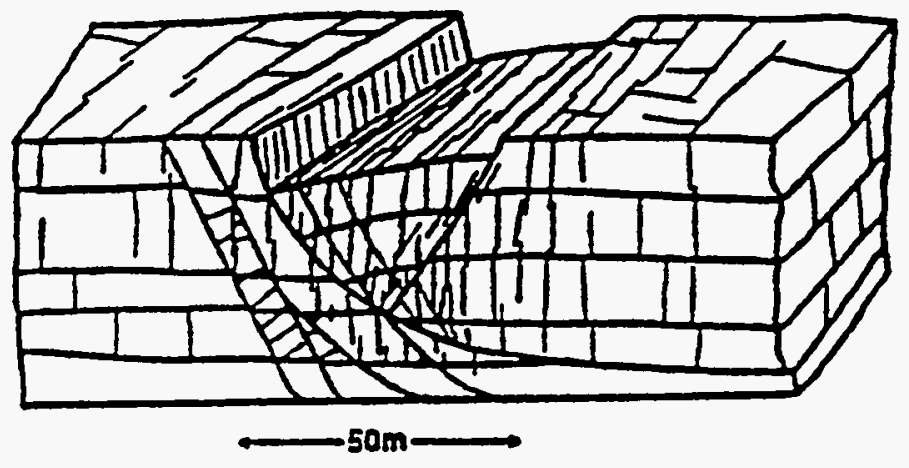

c.

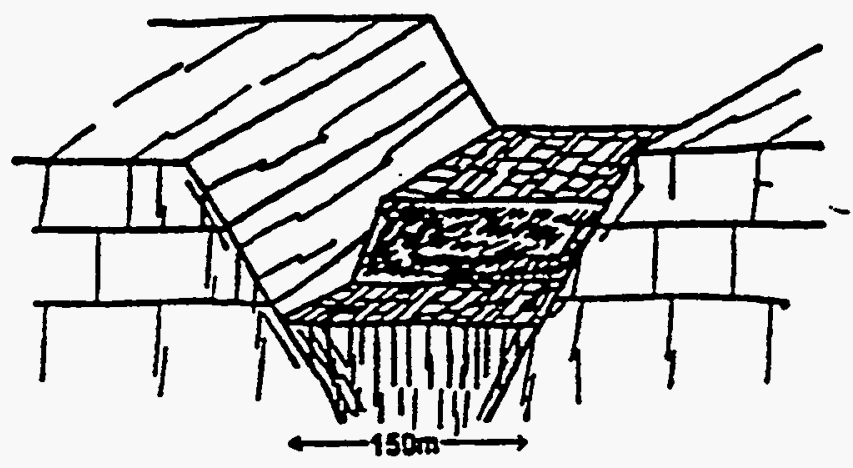

d.

Figure 7.1.6

Schematic Mlustrations of Structural Types and Associated Fractures ${ }^{9}$ 
Figure 7.3.1

Pearsall Field, Austin Chalk Reservoir Well A-1 Production Test Data K\&A Energy Cansultants. Inc.

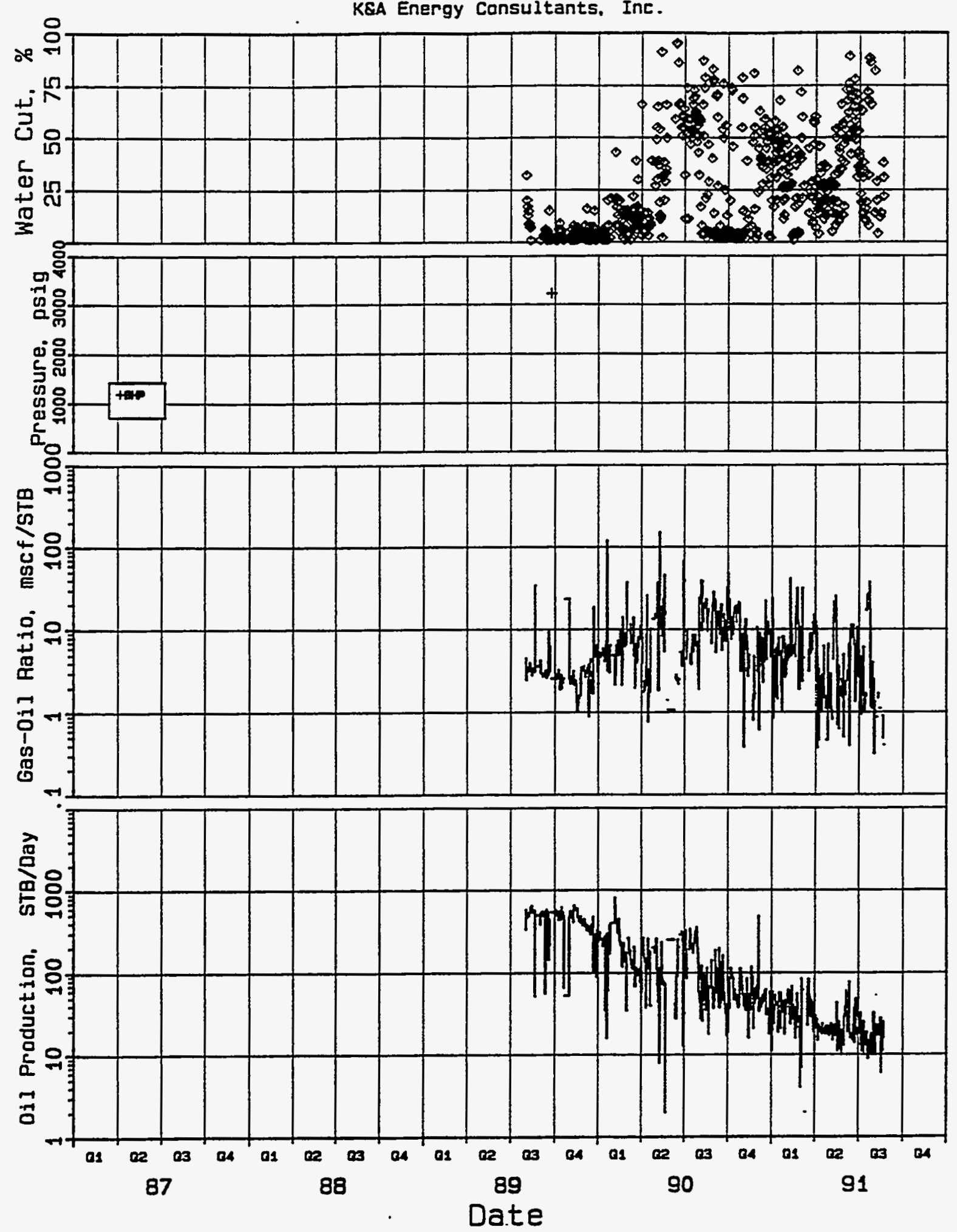


Figure 7.3.2

Pearsall Field, Austin Chalk Reservoir Well A-2 Production Test Data KEA Energy Consultants, Inc.

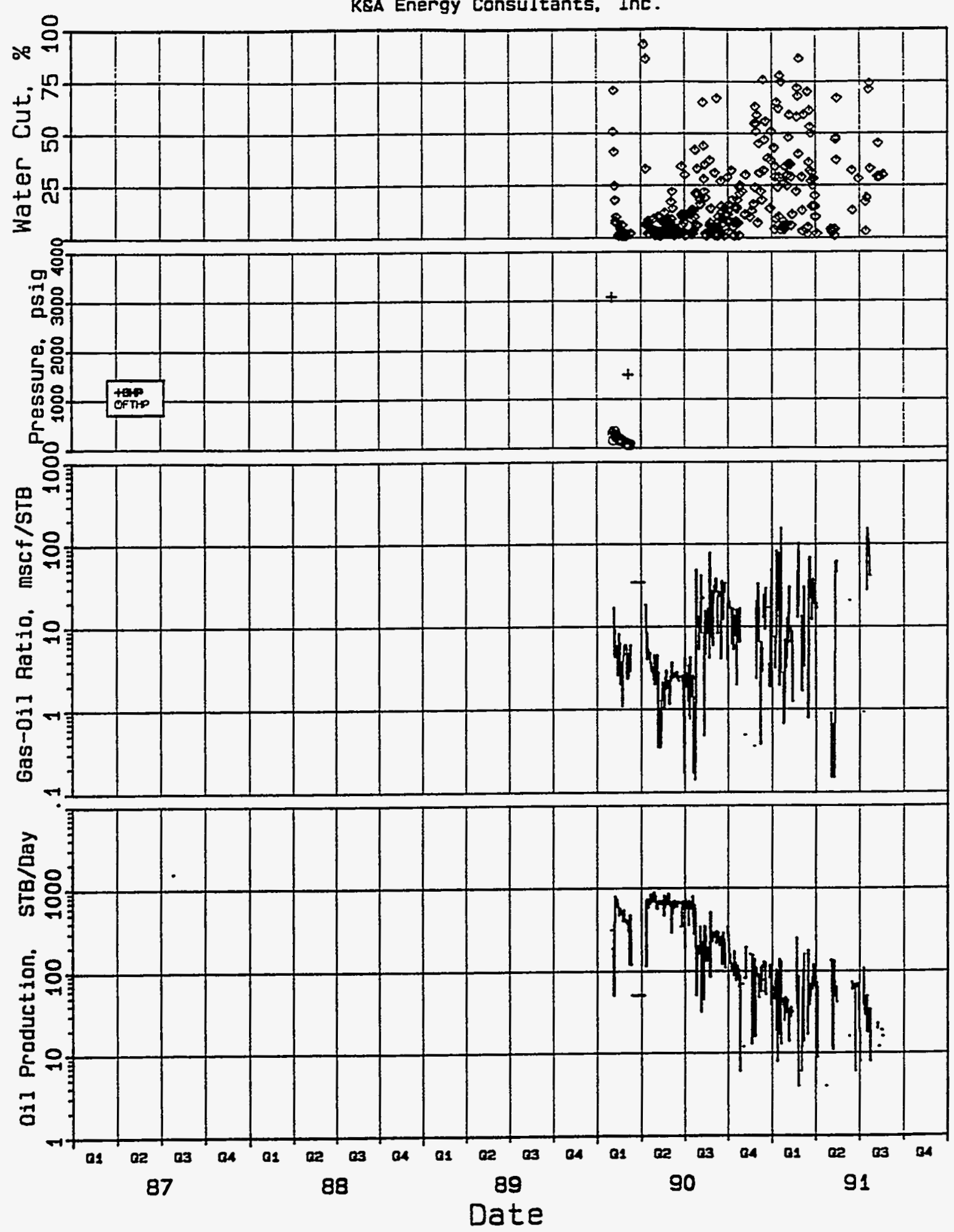


Figure 7.3.3

Pearsall Field, Austin Chalk Reservoir Well B-1 Production Test Data

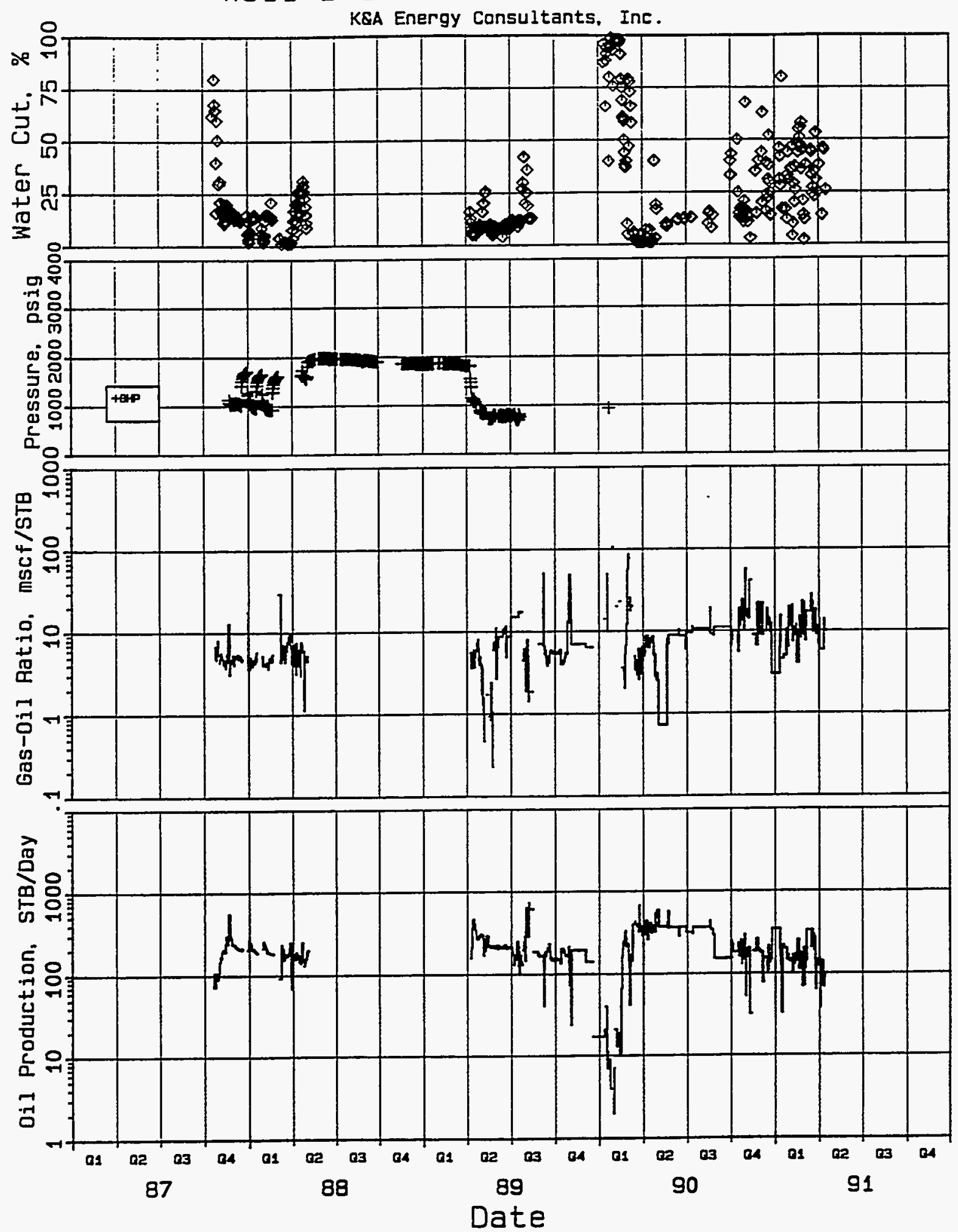


Figure 7.3.4

Pearsall Field, Austin Chalk Reservoir Well B-2 Production Test Data

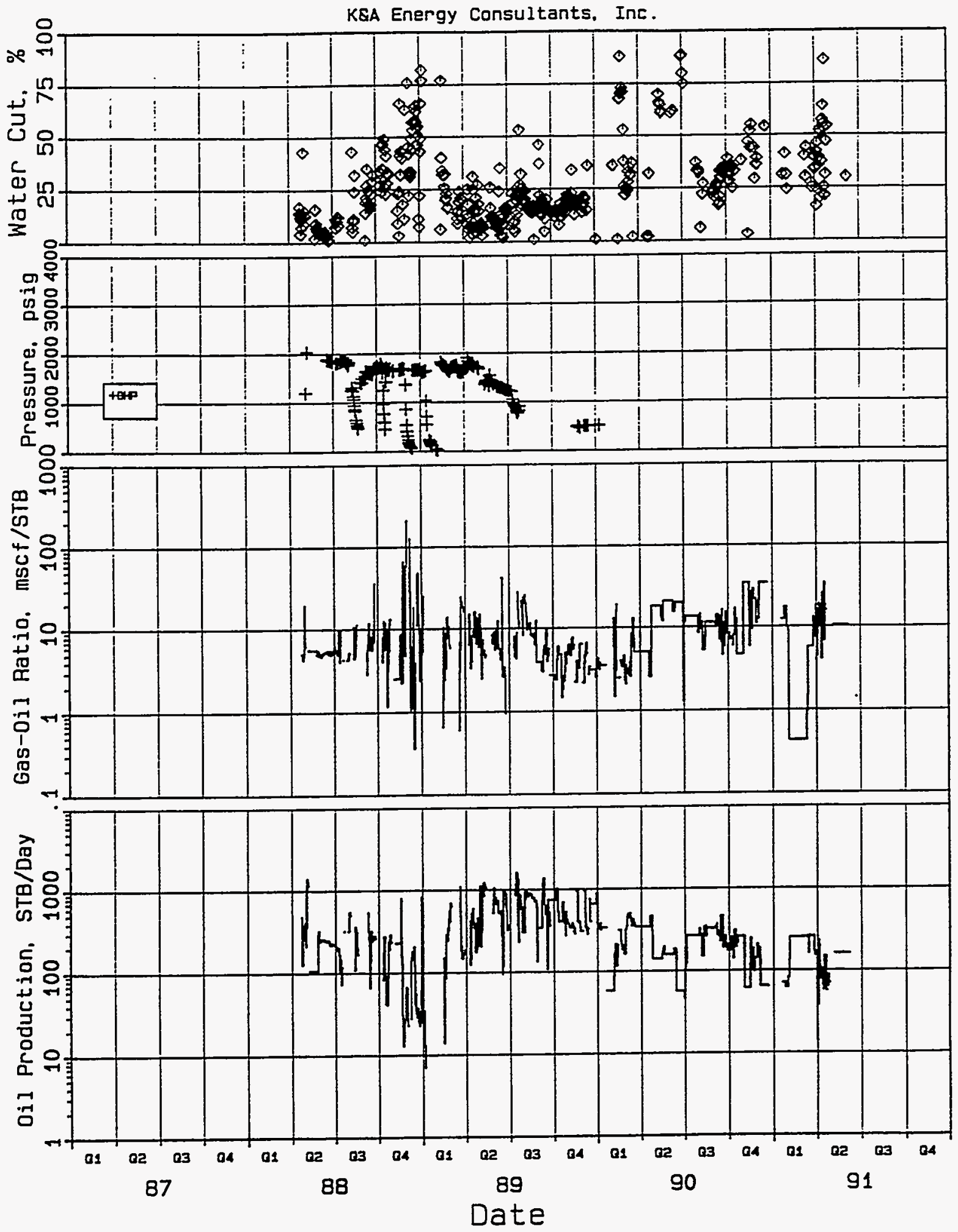


Figure 7.3.5

Pearsall Field, Austin Chalk Reservoir Well P-1 Production Test Data KEA Energy Consultants. Inc.

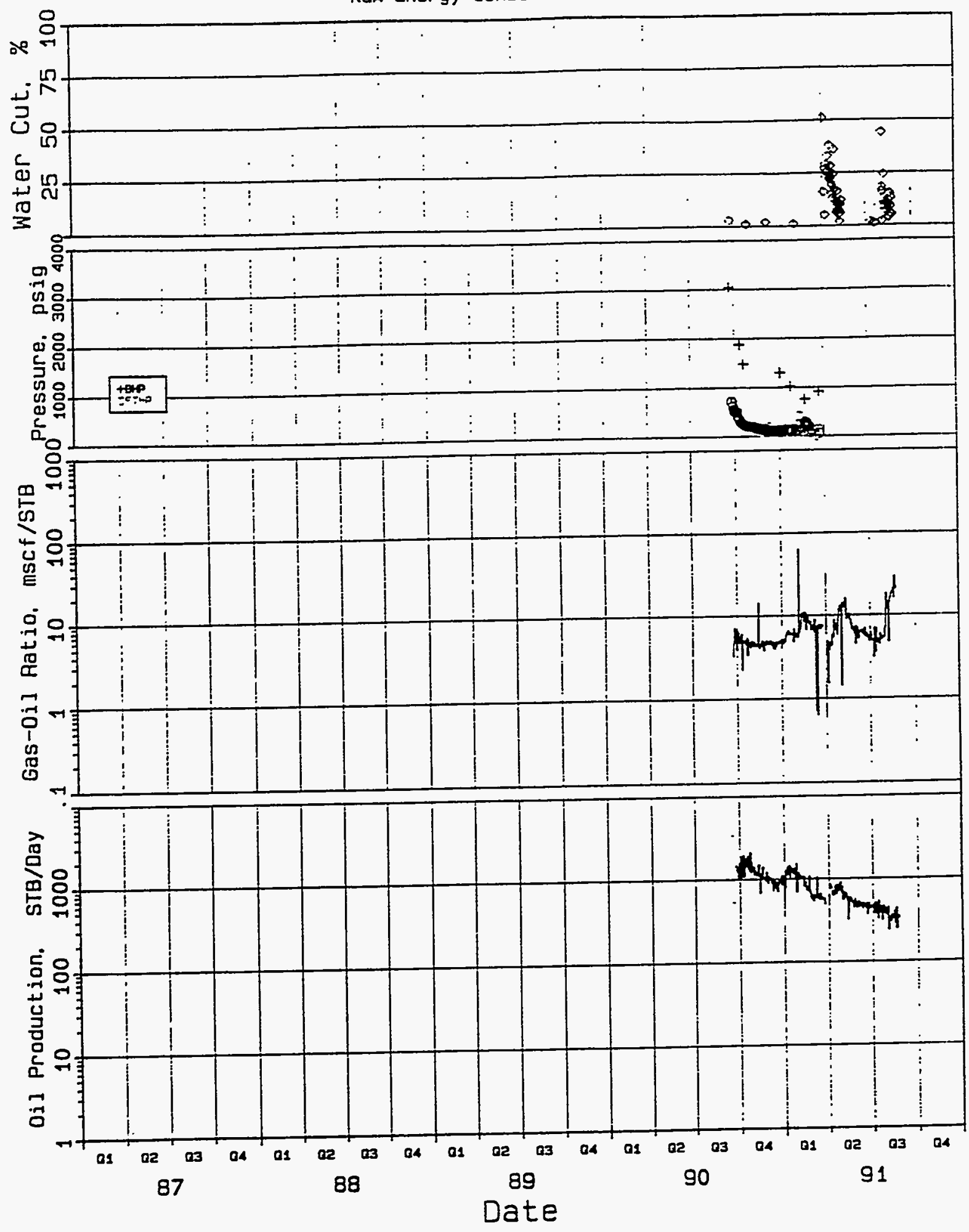




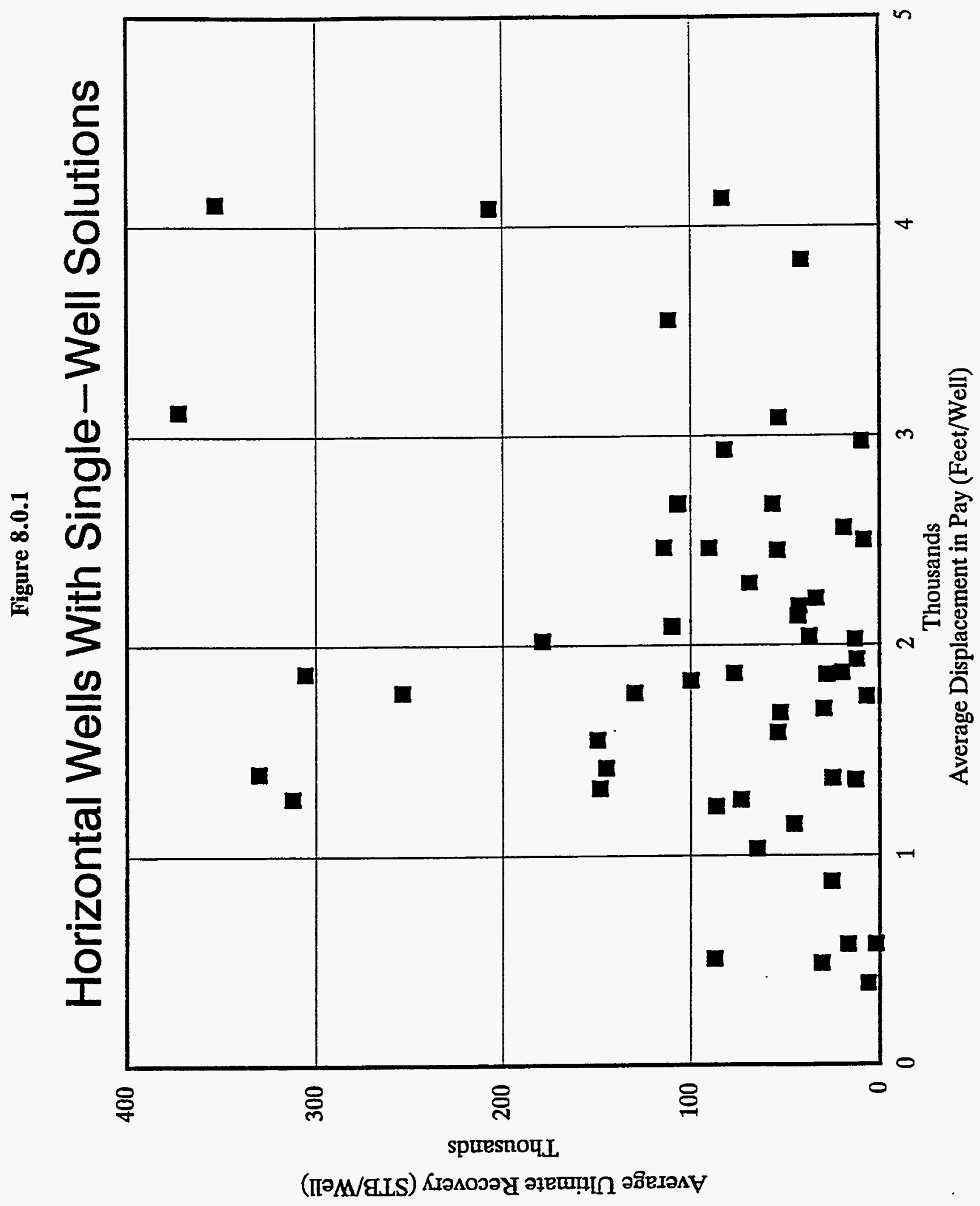


Figure 9.1.1

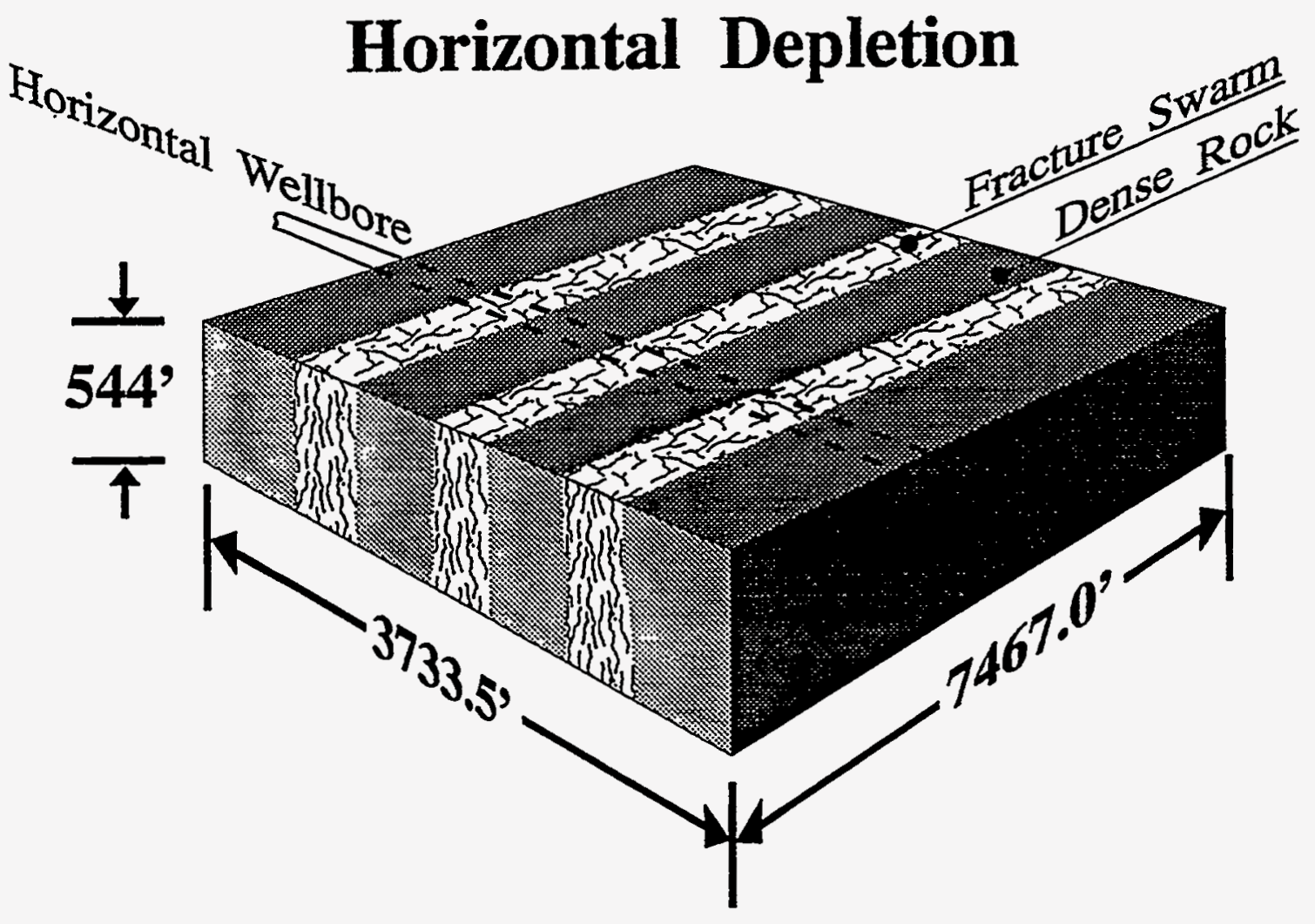

Figure 9.1.2

\section{Vertical Depletion}

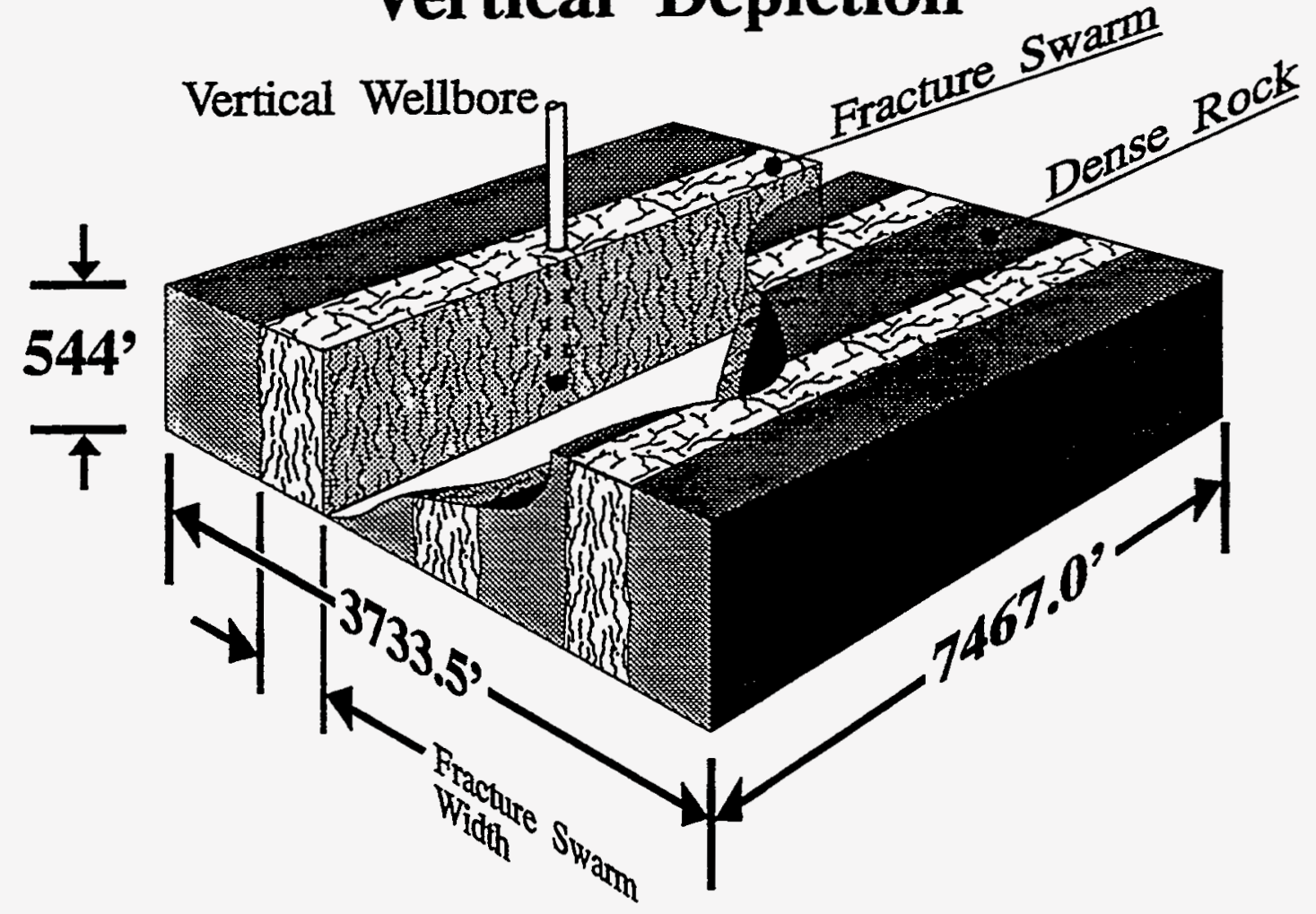


Figure 9.1.3

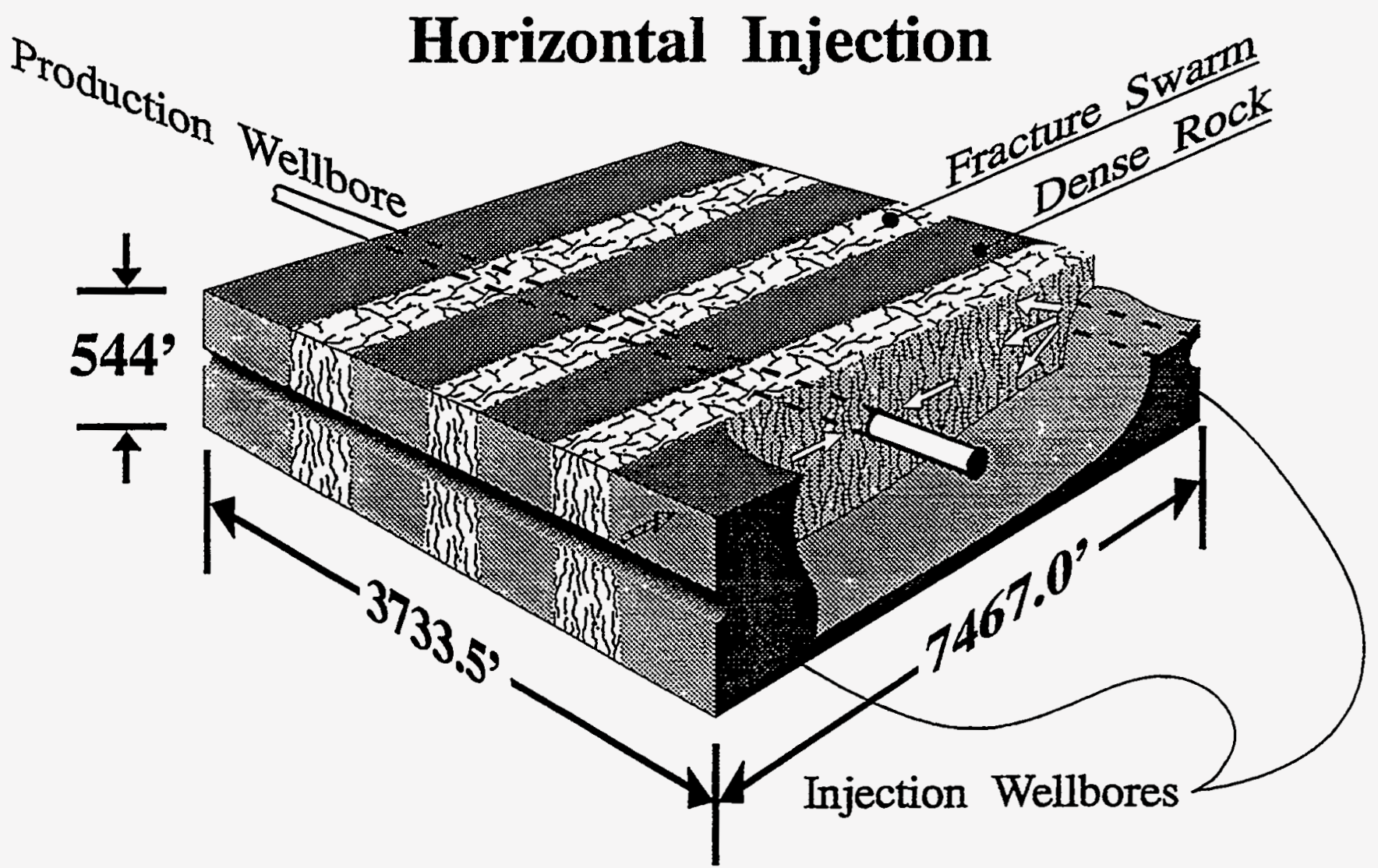

Figure 9.1.4

\section{Vertical Injection}

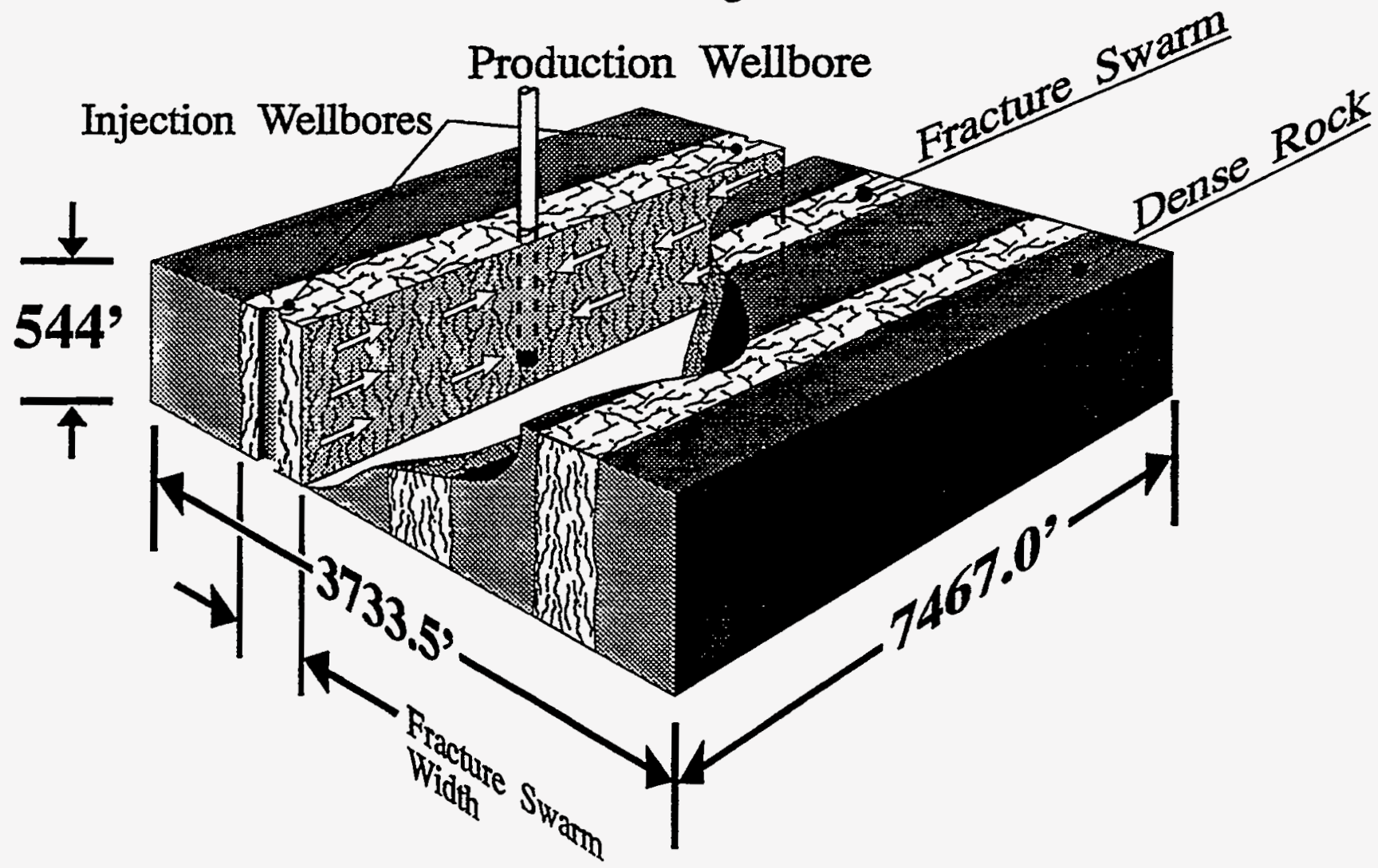


Figure 9.2.1

\section{SCHEMATIC OF GRID FOR HORIZONTAL DEPLETION MODEL}

웅

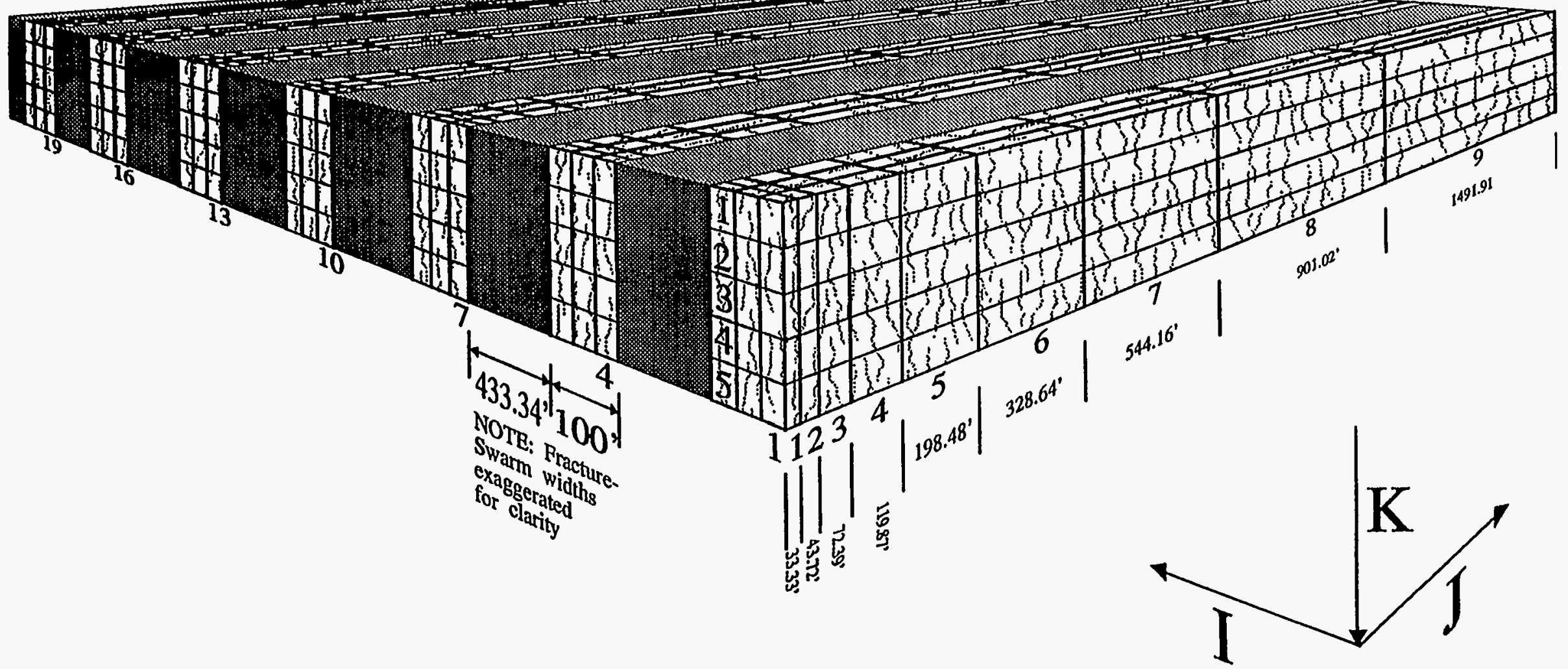




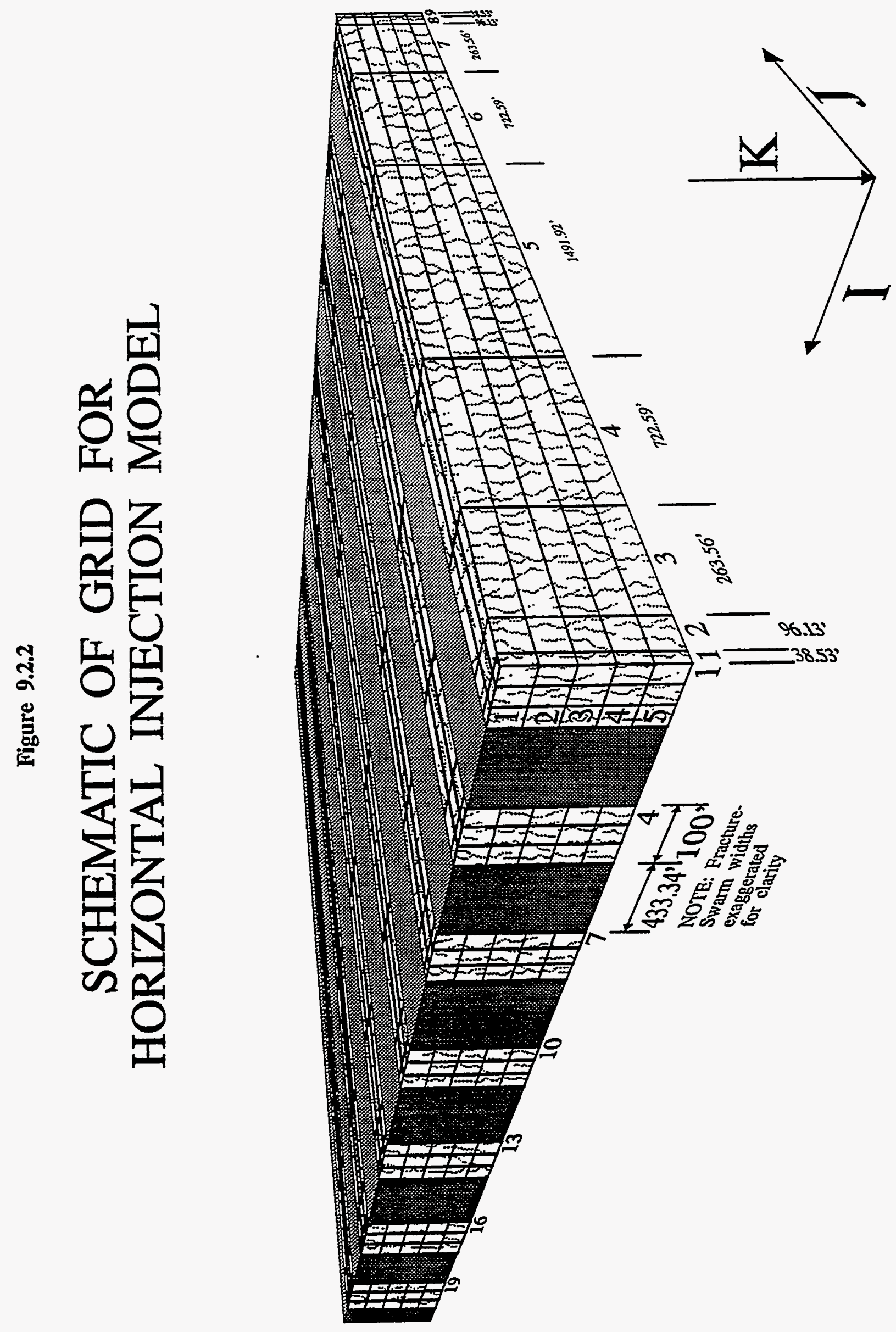




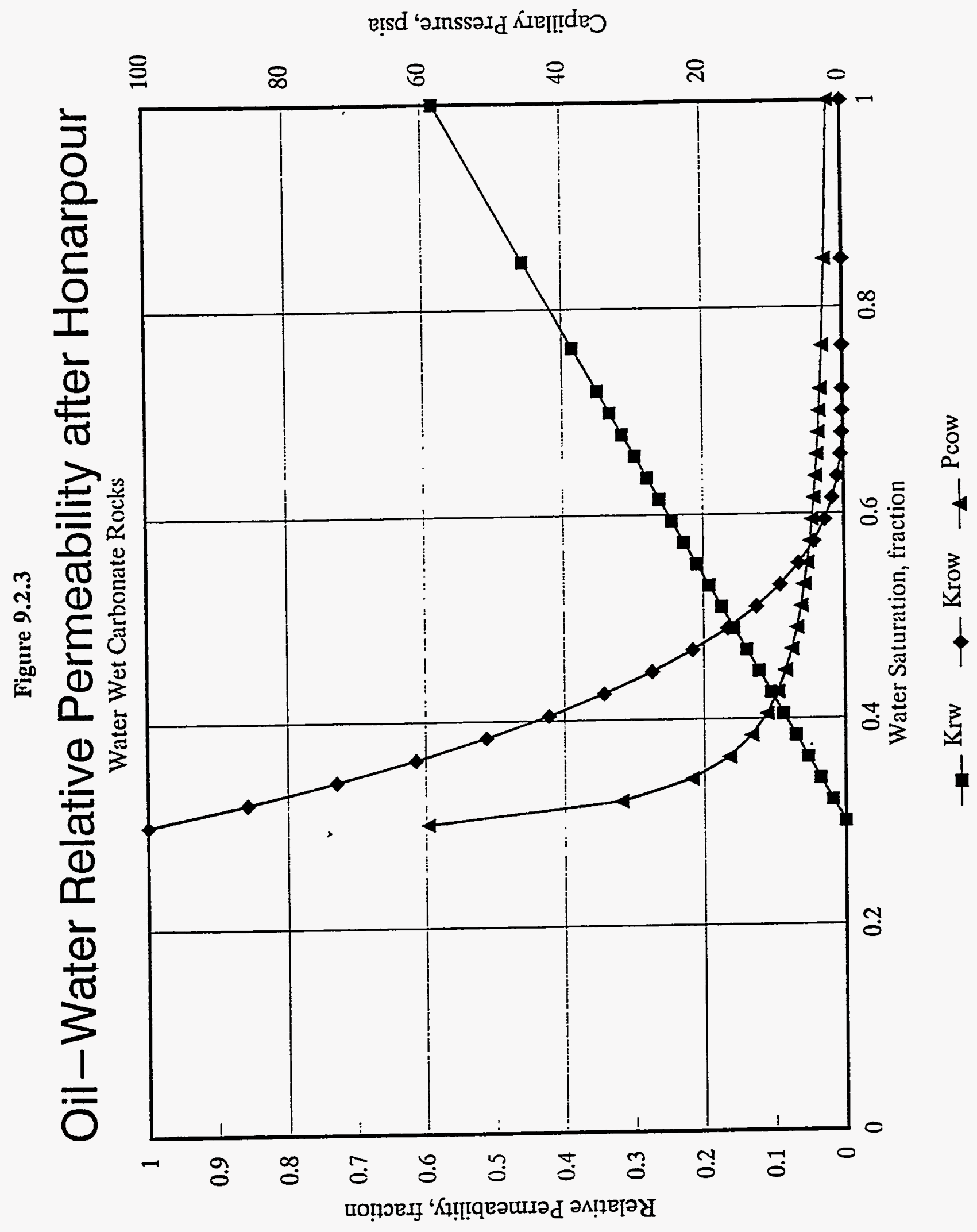


Figure 9.2.4

\section{Gas-Oil Relative Permeability after Honarpour}

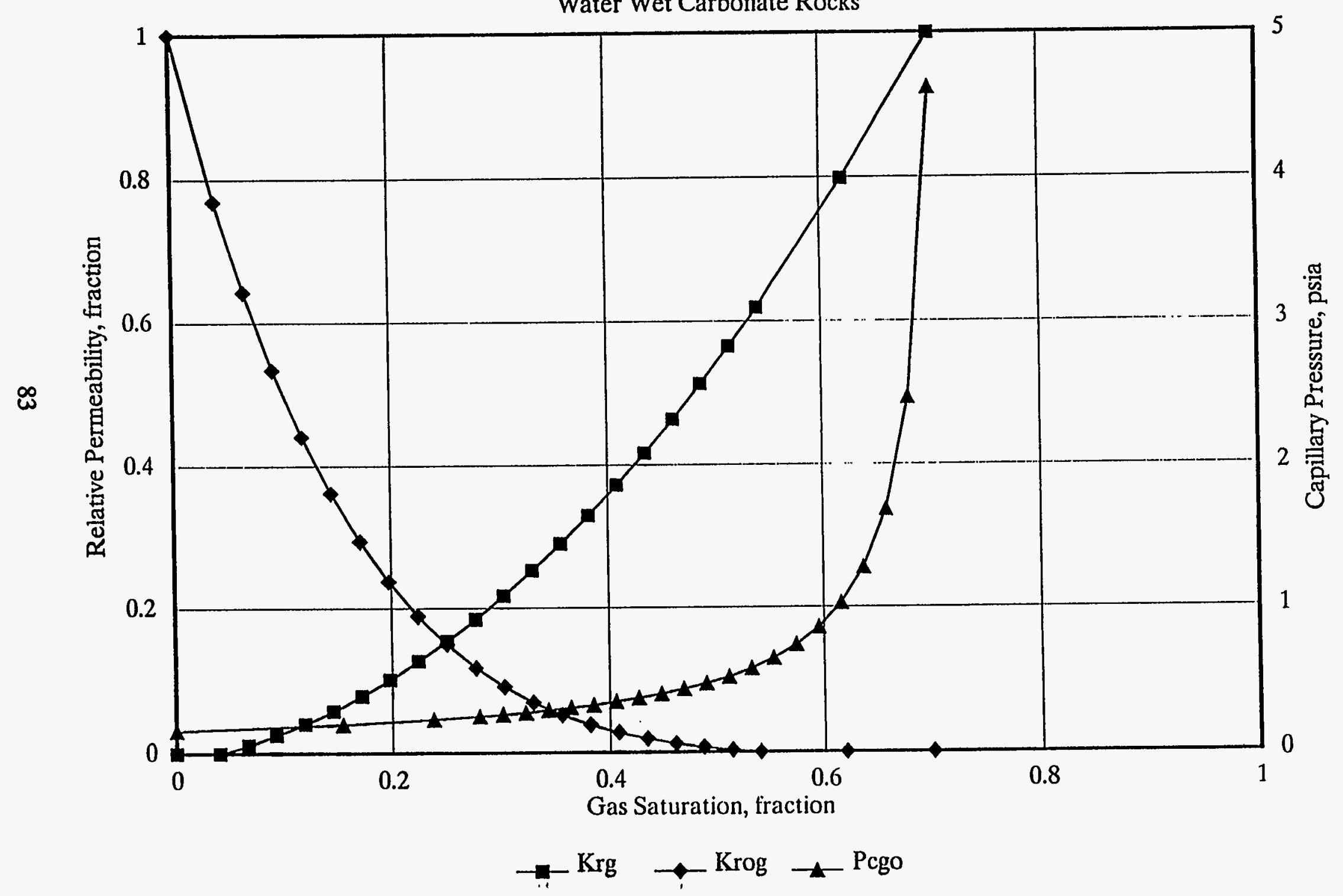


Figure 9.2.5

\section{Capillary Pressure vs Wetting Phase Saturation}

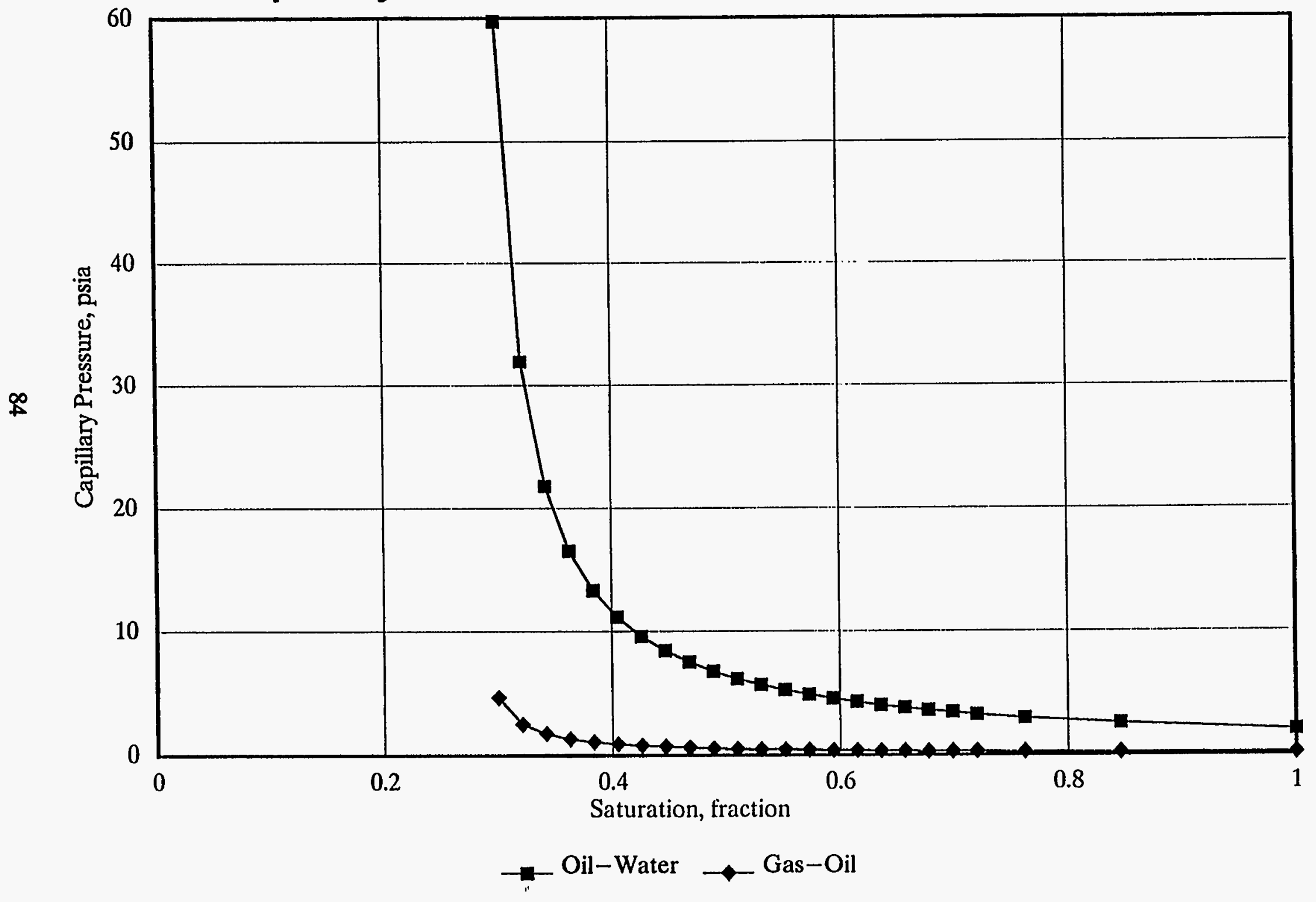




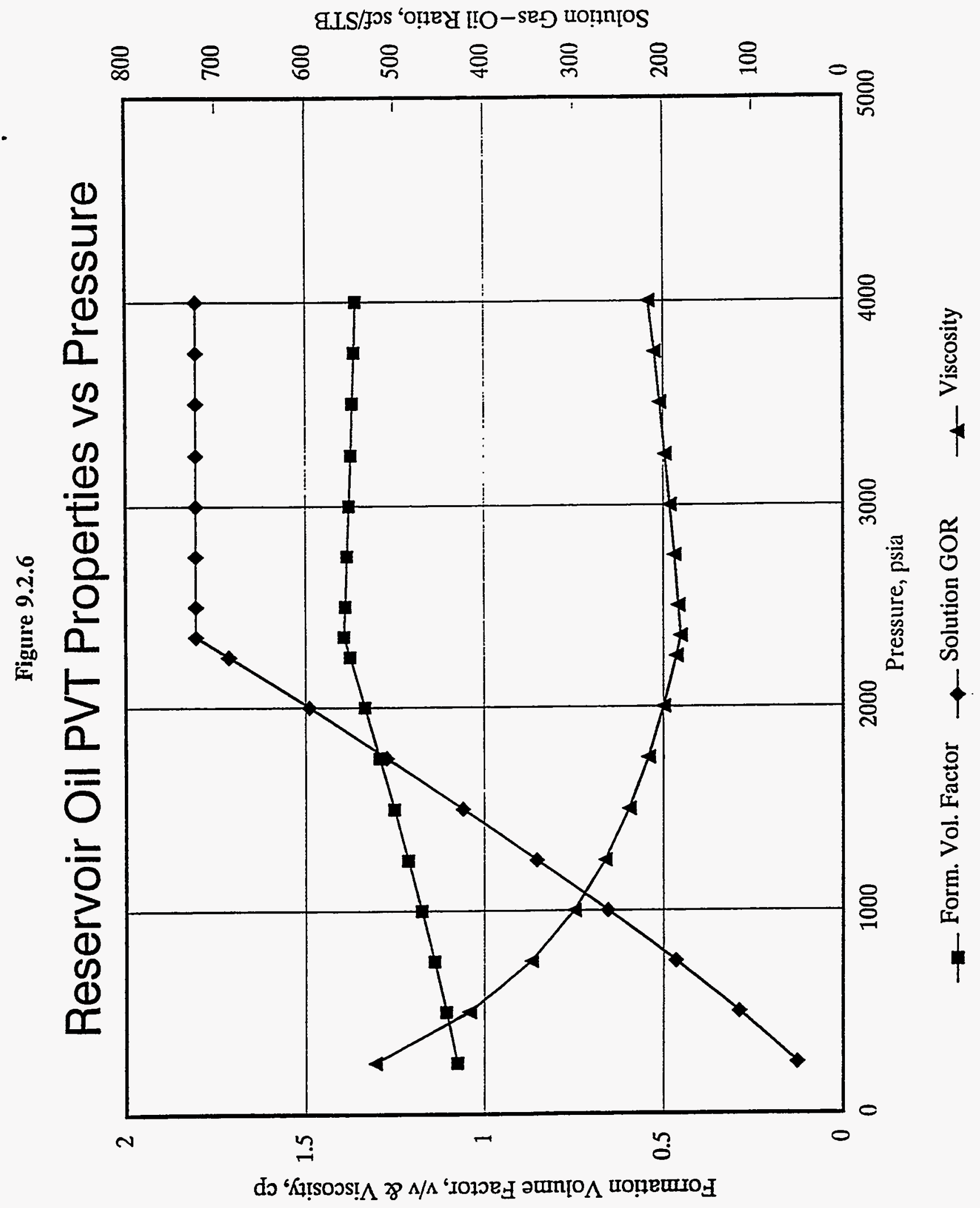




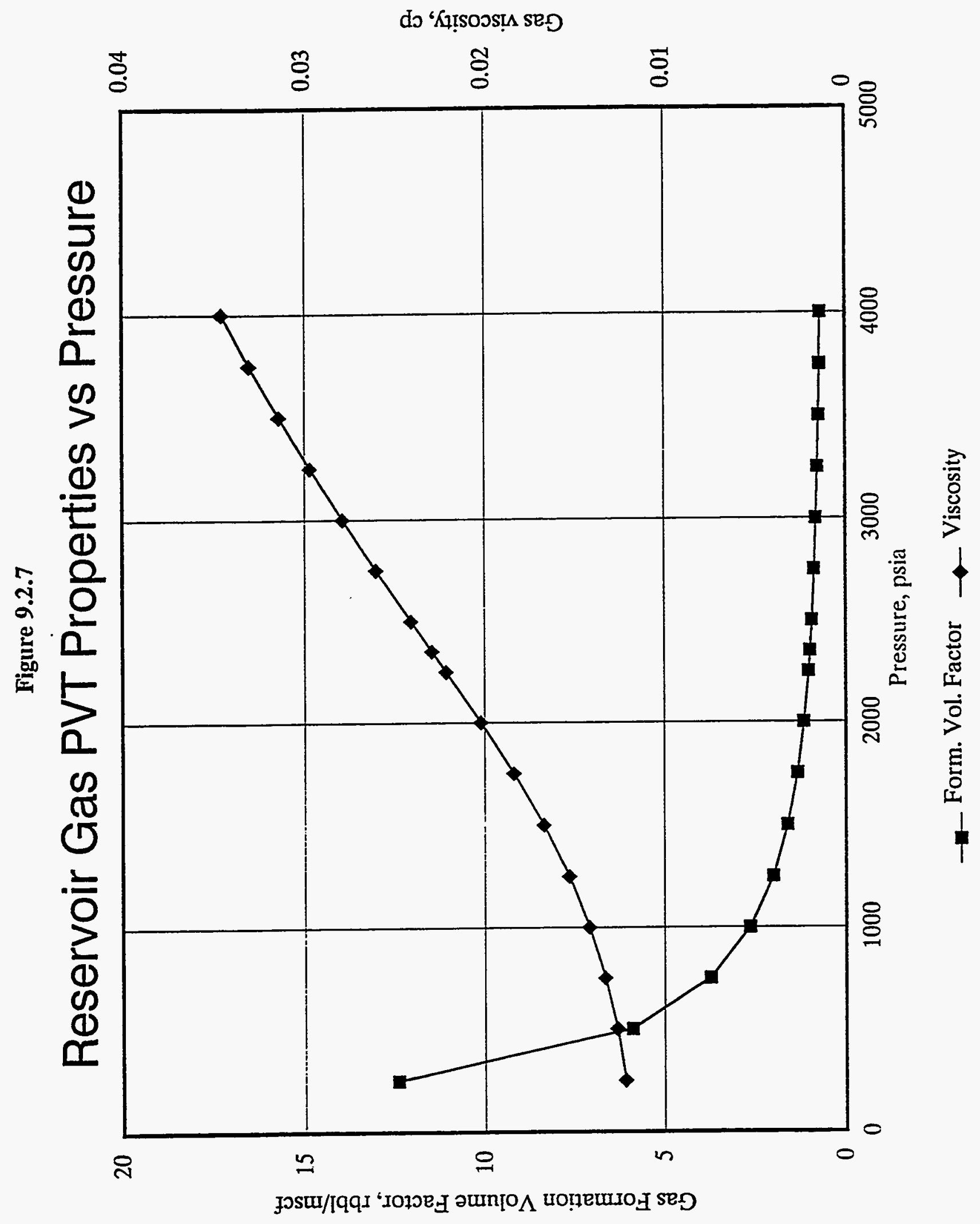




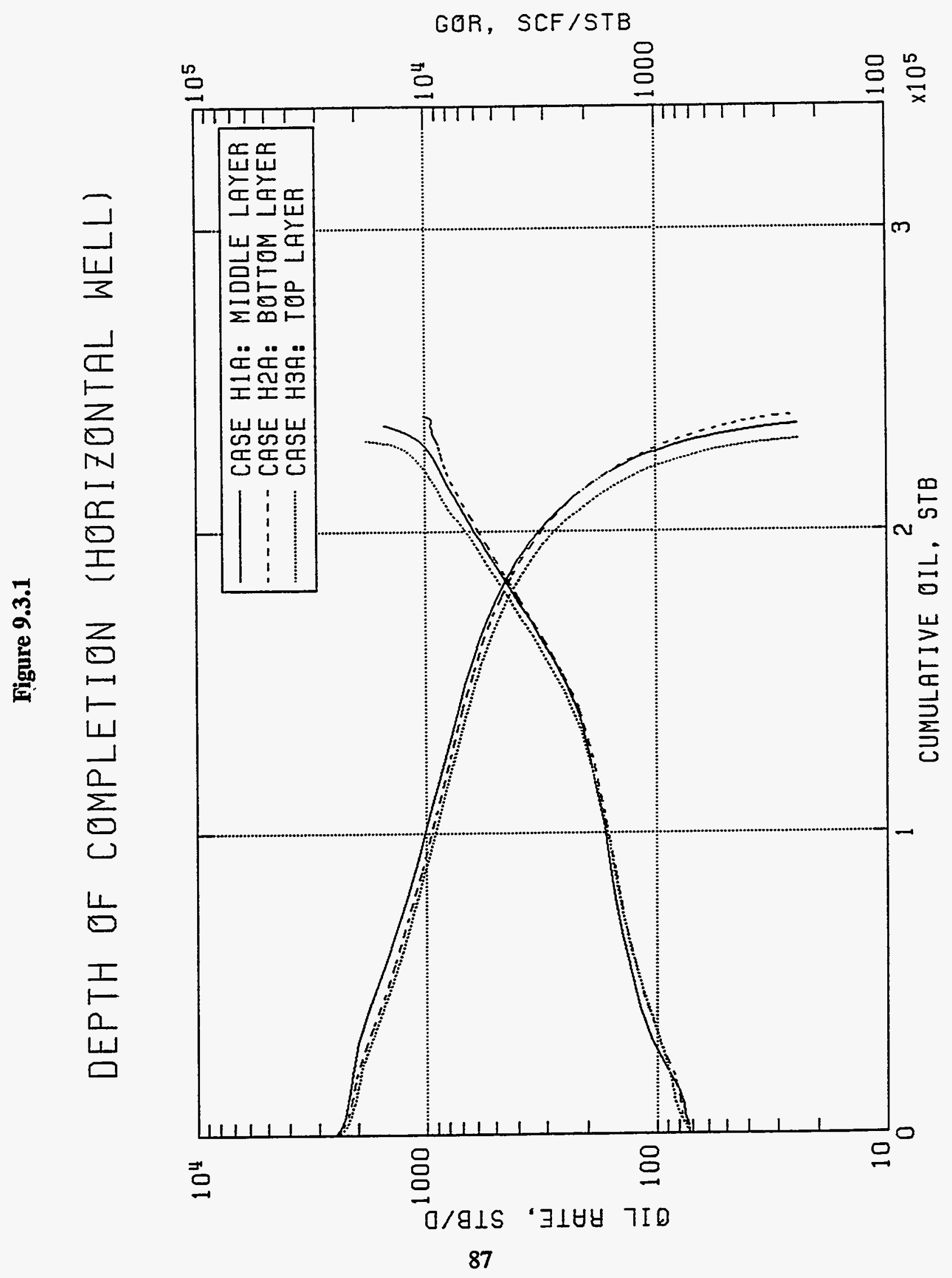


Figure 9.3.2

NUMBER OF FRACTURE SWARMS (HORIZONTAL WELL)

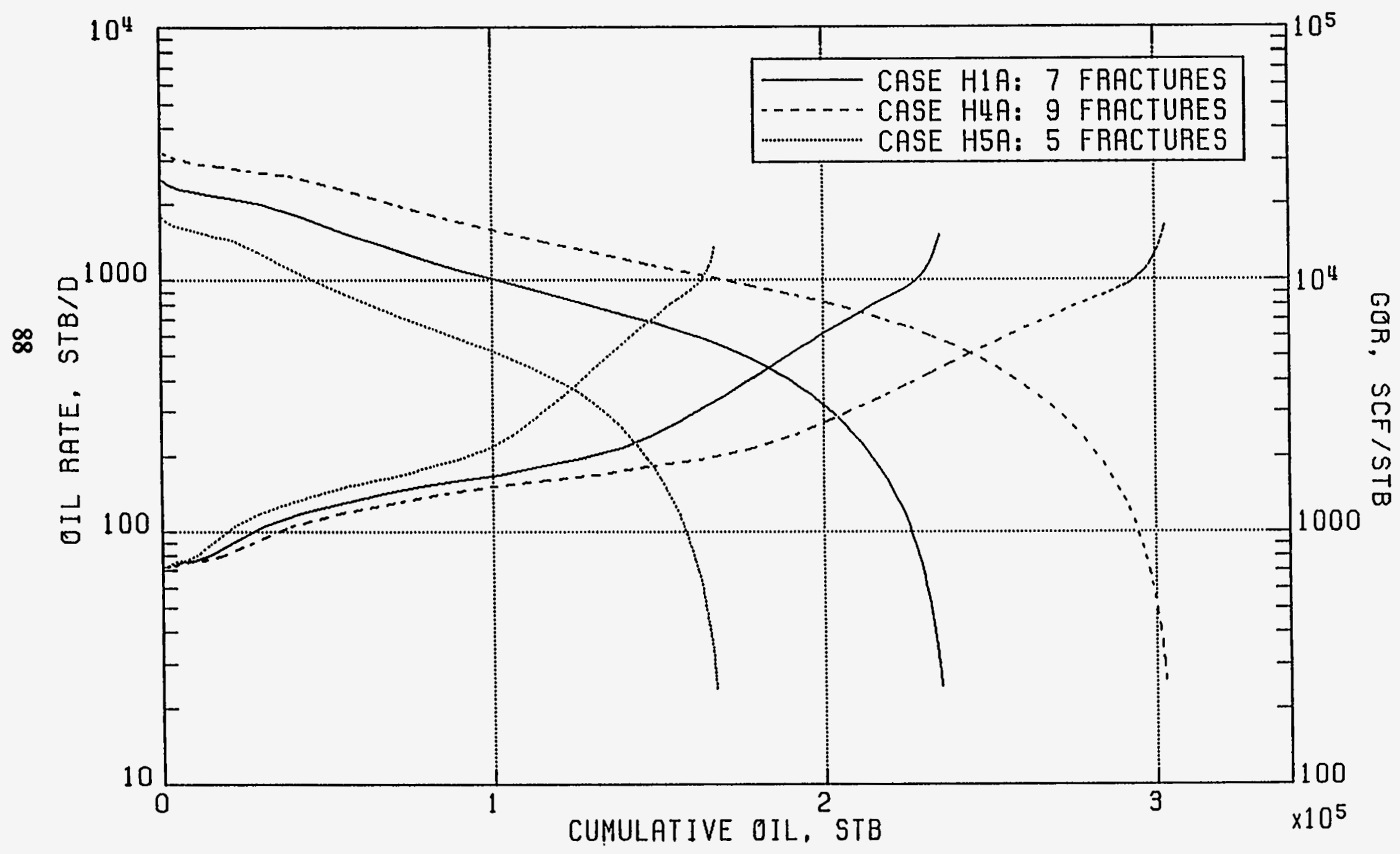




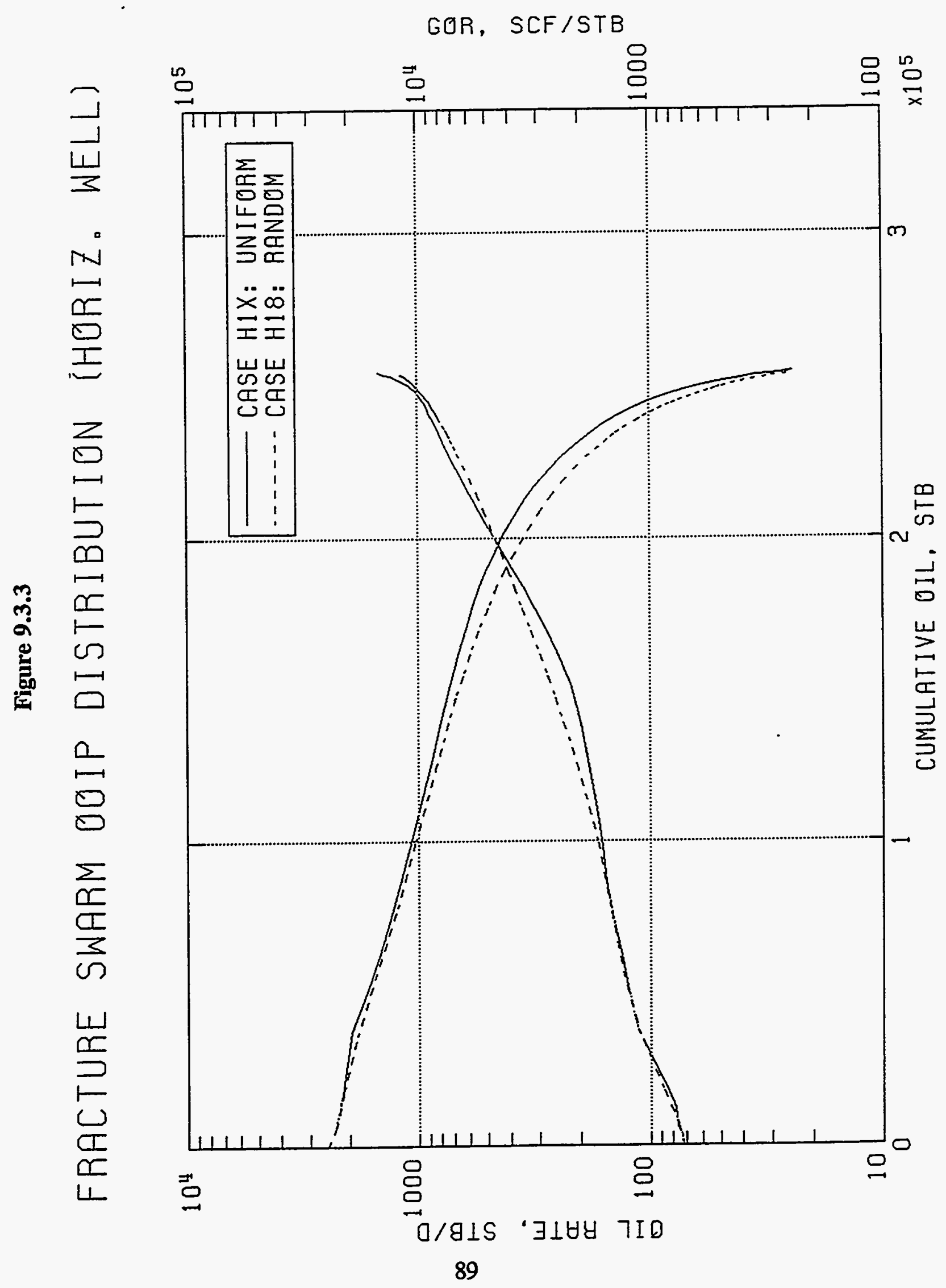




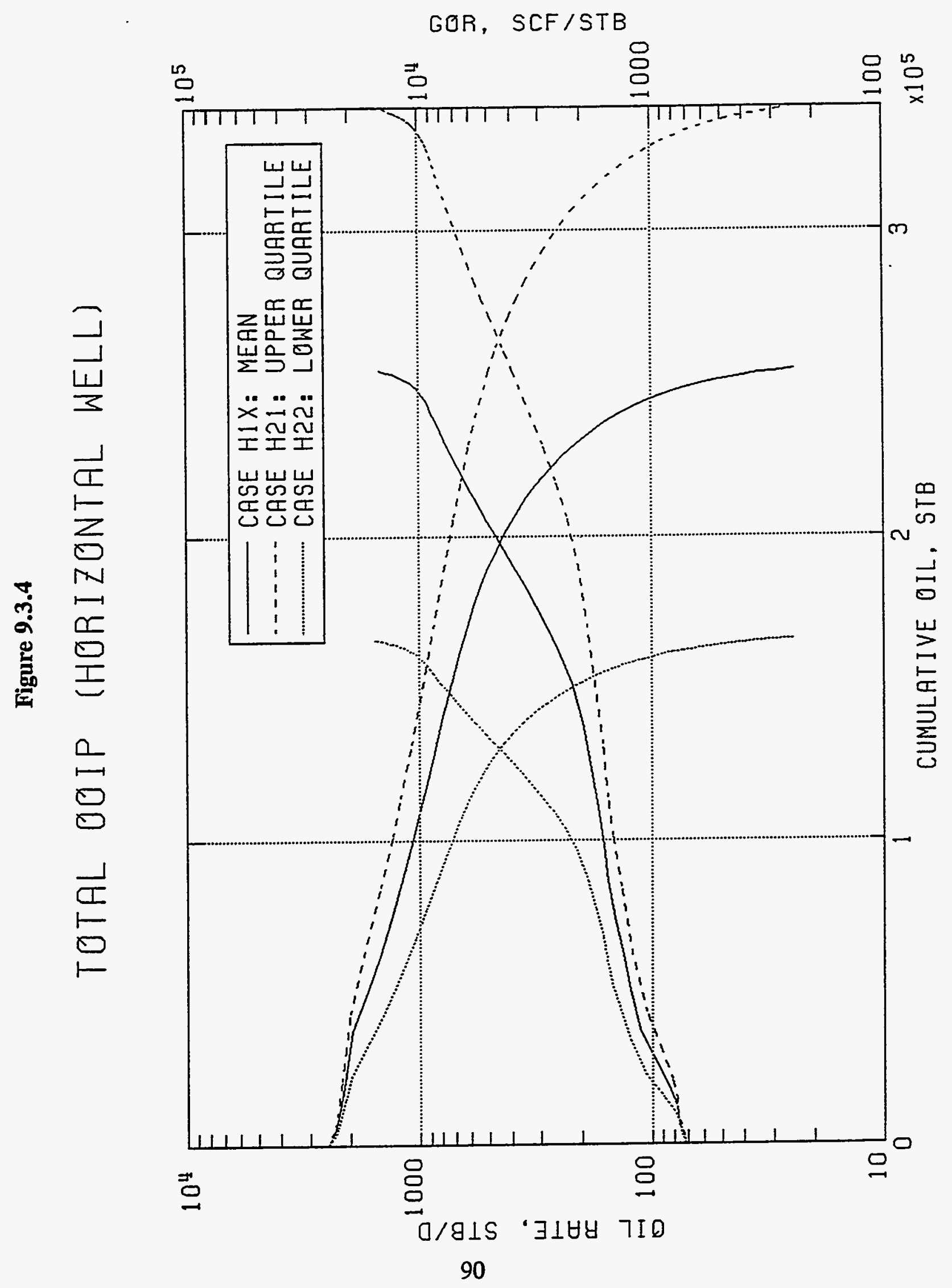




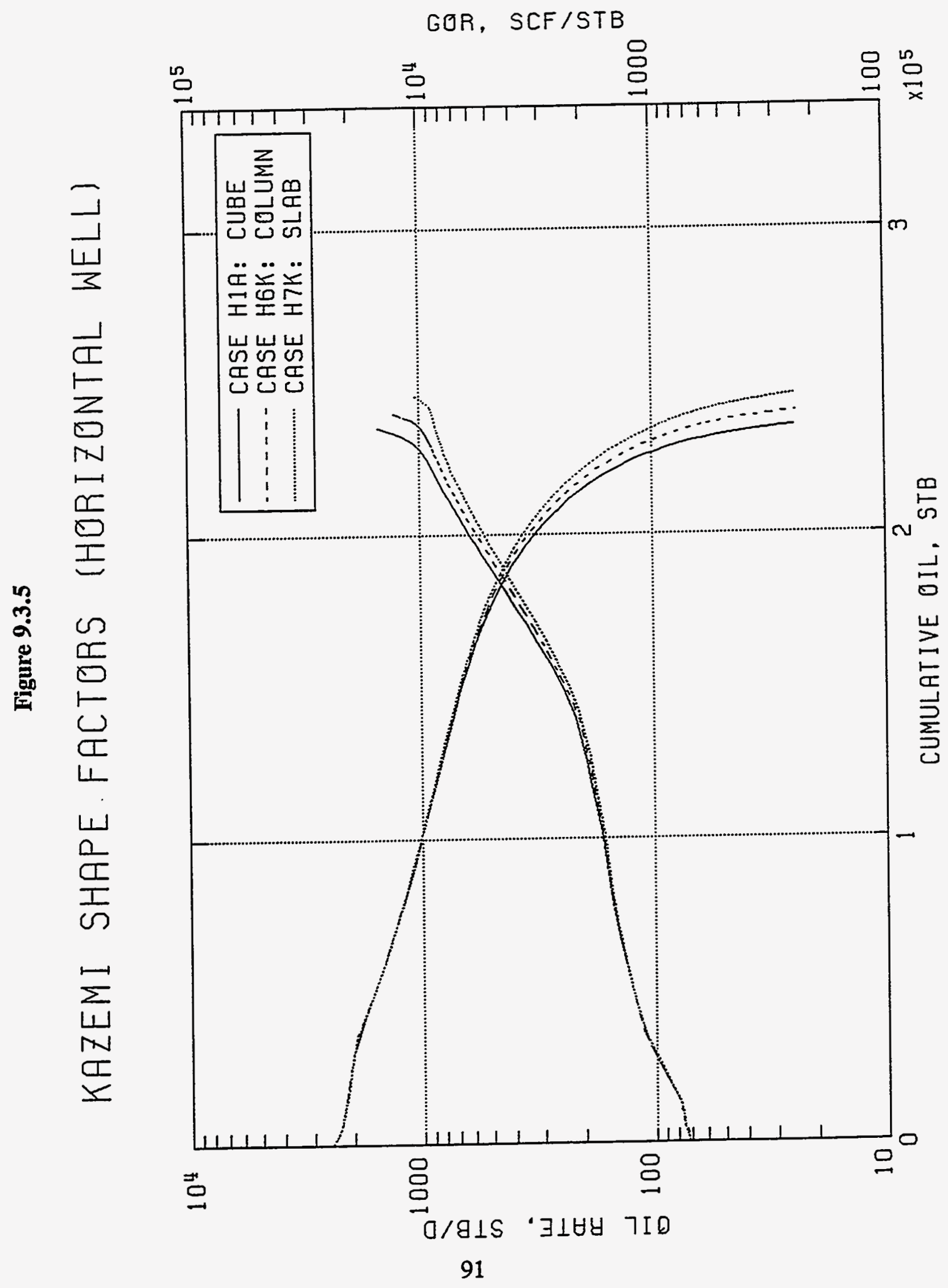




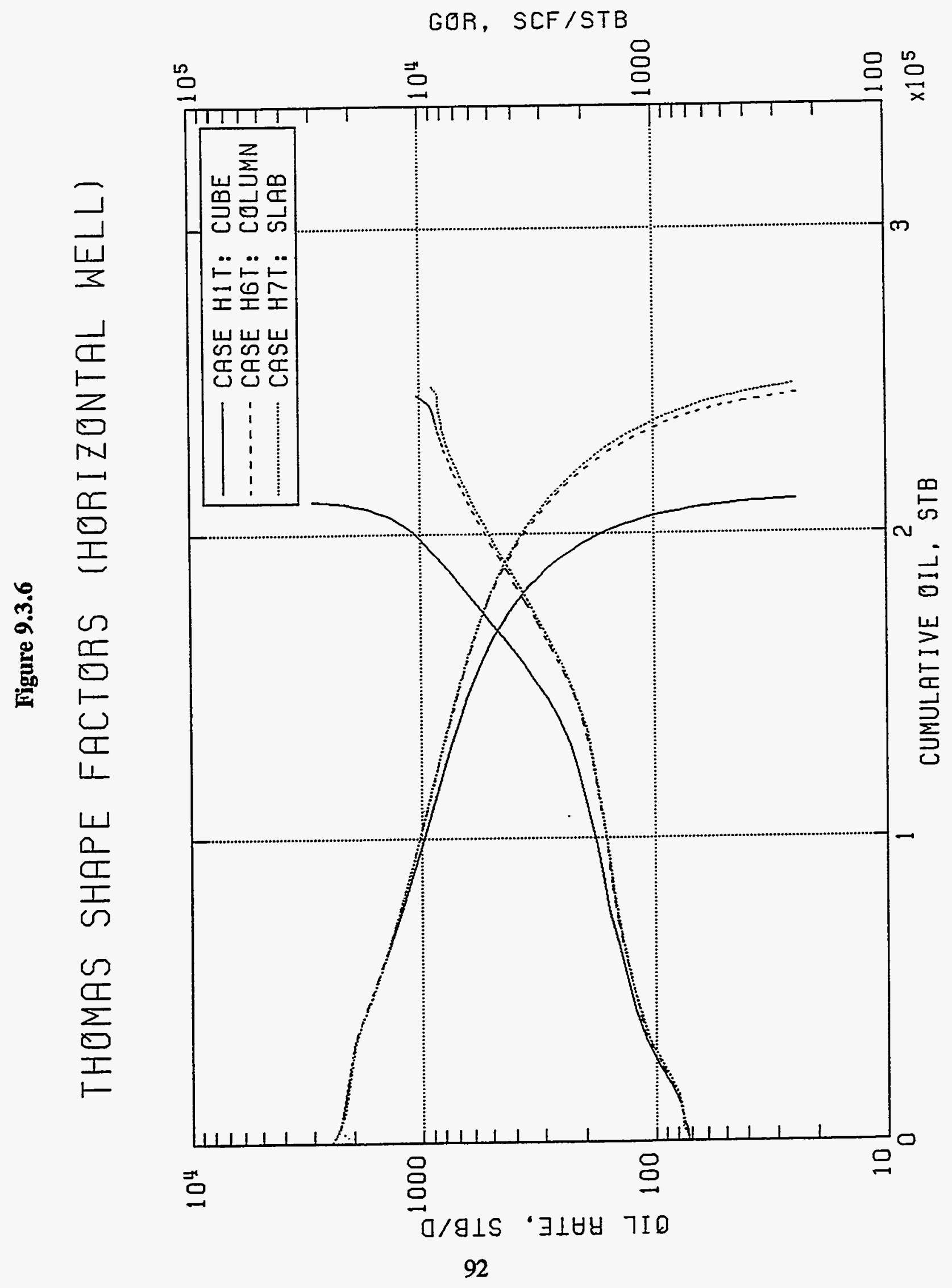


Figure 9.3.7

FRACTURE SPACING (HORIZONTAL WELL)

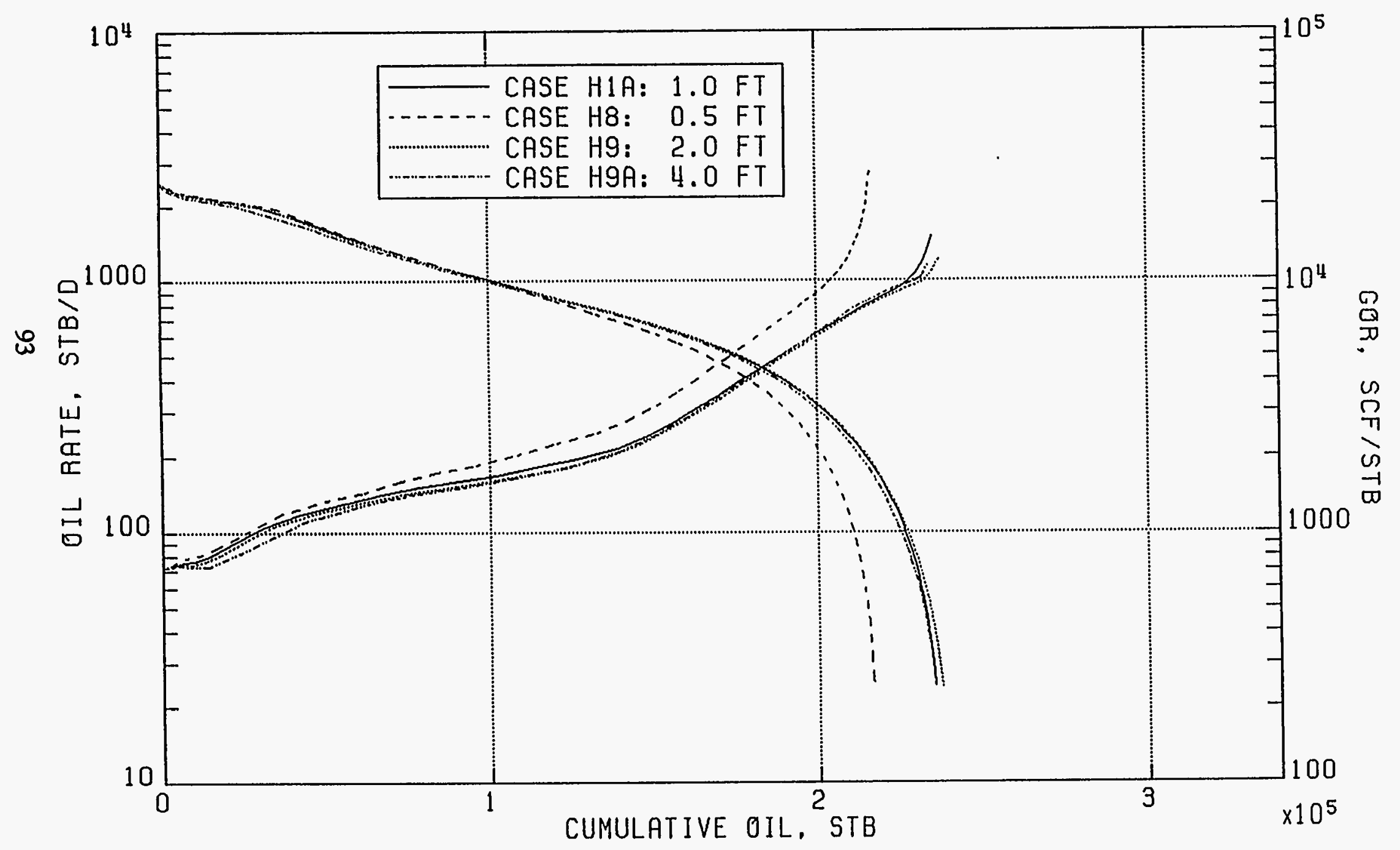




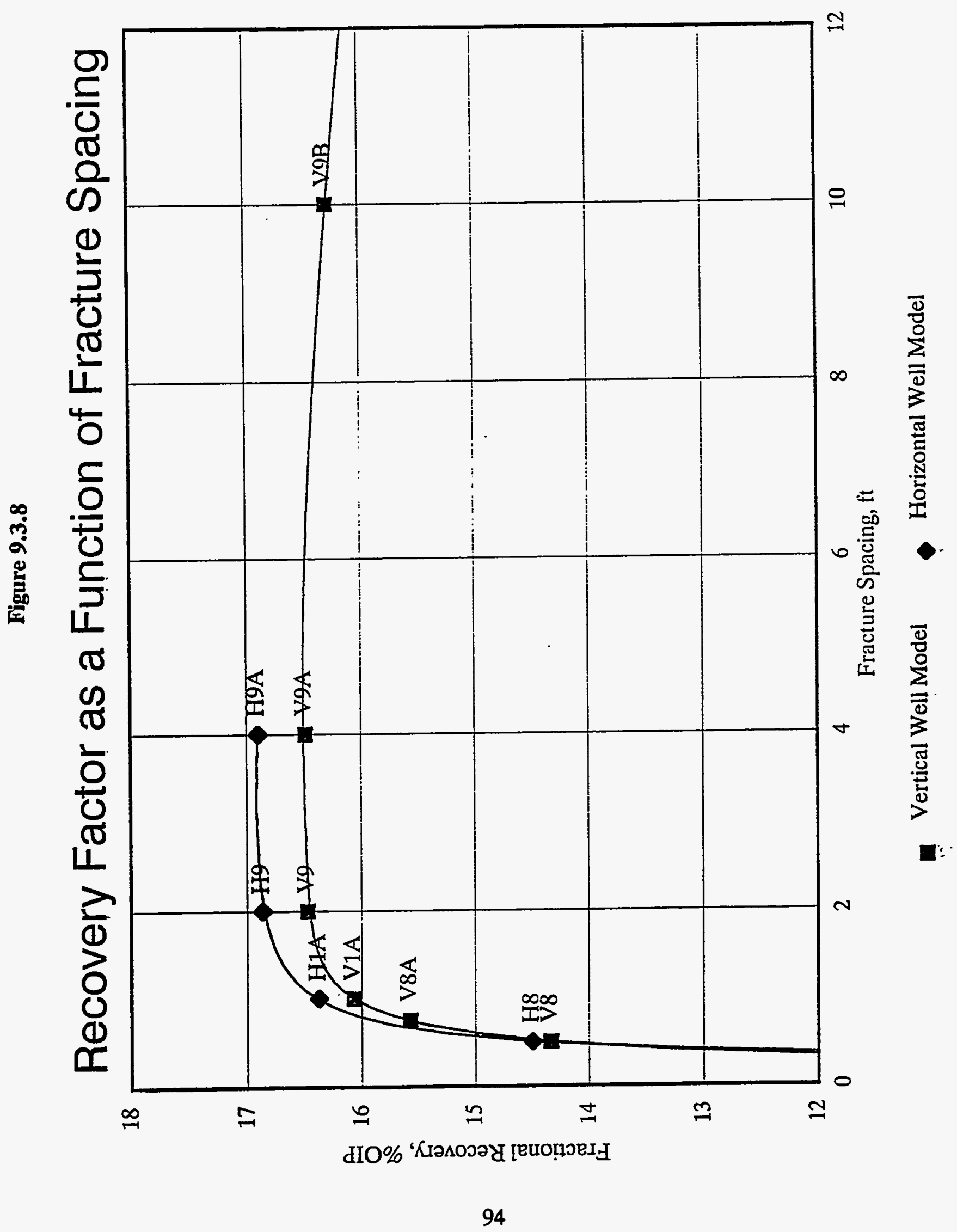




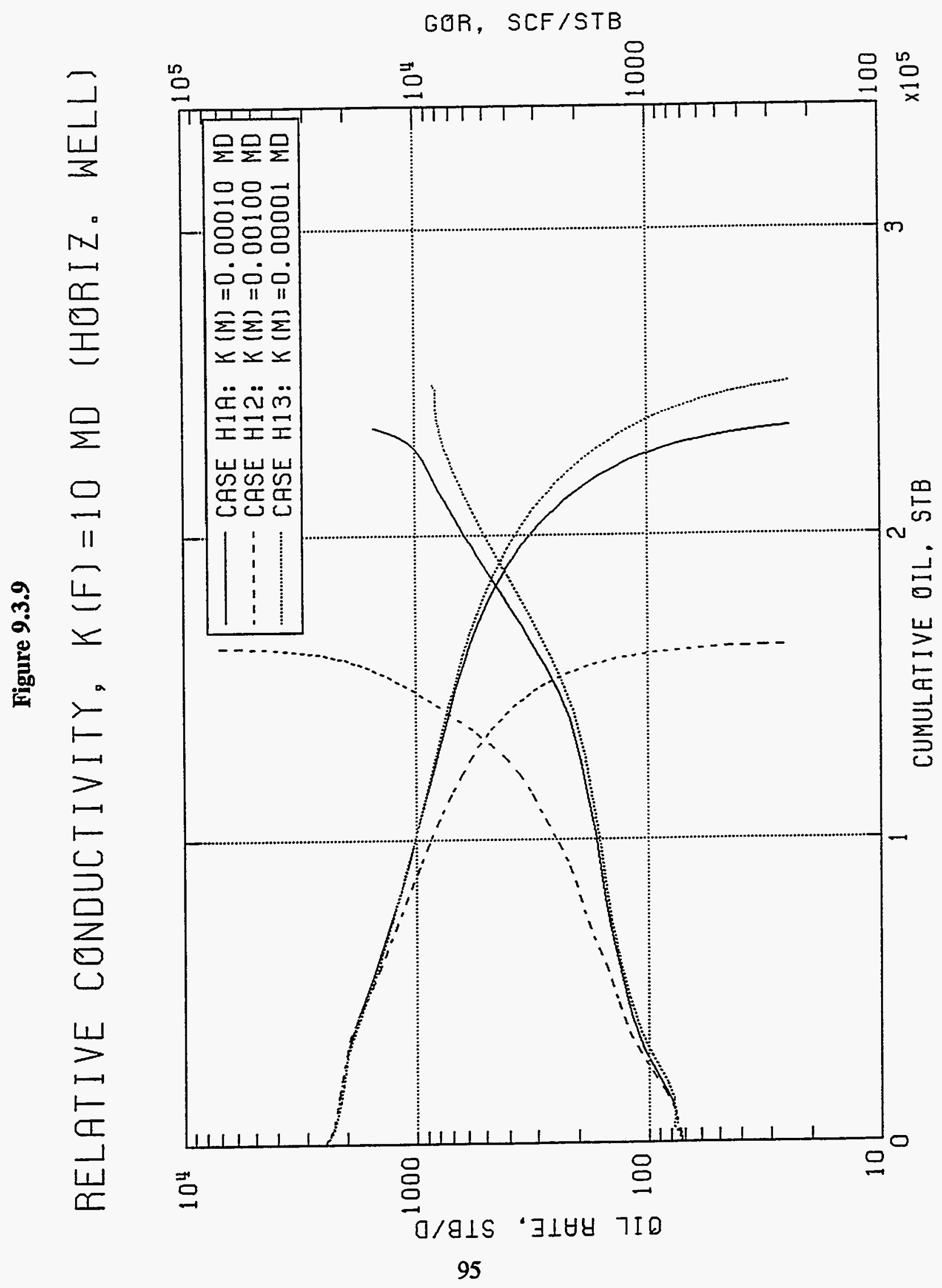


Figure 9.3.10

RELATIVE CONDUCTIVITY, $K(M)=0.0001$ MD (HORIZ.)

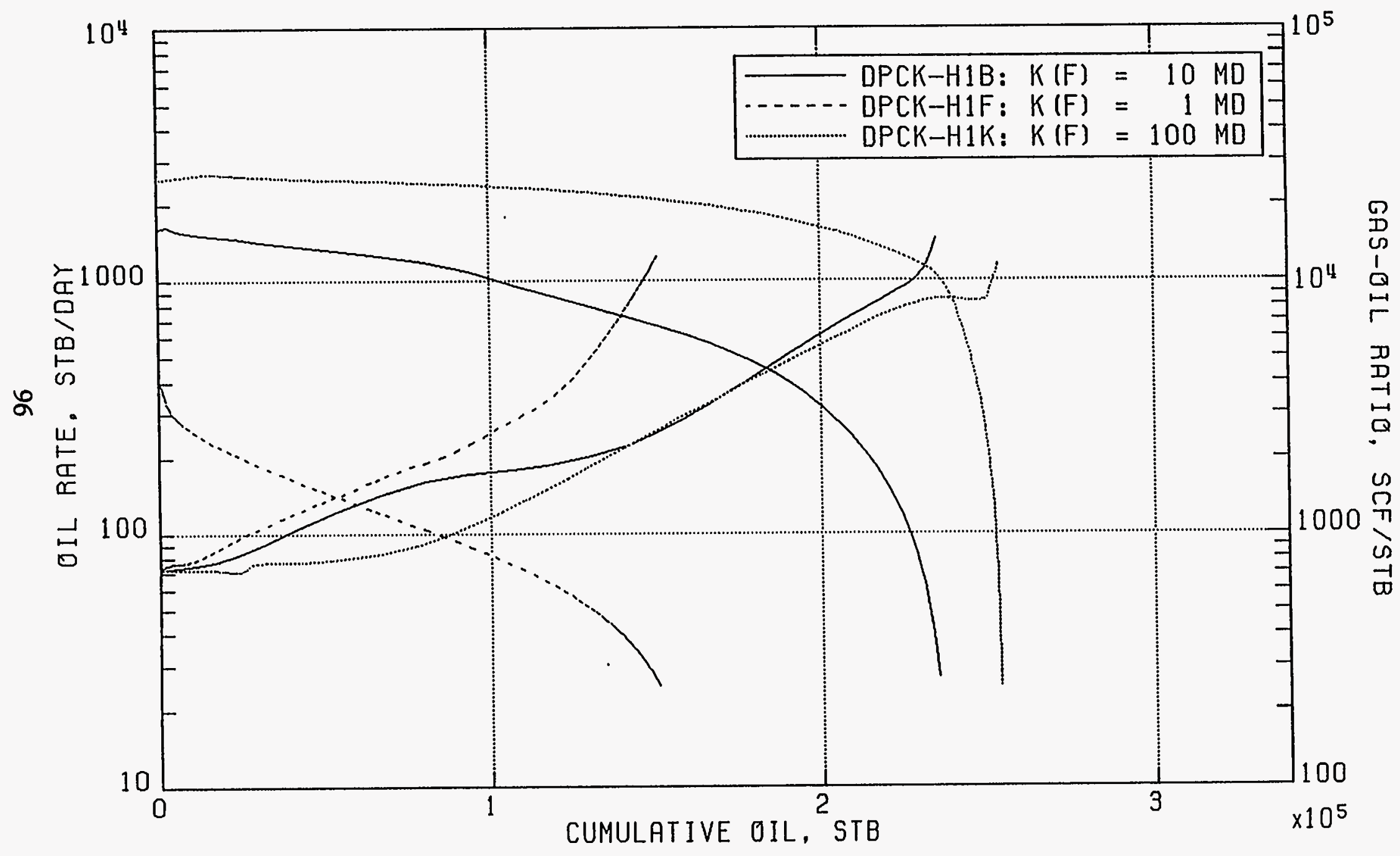




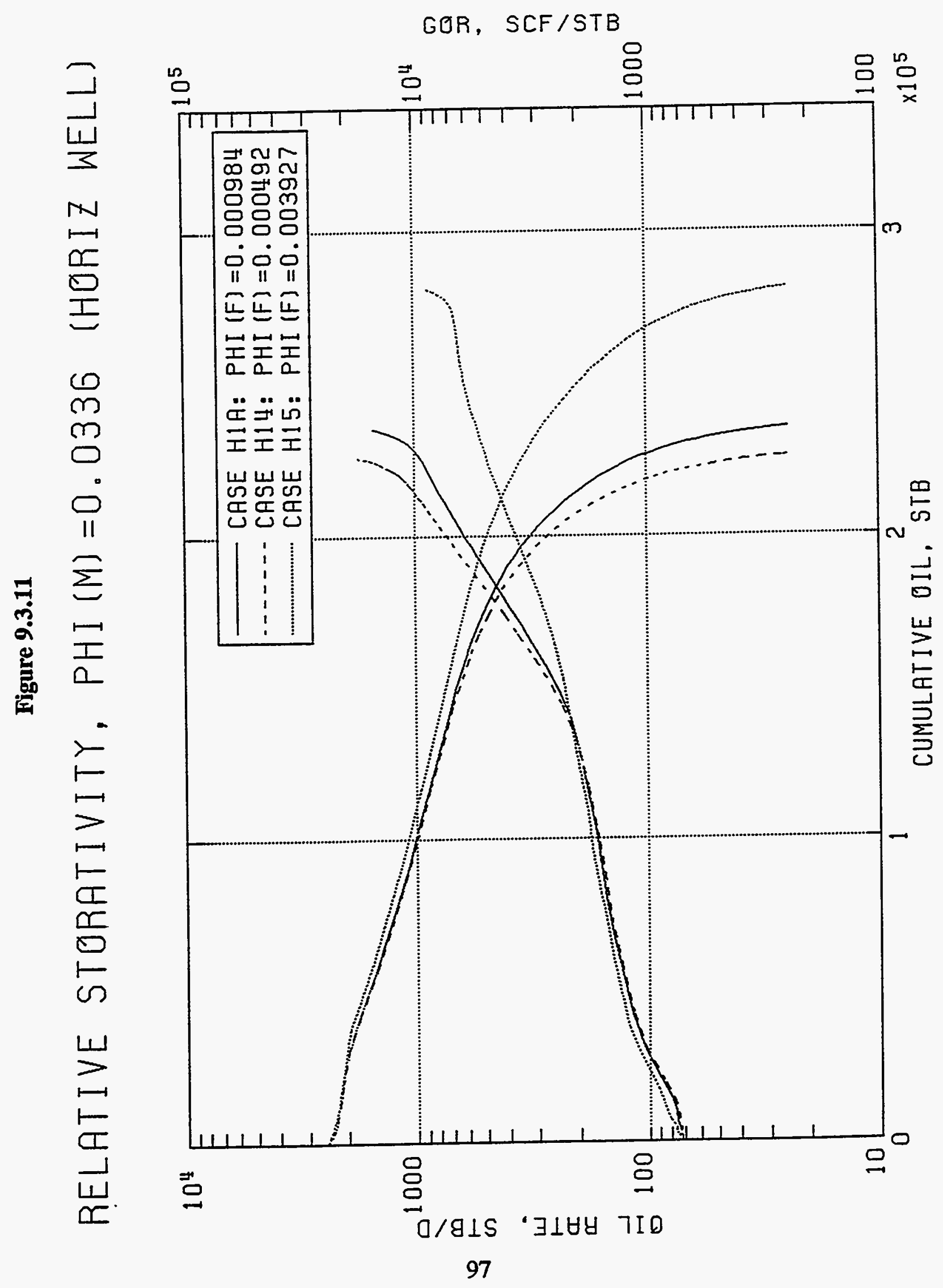




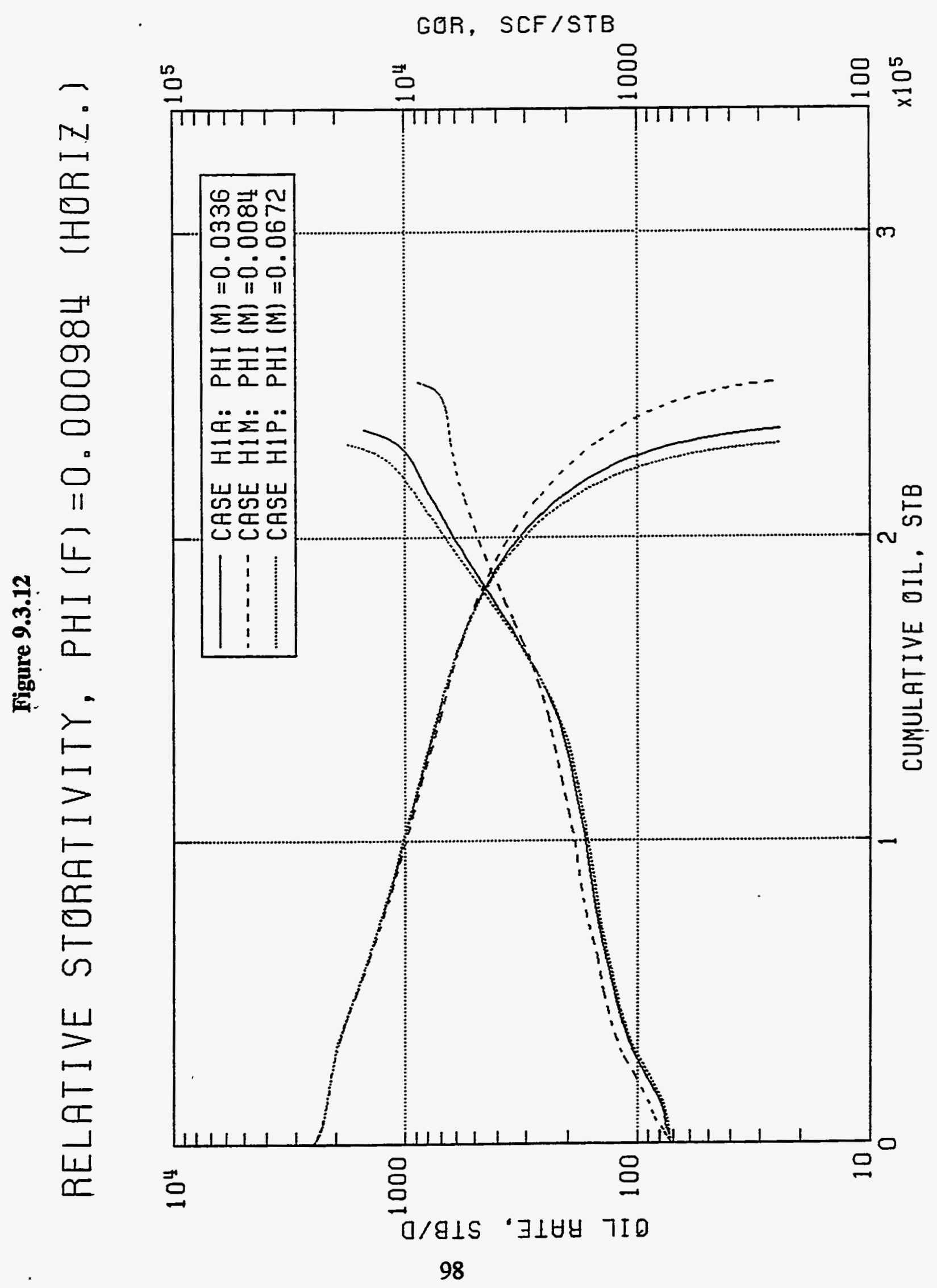


Figure 9.3.13

FRACTURE CAPILLARY PRESSURE (HORIZONTAL WELL)

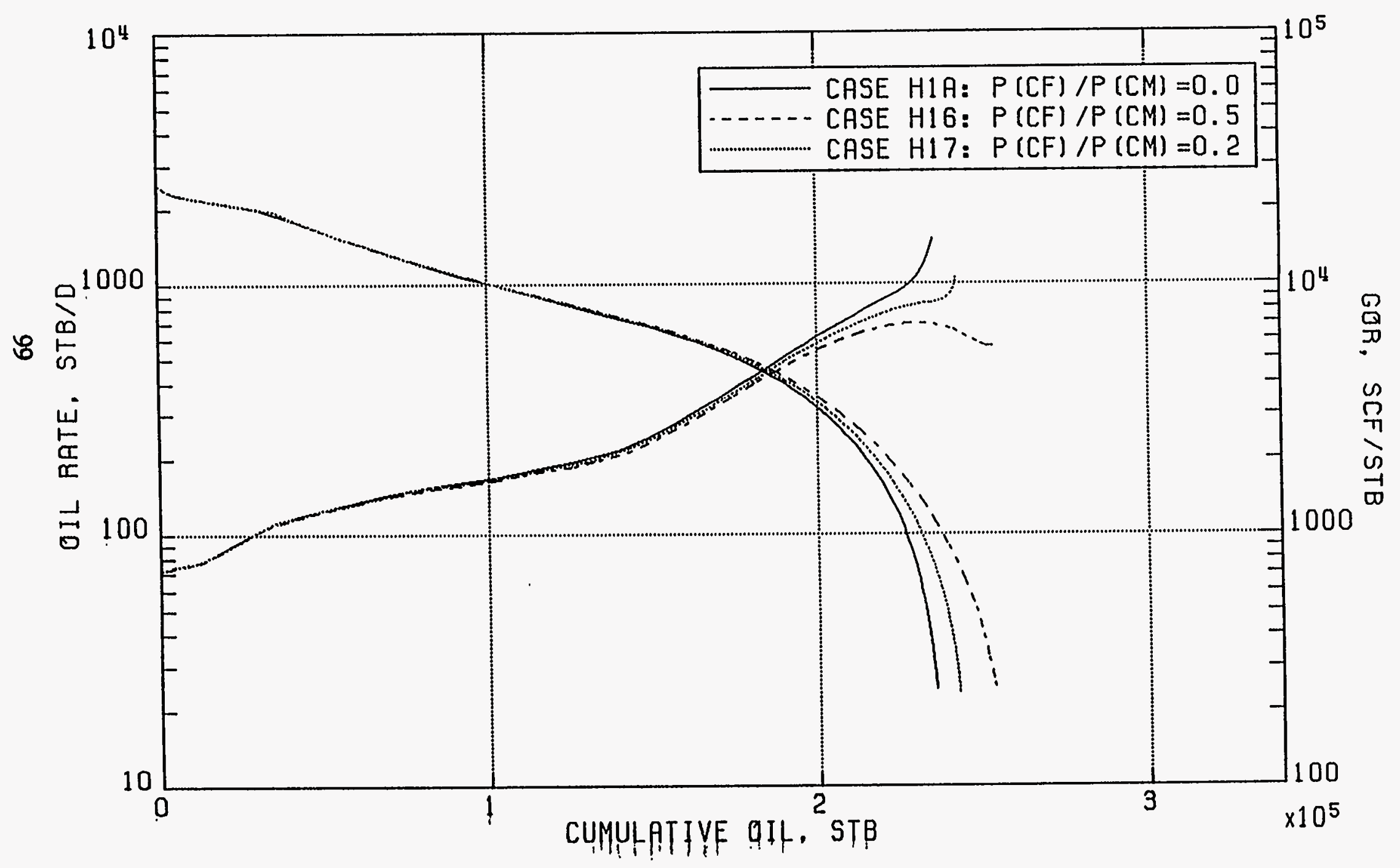




\section{APPENDIX A}

The variables used in the statistical analysis of vertical $v s$ horizontal well performance are tabulated below.

Table A-1

Statistical Analysis Variables.

\begin{tabular}{|c|c|}
\hline Variable & Description \\
\hline LEASE & TRRC Lease I.D., 5 char. \\
\hline VERTOR & $\begin{array}{l}\text { Well orientation, (V)ertical or } \\
\text { (H)orizontal. }\end{array}$ \\
\hline SOURCE & $\begin{array}{l}\text { Data source group code: } \\
1=\text { original } 97 \text { wells } \\
2=50 \text { well extension } \\
H=\text { combined horizontal wells } \\
V=\text { combined vertical wells }\end{array}$ \\
\hline LSENAME & Lease name, 40 char. \\
\hline COUNTY & County, 10 char. \\
\hline DISPAY & Displacement in pay, $\mathrm{ft}$. \\
\hline TOTDISP & Total horizontal displacement, $\mathrm{ft}$. \\
\hline COMPDATE & Completion date \\
\hline RATE3 & $1^{\star t}$ month production rate, $S T B / d$ \\
\hline RATE6 & $4^{\text {th }}$ month production rate, STB/d \\
\hline RATE9 & $T^{\text {th }}$ month production rate, STB/d \\
\hline RATE12 & $10^{\text {th }}$ month production rate, $\mathrm{STB} / \mathrm{d}$ \\
\hline RATE18 & $16^{\text {th }}$ month production, STB/d \\
\hline
\end{tabular}


Table A-1

Statistical Analysis Variables.

\begin{tabular}{|c|c|}
\hline Variable & Description \\
\hline CUM3 & Cumulative production, month 3 , STB \\
\hline CUM6 & Cumulative production, month 6 , STB \\
\hline CUM9 & Cumulative production, month 9 , STB \\
\hline CUM12 & Cumulative production, month 12 , STB \\
\hline CUM18 & Cumulative production, month 18, STB \\
\hline ULT & Cumulative ultimate, STB \\
\hline WELLS & Number of wells on lease \\
\hline AVGULT & Average uitimate recovery per well \\
\hline BBLPERFT & AVGULT/DISPPAY, STB/ft. \\
\hline AVGDISP & Average displacement in pay, $\mathrm{ft} /$ well \\
\hline AVGTDIS & Average total horiz. displ., ft/well \\
\hline LTYPE & $\begin{array}{l}\text { Lease type indicator: } \\
\text { SH = single well horizontal } \\
\text { SV = single well vertical } \\
\text { MH = multiple well horizontal } \\
\text { MV = multiple well vertical }\end{array}$ \\
\hline MIETH & $\begin{array}{l}\text { Initial producing method indicator: } \\
F=\text { flowing well } \\
P=\text { pumping well }\end{array}$ \\
\hline $\mathbf{N}$ & Hyperbolic decline exponent \\
\hline $\mathbf{D E}$ & Initial production decline rate, $\%$ \\
\hline
\end{tabular}


Table A-1

Statistical Analysis Variables.

\begin{tabular}{|c|c|}
\hline Variable & Description \\
\hline OII & Initial potential oil rate, STB/day \\
\hline GAS & Initial potential gas rate, mscf/d \\
\hline WTR & Initial potential water rate, STB/day \\
\hline VPROD & $\begin{array}{l}\text { Vertical well production indicator: } \\
\mathrm{N}=\text { no prior production from lease } \\
\mathrm{Y}=\text { lease has prior production }\end{array}$ \\
\hline SMTYPE & $\begin{array}{l}\text { Well solution type: } \\
S=\text { from single well lease } \\
M=\text { from multiple well lease }\end{array}$ \\
\hline TEST & Intermediate work area \\
\hline AVGULTX & Grouped average ult. rec., STB/well \\
\hline AVGDISPX & Grouped avg. displ. in pay, $\mathrm{ft} /$ well \\
\hline SMVHTYPE & $\begin{array}{l}\text { Group solution type indicator } \\
\text { SH = single well horizontal } \\
\text { SV = single well vertical } \\
\text { MH = multiple well horizontal } \\
\text { MV = multiple well vertical }\end{array}$ \\
\hline AVGULTA & $\begin{array}{l}\text { Avg. ult. rec. grouped by STB: } \\
\begin{array}{l}1 \leq 128,953 \\
2=128,954 \text { through } 250,686 \\
3 \geq 250,687\end{array}\end{array}$ \\
\hline AVGULTB & $\begin{array}{l}\text { Avg. ult. rec. grouped by frequency: } \\
\begin{array}{l}1=1^{\text {st }} \text { third } \\
2=2^{\text {nd }} \text { third } \\
3=\text { final third }\end{array}\end{array}$ \\
\hline
\end{tabular}


Table A-1

Statistical Analysis Variables.

\begin{tabular}{||c|c|}
\hline Variable & Description \\
\hline \hline AVGDISPA & Avg. displ. in pay grouped by value: \\
& $1 \leq 1712 \mathrm{ft}$. \\
& $2=1713$ through $2922 \mathrm{ft}$. \\
& $3 \geq 2923 \mathrm{ft}$. \\
\hline AVGDISPB & Avg. displ. in pay grouped by freq.: \\
& $1=1^{\text {z }}$ third \\
& $2=2^{\text {dd }}$ third \\
& $3=$ final third \\
\hline
\end{tabular}




\section{APPENDIX B}

The illustrations which follow summarize the statistical analyses discussed in Section 8.0 of this report. The illustrations are in a statistical "Boxplot" format. The box limits indicate the range of the middle half of the data known as the inter-quartile range (IRQ). The asterisk (*) is positioned within the box at the median value. The "whiskers" extend beyond either box end up to 1.5 times the IRQ or to the last data point within 1.5 times the IRQ, whichever is the lesser. Outlier points, $(0)$, are those falling beyond the whiskers and within 3.0 times the IRQ. An extreme outlier point, (E), is any data point outside of 3.0 times the IRQ. 


\section{Figure B.1 \\ Ultimate Oil Recovery Per Well \\ Versus Wellbore Orientation}

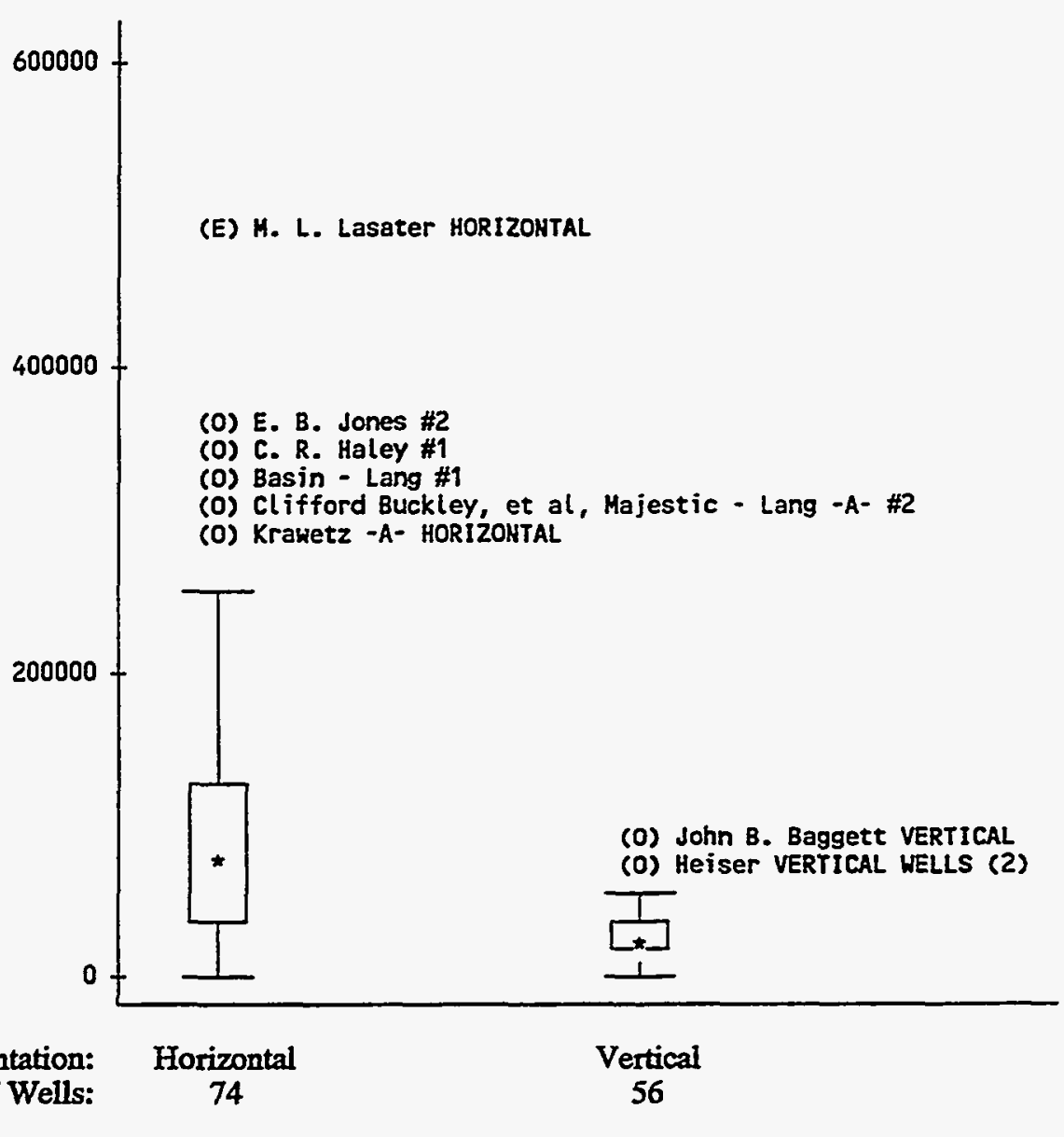

Horizontal Well Cases ....... 74

$\begin{array}{lllrlllr}\text { Mean } & 117431.7 & \text { Std Err } & 13861.52 & \text { Min } & 7220.000 & \text { Skewness } & 1.6868 \\ \text { Median } & 71148.50 & \text { Variance } & 1.42 E+10 & \text { Max } & 488670.0 & \text { S E Skew } & .2792 \\ 5 \% \text { Trim } & 104033.3 & \text { Std Dev } & 119241.3 & \text { Range } & 481450.0 & \text { Kurtosis } & 2.3016 \\ & & & & \text { IQR } & 94283.75 & \text { S E Kurt } & .5517\end{array}$

Vertical Well Cases . . . . . . . . 56

$\begin{array}{lllrlllr}\text { Mean } & 29273.18 & \text { Std Err } & 3136.999 & \text { Min } & 2108.000 & \text { Skewness } & 1.3193 \\ \text { Median } & 17060.00 & \text { Variance } & 5.51 E+08 & \text { Max } & 81888.00 & \text { S E Skew } & .3190 \\ \text { 5\% Trim } & 27798.88 & \text { Std Dev } & 23475.15 & \text { Range } & 79780.00 & \text { Kurtosis } & .6007 \\ & & & & \text { IQR } & 21888.75 & \text { S E Kurt } & .6283\end{array}$

Symbol Keys:
* - Median
(O) - Outlier
(E) - Extreme 
Figure B.2

Ultimate Oil Recovery Per Well

For Horizontal Wells

Based On Prior Production From

Vertical Well(s) On Same Lease

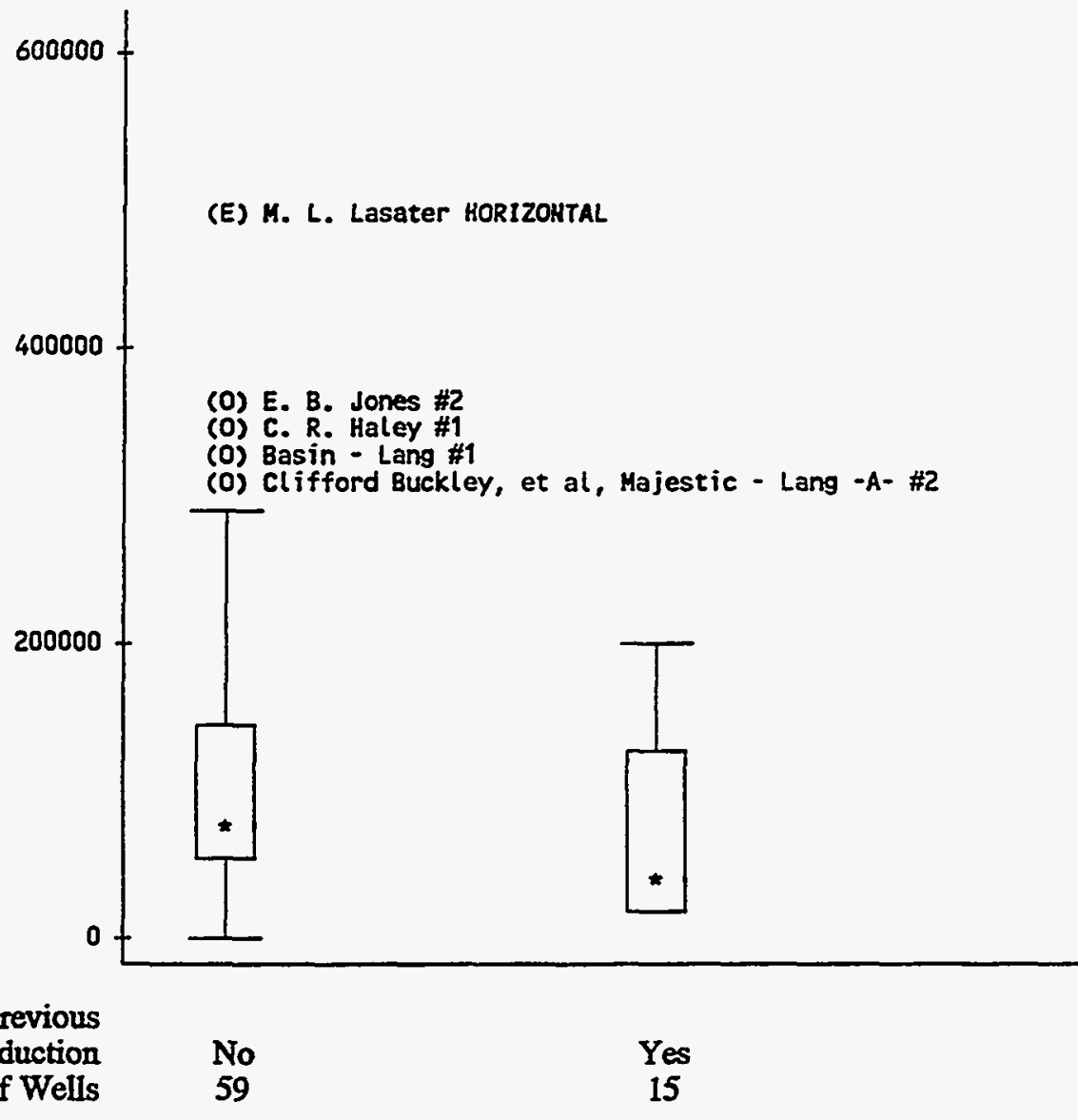

Vertical Production

Number of Wells

59

No Prior Vertical Production Cases . 59

$\begin{array}{lrlrlllr}\text { Mean } & 127878.4 & \text { Std Err } & 16670.50 & \text { Min } & 7220.000 & \text { Skewness } & 1.5207 \\ \text { Median } & 77151.00 & \text { Variance } & 1.64 E+10 & \text { Max } & 488670.0 & \text { S E Skew } & .3112 \\ \text { 5\% Trim } & 114462.1 & \text { Std Dev } & 128048.6 & \text { Range } & 481450.0 & \text { Kurtosis } & 1.4646 \\ & & & & \text { IQR } & 103241.0 & \text { S E Kurt } & .6133\end{array}$

Prior Vertical Production Cases .... 15

$\begin{array}{lllrllll}\text { Mean } & 76341.53 & \text { Std Err } & 16211.54 & \text { Min } & 19444.00 & \text { Skewness } & .7299 \\ \text { Median } & 43297.00 & \text { Variance } & 3.94 E+09 & \text { Max } & 207016.0 & \text { S E Skew } & .5801 \\ \text { 5\% Trim } & 72242.81 & \text { Std Dev } & 62787.01 & \text { Range } & 187572.0 & \text { Kurtosis } & -.8597 \\ & & & & \text { IQR } & 108377.0 & \text { S E Kurt } & 1.1209\end{array}$

Symbol Rey:
* - Median
(O) - Outlier
(E) - Extreme 


\section{Figure B.3}

Ultimate Oil Recovery Per Well

For Horizontal Wells

Based On Multiple Well Lease

Versus Single Well Lease

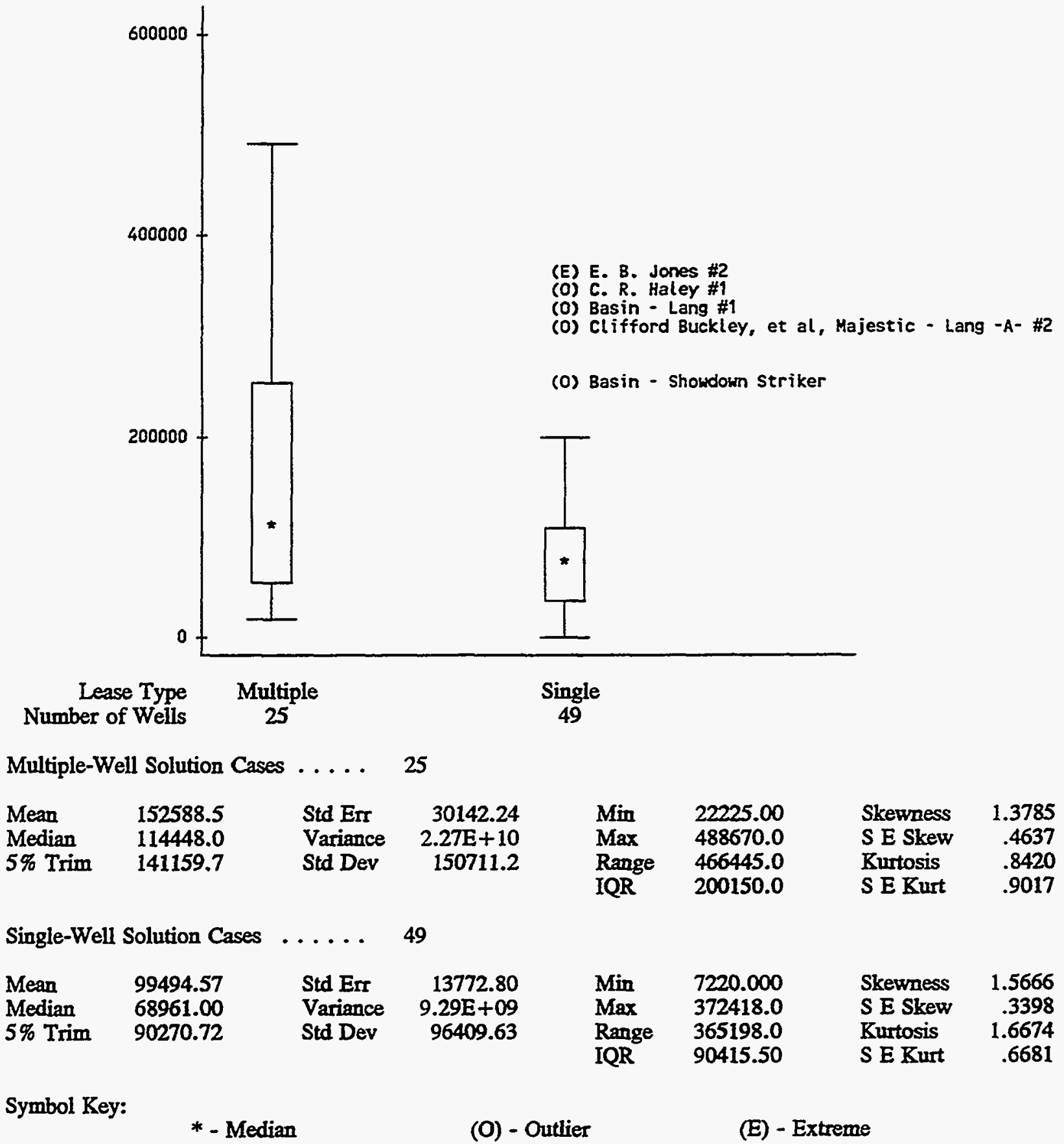


Figure B.4

Ultimate Oil Recovery Per Well For

Horizontal Wells On Single Well Leases

Based On Initial Production Method -

Flowing or Pumping

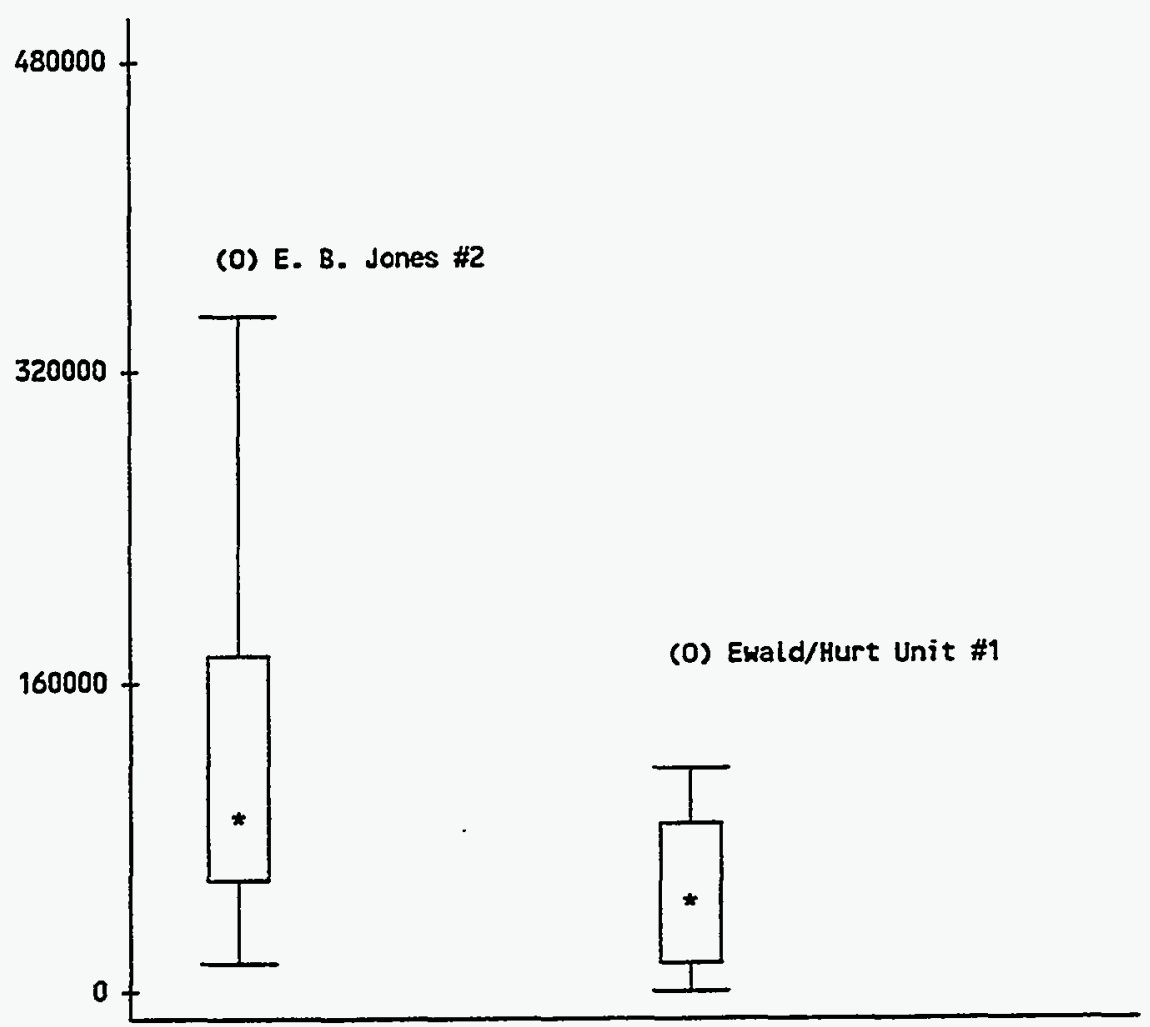

Production Method

Number of Wells

Flowing

27

Pumping

22

Flowing Cases ........... 27

$\begin{array}{lllrlllr}\text { Mean } & 136267.2 & \text { Std Err } & 21445.27 & \text { Min } & 13074.00 & \text { Skewness } & 1.0019 \\ \text { Median } & 90531.00 & \text { Variance } & 1.24 E+10 & \text { Max } & 372418.0 & \text { S E Skew } & .4479 \\ \text { 5\% Trim } & 130266.9 & \text { Std Dev } & 111432.9 & \text { Range } & 359344.0 & \text { Kurtosis } & -.3355 \\ & & & & \text { IQR } & 153067.0 & \text { S E Kurt } & .8721\end{array}$

Pumping Cases ........... 22

$\begin{array}{lllrlllr}\text { Mean } & 54364.55 & \text { Std Err } & 9532.782 & \text { Min } & 7220.000 & \text { Skewness } & 1.1755 \\ \text { Median } & 37669.00 & \text { Variance } & 2.00 \mathrm{E}+09 & \text { Max } & 179068.0 & \text { S E Skew } & .4910 \\ \text { 5\% Trim } & 50387.87 & \text { Std Dev } & 44712.71 & \text { Range } & 171848.0 & \text { Kurtosis } & 1.1881 \\ & & & & \text { IQR } & 63929.75 & \text { S E Kurt } & .9528\end{array}$

Symbol Key:
* - Median
(O) - Outlier
(E) - Extreme 
Figure B.5

Wellbore Displacement in Pay Zone

Versus Wellbore Orientation

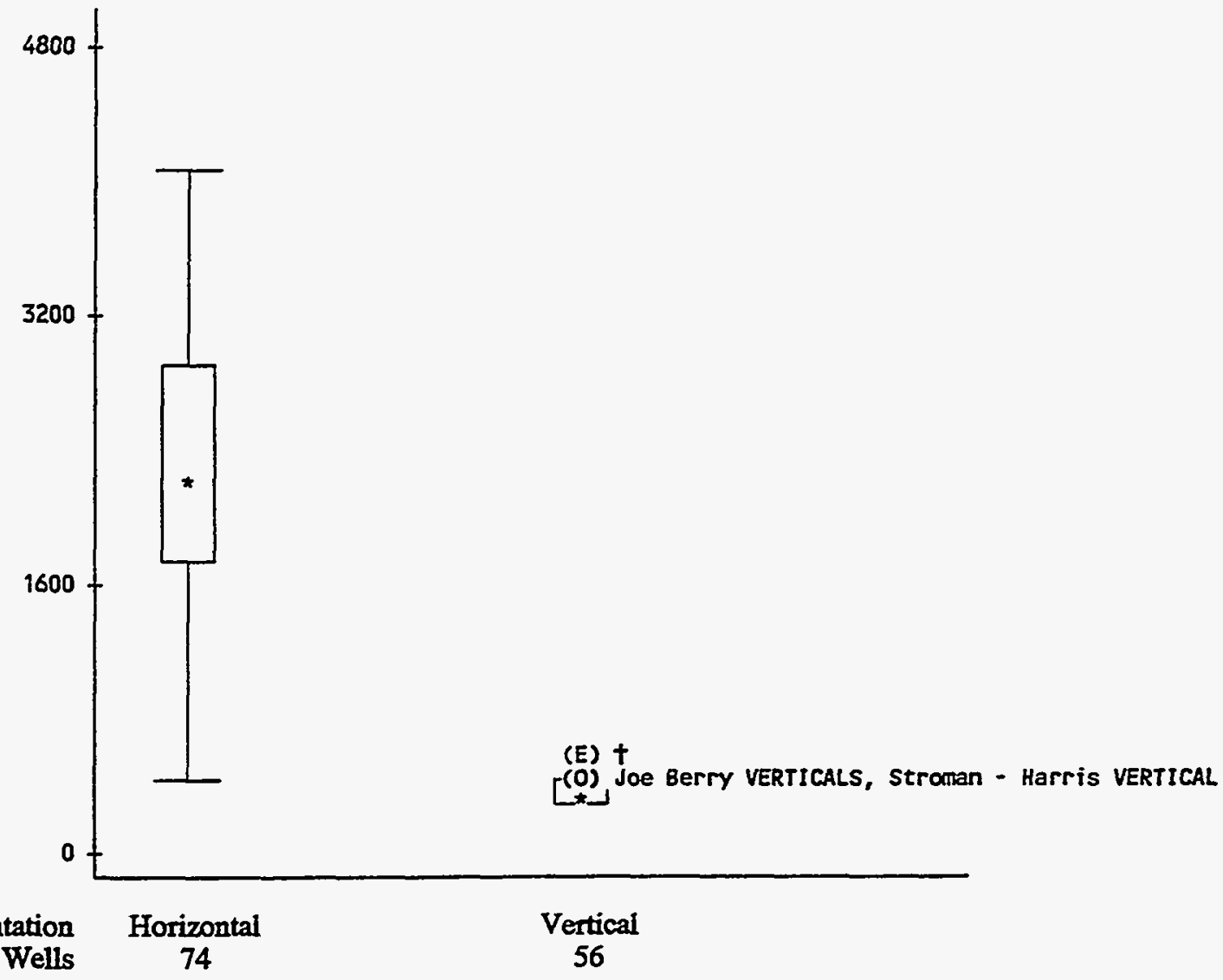

Horizontal Cases . . . . . . . . . 74

$\begin{array}{llllllll}\text { Mean } & 2271.514 & \text { Std Err } & 105.0794 & \text { Min } & 502.0000 & \text { Skewness } & .3172 \\ \text { Median } & 2181.667 & \text { Variance } & 817084.7 & \text { Max } & 4133.000 & \text { S E Skew } & .2792 \\ 5 \% \text { Trim } & 2254.943 & \text { Std Dev } & 903.9274 & \text { Range } & 3631.000 & \text { Kurtosis } & -.5860 \\ & & & & \text { IQR } & 1315.875 & \text { S E Kurt } & .5517\end{array}$

Vertical Cases $\ldots \ldots \ldots \ldots \ldots . \quad 56$

$\begin{array}{lrlrlrrr}\text { Mean } & 355.0536 & \text { Std Err } & 10.1024 & \text { Min } & 240.8000 & \text { Skewness } & 1.2257 \\ \text { Median } & 332.9022 & \text { Variance } & 5715.320 & \text { Max } & 570.0000 & \text { S E Skew } & .3190 \\ 5 \% \text { Trim } & 350.0706 & \text { Std Dev } & 75.5997 & \text { Range } & 329.2000 & \text { Kurtosis } & 1.6497 \\ & & & & \text { IQR } & 56.4457 & \text { S E Kurt } & .6283\end{array}$

Symbol Key:
* - Median
(O) - Outlier
(E) - Extreme

† A.Kraketz -15- VERTICAL, F.J.Avant VERTICAL WELL, Haukins VERTICAL WELL (1) 
Figure B.6

Ultimate Oil Recovery Per Displacement

Versus Wellbore Orientation

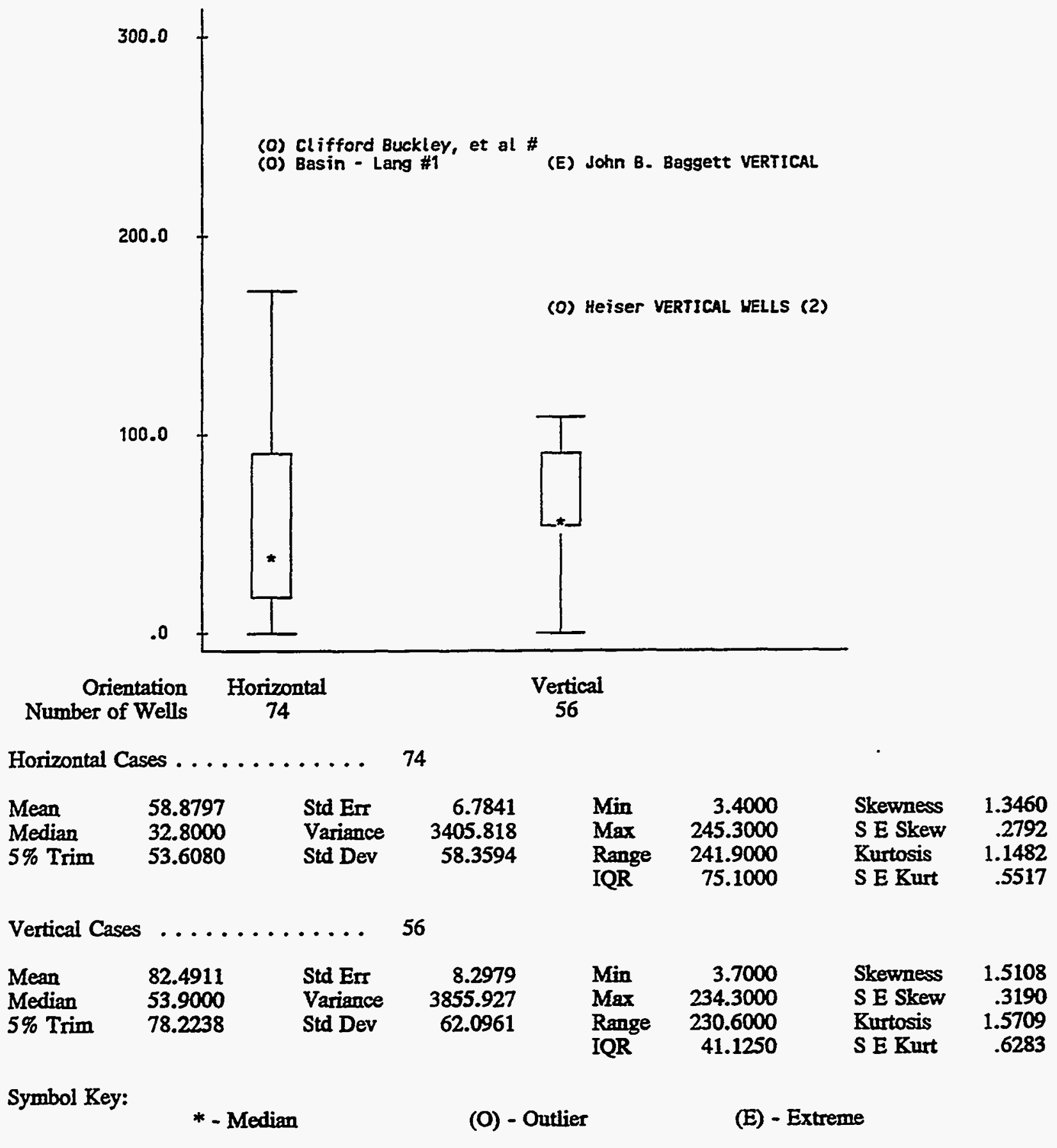


Figure B.7

Ultimate Oil Recovery Per Displacement

For Horizontal Wells

Based On Prior Production From

Vertical Well(s) On Same Lease

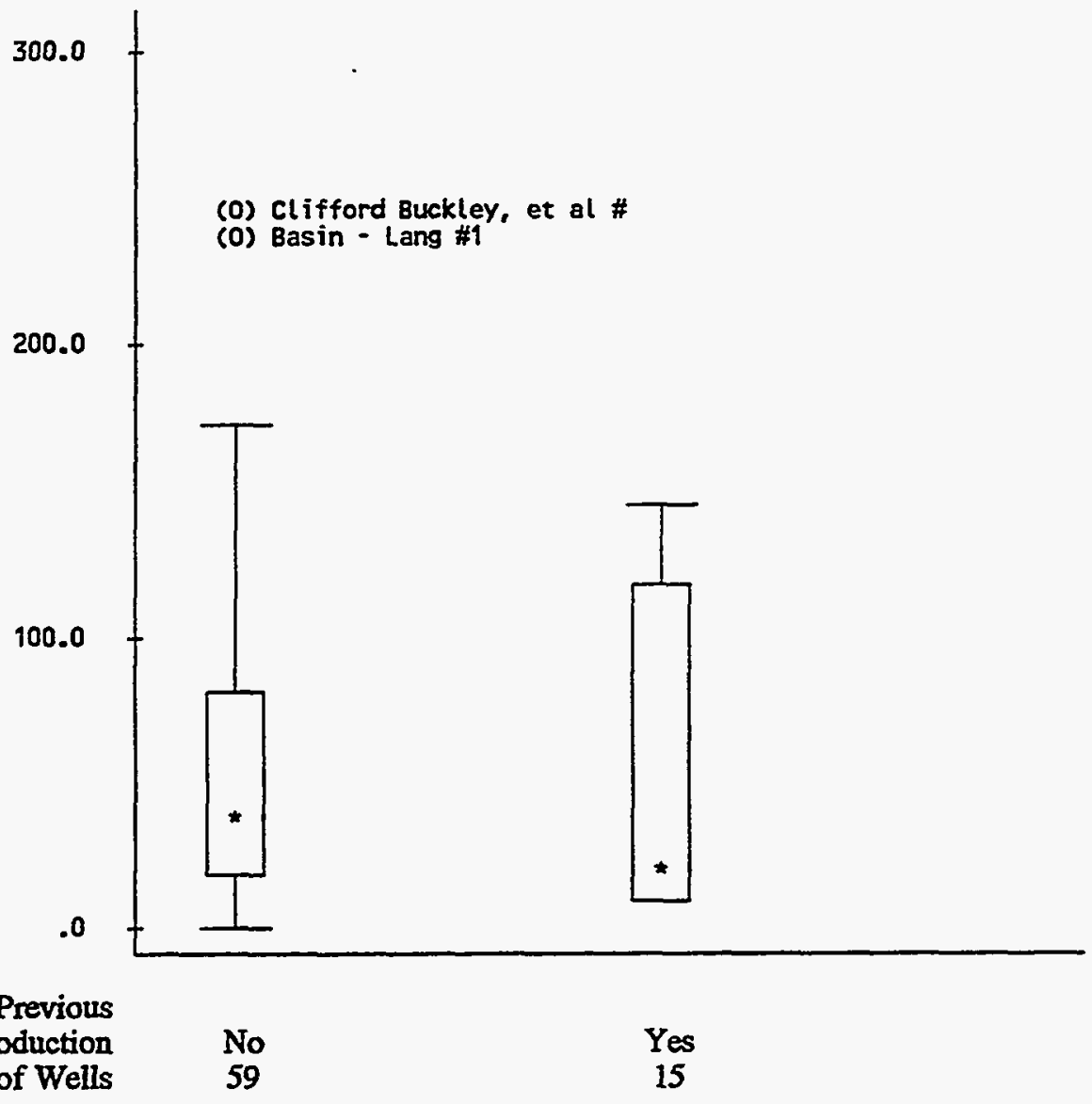

Vertical Production Number of Wells

No

No Prior Vertical Production Cases . 59

$\begin{array}{lrlrlrlr}\text { Mean } & 59.0475 & \text { Std Err } & 7.6442 & \text { Min } & 3.4000 & \text { Skewness } & 1.4983 \\ \text { Median } & 36.7000 & \text { Variance } & 3447.587 & \text { Max } & 245.3000 & \text { S E Skew } & .3112 \\ \text { 5\% Trim } & 53.2035 & \text { Std Dev } & 58.7162 & \text { Range } & 241.9000 & \text { Kurtosis } & 1.7594 \\ & \text { IQR } & 68.6000 & \text { S E Kurt } & .6133 & & & \end{array}$

Prior Vertical Production Cases .... 15

$\begin{array}{lrlrlrlr}\text { Mean } & 58.2200 & \text { Std Err } & 15.2216 & \text { Min } & 7.6000 & \text { Skewness } & .8054 \\ \text { Median } & 21.3000 & \text { Variance } & 3475.460 & \text { Max } & 145.7000 & \text { S E Skew } & .5801 \\ 5 \% \text { Trim } & 56.1722 & \text { Std Dev } & 58.9530 & \text { Range } & 138.1000 & \text { Kurtosis } & -1.3181 \\ & \text { IQR } & 135.5000 & \text { S E Kurt } & 1.1209 & & & \end{array}$

Symbol Key:
* - Median
(O) - Outlier
(E) - Extreme 
Figure B.8

\section{Ultimate Oil Recovery Per Displacement \\ For Horizontal Wells \\ Based On Multiple Well Lease \\ Versus Single Well Lease}

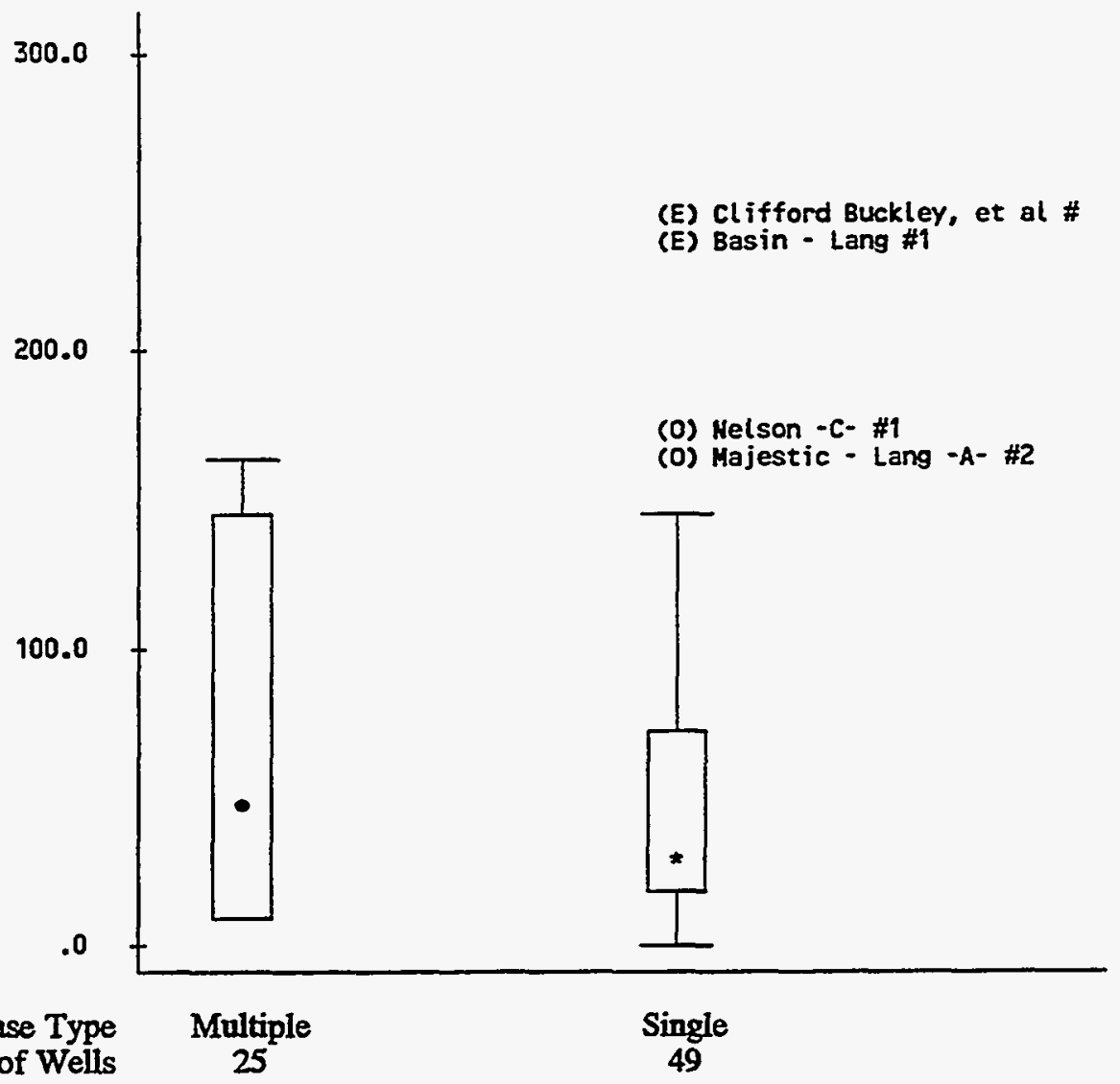

Multiple-Well Solution Cases . . . . 25

\begin{tabular}{|c|c|c|c|c|c|c|c|}
\hline $\begin{array}{l}\text { Mean } \\
\text { Median } \\
5 \% \text { Trim }\end{array}$ & $\begin{array}{l}68.3120 \\
43.9000 \\
66.2578\end{array}$ & $\begin{array}{l}\text { Std Err } \\
\text { Variance } \\
\text { Std Dev }\end{array}$ & $\begin{array}{r}12.1050 \\
3663.254 \\
60.5248\end{array}$ & $\begin{array}{l}\text { Min } \\
\text { Max } \\
\text { Range }\end{array}$ & $\begin{array}{r}10.2000 \\
163.4000 \\
153.2000\end{array}$ & $\begin{array}{l}\text { Skewness } \\
\text { S E Skew } \\
\text { Kurtosis }\end{array}$ & $\begin{array}{r}.5396 \\
.4637 \\
-1.4647 \\
.9017\end{array}$ \\
\hline
\end{tabular}

Single-Well Solution Cases $\ldots . . .49$

$\begin{array}{lrlrlrlr}\text { Mean } & 54.0673 & \text { Std Err } & 8.1792 & \text { Min } & 3.4000 & \text { Skewness } & 1.8664 \\ \text { Median } & 31.5000 & \text { Variance } & 3278.075 & \text { Max } & 245.3000 & \text { S E Skew } & .3398 \\ \text { 5\% Trim } & 47.1577 & \text { Std Dev } & 57.2545 & \text { Range } & 241.9000 & \text { Kurtosis } & 3.3665 \\ & & & & \text { IQR } & 54.4500 & \text { S E Kurt } & .6681\end{array}$

Symbol Key:
* - Median
(O) - Outlier
(E) - Extreme 


\section{Figure B.9}

Ultimate Oil Recovery Per Displacement For Horizontal Wells On Single Well Leases

Based On Initial Production Method -

Flowing or Pumping

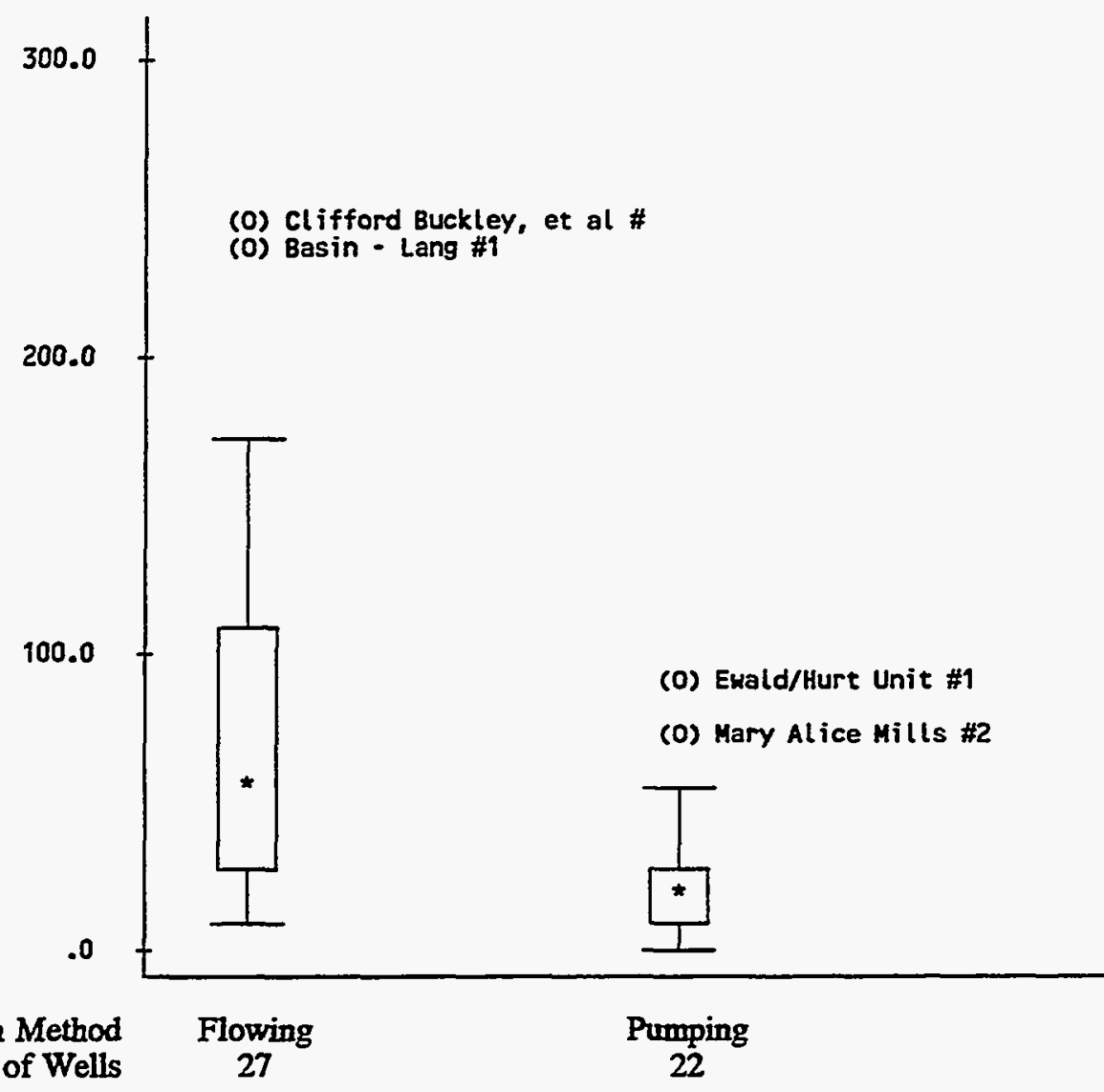

Production Method

Number of Wells

lowing

22

Flowing Cases .......... 27

$\begin{array}{lrlrlrlr}\text { Mean } & 77.1296 & \text { Std Err } & 12.8066 & \text { Min } & 6.7000 & \text { Skewness } & 1.2532 \\ \text { Median } & 54.7000 & \text { Variance } & 4428.252 & \text { Max } & 245.3000 & \text { S E Skew } & .4479 \\ \text { 5\% Trim } & 71.7716 & \text { Std Dev } & 66.5451 & \text { Range } & 238.6000 & \text { Kurtosis } & .9265 \\ & \text { IQR } & 90.5000 & \text { S E Kurt } & .8721 & & & \end{array}$

Pumping Cases .......... 22

$\begin{array}{lllrlrlr}\text { Mean } & 25.7636 & \text { Std Err } & 4.7052 & \text { Min } & 3.4000 & \text { Skewness } & 1.5005 \\ \text { Median } & 19.0500 & \text { Variance } & 487.0662 & \text { Max } & 88.6000 & \text { S E Skew } & .4910 \\ 5 \% \text { Trim } & 23.6071 & \text { Std Dev } & 22.0696 & \text { Range } & 85.2000 & \text { Kurtosis } & 2.2105 \\ & & & & \text { IQR } & 23.6000 & \text { S E Kurt } & .9528\end{array}$

Symbol Key:

* - Median

(O) - Outlier

(E) - Extreme 


\section{APPENDIX C}

\section{TETRAD}

TETRAD is a state-of-the-art three-dimensional numerical reservoir simulator that can function in one of four modes:

Black Oil - $\quad$ Isothermal with three phases, water, gas, and oil and three component, also usually designated as water, gas, and oil. The gas component can dissoive in both the water and oil phases to represent solution gas. The oil component can be present in both the gas and water phases, to represent condensate or oil-in-water emulsion.

Multicomponent - Isothermal with three phases, water, gas, and oil. The hydrocarbon phases may each be muiticomponent and hydrocarbon components may be present in any phase.

Thermal - $\quad$ Thermal with three phases, water, gas, and oil. All three phases may be multicomponent. Any component may be present in any phase.

Geothermal - Thermal with two phases, water and gas (no oil phase). The water and gas phases may be multicomponent. Any component may be present in any of the two phases.

The program has been extensiveiy tested on a wide variety of problems in user environments ranging from major oil companies to independent consulting firms. It has been successfully installed on computers ranging from PC's to Cray supercomputers.

Program input is keyword driven and free format under the rules of FORTRAN 77. Default variables are extensively defined to facilitate problem set up.

The program has been efficiently interfaced to a front end gridding and data preparation package and a post processing mapping and graphics package to facilitate both data preparation and the presentation of results.

The grid algorithms will accept irregular and curvilinear grids and localized grid refinement. Any grid node may be coupled to any other grid node, to facilitate juxtaposition of nonconforming layers due to faulting and the irregular coupling of grid nodes due to grid refinement.

The initialization of saturations and pressures account for the presence of fluid contacts within a grid block. Contacts can either be sharp or with a transition zone as defined by the capillary pressure. 
The simulator formulation provides a wide range of options for the degree of implicitness of the numerical solutions:

- fully implicit

- linearized implicit

- dynamically implicit

- sequentially implicit

- IMPES

Optional features of TETRAD include:

- Dual porosity/dual permeability can be treated in all four modes.

- Fully implicit treatment of flow in the wellbore from the reservoir to the surface. Wellbores can assume any inclination from horizontal to vertical.

- Control over the degree of numerical dispersion.

- Permeability can vary with reservoir pressure and temperature in a spatially dependent fashion.

- The input capillary pressure curves can be scaled to the porosity and permeability of each grid block according to the Leverett $J$ function.

- Analytical aquifers can be tied to the model at any block. The aquifer options provided are:

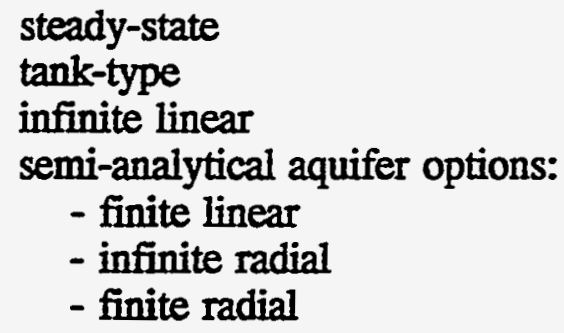

- Porosity and permeability hysterisis due to non-elastic deformation of the porous media.

- Controlled automatic switching of a well from injection to production and vice versa for cyclic "huff and puff" operation.

- Simulation of the electrical resistive heating method for enhanced recovery of heavy oils.

- Vectorised solver for use on vector computers. 


\section{TETRAD}

\section{TYPES OF PROBLEMS}

TETRAD is applicable to an unusually broad spectrum of problems:

Reservoir Fluid Types

- Volatile oil

- Dry gas

- Gas condensate

- Geothermal

- Black oil

Recovery Processes

- Primary depletion.

- Waterflooding

- Gas injection

- Aquifer influx

- Gas cycling

- Miscible flooding

- Steam flooding

- Electrical heating

- Horizontal wells

Single Well Studies

- Water and gas coning or cusping

- -Steam "huff and puff"

- Pressure transient tests

- Fluid flow in wellbore and pipes

Complex Porous Media

- Dual porosity/dual permeability

- Fractured systems

- Vugular

- Stress dependent porosity and permeability

Simulation of Laboratory Experiments

- Fluid displacement studies

- Fractured core studies

- Flash experiments 


\section{Special Applications}

- Oil-in-water emulsions

- Tracer injection tracking

- Research into simulation techniques.

- Dissolved gas-in-water systems.

- Slug flow (reduced numerical dispersion required)

- Non-elastic deformation of porous media 
TETRAD

MODEL PERFORMANCE

The numbers of time steps and Newton iterations required to solve published SPE Comparative Solution Project Problems are given in the following tabulation. All simulations were performed on a 32 bit computer using double precision. The numbers required for a given installation may vary slightly from the tabulated values, depending on the accuracy of the machine.

\section{Computational Effort Requirements \\ SPE Comparative Solution Project Problems}

\begin{tabular}{|c||l|c|c||}
\hline $\begin{array}{c}\text { Solution } \\
\text { Project }\end{array}$ & Problem Description \& Variations & $\begin{array}{c}\text { Time Steps } \\
\text { Required }\end{array}$ & $\begin{array}{c}\text { Total Newton } \\
\text { Iterations }\end{array}$ \\
\hline \hline \multirow{2}{*}{ First } & 3D Black Oil: & 17 & 72 \\
& $\begin{array}{l}\text { fixed } \mathrm{p}_{\mathrm{b}} \\
\text { variable } \mathrm{p}_{\mathrm{b}}\end{array}$ & 17 & 79 \\
\hline Second & 2D Radial Coning & 7 & 40 \\
\hline Fourth & Thermal, Steam Flooding: & & \\
& 2D radial huff \& puff & 85 & 282 \\
& 3D heavy oil & 35 & 195 \\
& 3D volatile oil & 35 & 200 \\
\hline Sixth & Dual Porosity, 2D Vert. water inj. & 29 & 96 \\
\hline
\end{tabular}




\section{TETRAD}

\section{MODEL FORMULATION BASICS}

\section{Phases and Components}

Petroleum and natural gas reservoir systems are formulated as three phase, water, gas, and oil. Geothermal reservoirs have only two phases, gas and liquid.

Reservoir fluid systems have a total of $n_{t}$ components, comprised of $n_{w}$ water components, and $\mathrm{n}_{\mathrm{t}}-\mathrm{n}_{\mathrm{w}}$ hydrocarbon components.

Component 1 is generally the pure water component in the water phase. Components 2 through $\mathrm{n}_{\mathrm{w}}$ are referred to as tracer components in the water phase and can only be present in a thermal or geothermal simulation. They can be used to model a tracer such as deuterium, tritium, or dissolved gas such as $\mathrm{CO}_{2}$, or dissolved salt.

Components $n_{w}+1$ through $n_{t}$ are the hydrocarbon components, in order of increasing molecular weight. They are not present in geothermal simulations.

\section{Conservation Equations}

In a black oil or multicomponent simulation, there are $n_{t}$ conservation equations, one for each component. In a thermal or geothermal simulation, there are $n_{t}+1$ conservation equations, the extra equation being the energy conservation equation.

\section{Fundamental Variables}

TETRAD regards the following as fundamental variables:

- pressure (P)

- saturations of oil, gas and water phases $\left(S_{o}, S_{g}, S_{w}\right)$

- temperature (T)

- component mole fractions in water, gas, oil phases $(\mathrm{W}, \mathrm{Y}, \mathrm{X})$ 


\section{Primary Variables}

The number of primary variables is always the same as the number of conservation equations; however, the choice of primary variables depends on the type of simulation, and the presence of phases. Variable substitution is used depending on the phase status. Possible primary variables are:

$-\mathrm{P}$

- $S_{g}$, or $X(2)$, or $T$

- $S_{o}$, or $Y\left(n_{\imath}\right)$, except for geothermal

- W(2) through $W\left(n_{w}\right)$ for thermal or geothermal

- $X\left(n_{w}+2\right)$ through $X\left(n_{r}-1\right)$ for multicomponent

$-X\left(n_{w}+1\right)$ through $X\left(n_{t}-1\right)$ for thermal

All other variables are secondary variables.

\section{Constraint Equations}

The constraining equations are as follows:

$$
\begin{aligned}
& S_{0}+S_{g}+S_{w}=1 \\
& \Sigma W=1 \\
& \Sigma Y=1 \\
& \Sigma X=1
\end{aligned}
$$

\section{Equilibrium Constants}

The mole fractions are related through the equilibrium constants ( $\mathrm{K}$ and $\mathrm{F}$ values). Usually, the $F$ values will be zero.

For the water components:

$$
\begin{aligned}
& Y_{i}=K_{i} W_{i}=1, n_{w} \\
& X_{i}=F_{i} W_{i}=1, n_{w}
\end{aligned}
$$


For the hydrocarbon components:

$$
\begin{aligned}
& Y_{i}=K_{i} X_{i}=n_{w}+1, n_{t} \\
& W_{i}=F_{i} X_{i}=n_{w}+1, n_{i}-1 \\
& W\left(n_{2}\right)=F(n t) Y\left(n_{v}\right) \text { black oil and multicomponent mode } \\
& W\left(n_{v}\right)=F\left(n_{v}\right) X\left(n_{v}\right) \text { thermal mode }
\end{aligned}
$$

The equilibrium constants, $\mathrm{K}$ are functions of pressure and temperature.

As TETRAD always works with mole fractions, black oil PVT data are used internally to construct the equivalent $K$ values for the phase equilibria.

\section{Solution Procedure}

In a black oil simulation, with all phases present, the primary variables are $\mathrm{P}, \mathrm{S}_{\mathrm{g}}$, and $\mathrm{S}_{\mathrm{o}}$. If the gas phase disappears, $X(2)$ replaces $S_{z}$ as a primary variable, (this is equivalent to solving for $R_{3}$, the solution gas-oil ratio). If the oil phase disappears, $Y\left(n_{\nu}\right)$, ( $n_{t}$ being 3 in this case) replaces $\mathrm{S}_{\mathrm{o}}$ as a primary variable. This is equivalent to solving for the gas-condensate ratio. Once the primary variables have been found, the remaining fundamental variables can be determined from the constraint equations and equilibrium relationships. All other variables (densities, etc.) are functions of the fundamental variables.

In a multicomponent simulation when all phases are present, the primary variables are $P, S_{g}, S_{0}$, and $\mathrm{X}(3)$ through $\mathrm{X}\left(\mathrm{n}_{\mathrm{i}}-1\right)$. Variable substitution is performed in exactly the same manner as for black oil.

In a thermal simulation with all phases present, the primary variables are $P, S_{g}, S_{o}$, W(2) through $W\left(n_{w}\right)$ and $X\left(n_{w}+1\right)$ through $X\left(n_{t}-1\right)$. If the gas phase or the water phase disappear (e.g. superheated steam), $T$ replaces $S_{g}$ as a primary variable. The oil phase is not allowed to disappear in a thermal simulation, although the oil saturation can go to zero. This is done by means of a pseudo $\mathrm{K}$ value for the heavy oil component to prevent further evaporation as the oil saturation approaches zero.

In a geothermal simulation, the primary variables are $P, S_{g}$, and $W(2)$ through $W\left(n_{w}\right)$. Variable substitution is performed in the same manner as for thermal.

In constructing the Jacobian, the primary variables are aligned on the conservation equations to make the resulting matrix as diagonally dominant as possible. 


\section{Dual Porosity}

When invoked, the number of grid blocks is doubled and a dual grid is set up. The first $N / 2$ grid blocks then represent the fracture system and the last $N / 2$ the matrix system. The grid parameters, such as grid block sizes and formation tops are automatically dualled. Thus, the two grids occupy the same spatial positions. Each grid block in the fracture system is connected to the equivalent grid block in the matrix system by a special interaction, namely the fracture-matrix interaction.

Optionally, matrix-matrix interblock connection can be set up. These interactions then represent first degree couplings and are included as such in the inner LDU factorization and iterative inversion. However, if any of the matrix-matrix transmissibilities are specified as zero, the corresponding interblock connections are omitted to save storage. These interactions then represent third degree couplings in the inner LDU factorization, and are not included in the default second degree factorization. In this circumstance, the number of inner iterations can increase significantly, depending on the problem. The situation can be overcome by specifying either, low matrix-matrix transmissibilities, or third degree inner LDU factorization. Both alternatives increase the storage requirement.

\section{Implicit Wellbore Simulation}

For implicit wellbores, the flow in the wellbore is modelled as part of the overall grid. This option allows the definition of additional grid blocks to represent the wellbore. The wellbore blocks will be automatically coupled to each other in the direction of the wellbore, and to the reservoir grid blocks. Two sets of relative permeabilities will generally be required, one for the wellbore blocks, another for the reservoir blocks.

Implicit wellbore modelling may not be combined with local grid refinement or dual porosity.

\section{Numerical Dispersion Control}

Weighting options are provided for relative permeabilities and viscosity.

Relative permeability weighting parameters can be specified as follows:

A zero value to indicate no dispersion control resulting in single point upstream mobility weighting.

A value of 1.0 to define a strict second order method in space. Values between 0.0 and 1.0 give a mixture of single point upstream and the second order method.

Values greater than 1.0 can be used if more dispersion control is required. On slug type problems of near unit viscosity ratio, a well defined slug can be obtained by raising the weighting parameter to about 4. On Buckley-Leverett type problems, sharp shock fronts can be obtained using a parameter of about 2 . 
Viscosity weighting parameters can be assigned to each phase. A parameter of 0.5 yields a central difference while 1.0 gives single point upstream. Any value between 0.5 and 1.0 can be used.

\section{Deformation Model}

The basis of the deformation model is described in SPE paper 18752, published in SPE Reservoir Engineering, May 1991. The approach was specifically developed for application to the Cold Lake reservoir in northeastern Alberta. In an injection cycle, porosities are assumed to follow an elastic compressibility curve until some deformation pressure is exceeded; thereafter, a dilation curve with a much greater compressibility is followed. During the subsequent production cycle, porosities follow the shifted (along dilation path) elastic curve until pressure falls below a recompaction pressure; thereafter, a recompaction curve of elevated compressibility is followed.

Permeability is treated as a function of the porosity change as follows:

$$
k_{\mathrm{p}}=\mathrm{k}_{0} \mathrm{e}^{\mathrm{c}}
$$

where

$$
C=b\left(\phi_{0}-\phi_{n}\right) /\left(1-\phi_{0}\right)
$$

$\phi_{0}=$ porosity at initial conditions

$\phi_{\mathrm{n}}=$ porosity at $\mathrm{n}$ time level

and

$$
\mathrm{b}=\text { fitting coefficient }
$$

